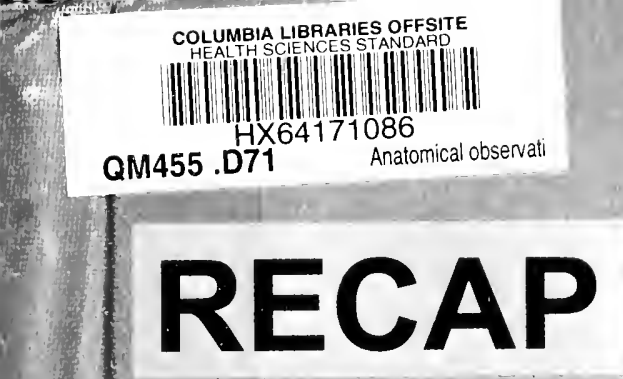




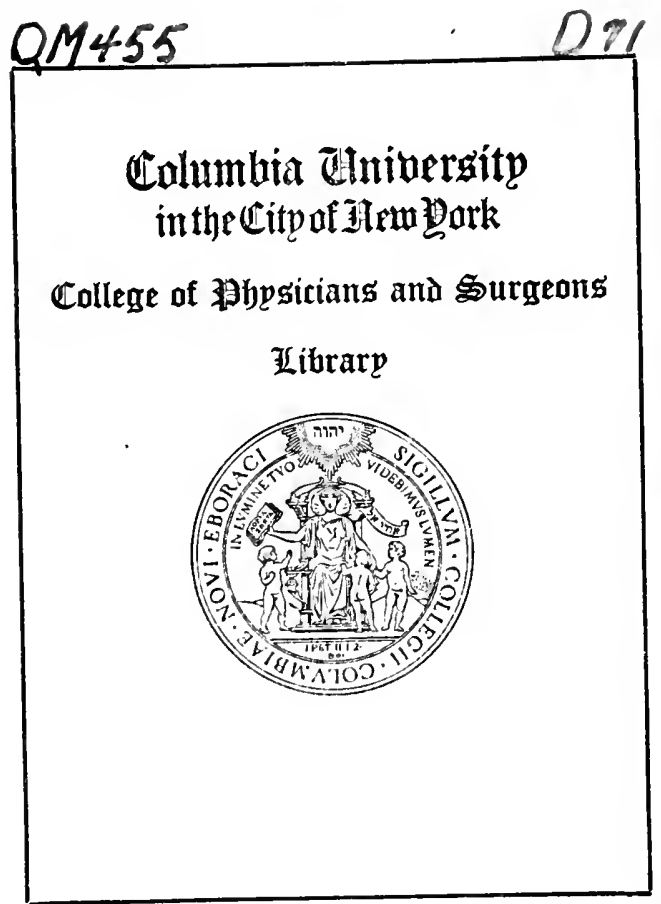


Digitized by the Internet Archive in 2010 with funding from

Open Knowledge Commons (for the Medical Heritage Library project) 
ANATOMICAL OBSERVATIONS ON THE BRAIN AND SEVERAL SENSE-ORGANS OF THE BLIND DEAFMUTE, LAURA DEWEY BRIDGMAN.

HENRY H. DONALDSON, PH. D., Assistant Professor of Neurology at Clark University, Worcester, Mass.

Reprinted from The American Fournal of Psychology, Vol. III, No. 3, Sept., 189o, pp. 293-342, Plates I and II; and Vol. IV, No. 2, Dec., ISqI, pp. 248-294, Plates III and IV. 


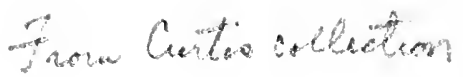

$$
\begin{aligned}
& 0.9455 \\
& D 71
\end{aligned}
$$




\section{ANATOMICAL OBSERVATIONS ON THE BRAIN AND SEVERAL SENSE- ORGANS OF THE BLIND DEAF-MUTE, LAURA DEWEY BRIDGMAN.}

Henry H. Donaldson, Ph. D.

Reprint from the American Journal of Psychology, Vol. III, No. 3, 1890.

I.

Through the exertions of President G. Stanley Hall, the brain in question was obtained and was put by him in my hands for description. Several gentlemen whose names will dnly appear have assisted by describing the sense-organs. I am under obligation to others for facilitating the work in many ways, and especially to Prof. W. F. Whitney and his colleagues of the Harvard Medical School, Prof. B. G. Wilder of Cornell University, and Prof. C. K. Mills of the University of Pennsylvania, for the privilege of examining specimens in their possession. For the opportunity to consult the literature I am indebted to the exceptional facilities offered by the Library of the Surgeon General at Washington of which I have made much use.

In the study of this case it has been my aim to give as full a description as the material in my hands would warrant, and for this purpose I have applied a large number of tests to the brain, to determine, if possible, whether the peculiar mental existence of Laura Bridgman, which was the result of 
her defective sense-organs, has left any trace on her brain, or whether such anomalies as may be observed are sufficiently explained when considered as the direct consequences of the initial defect alone. This is, therefore, a special study in the general field of the inter-relation of brain structure and intelligence. What might be expected to come from the various tests will be discussed under the separate headings, and I shall leave such generalizations as are possible until the special points have been set forth.

\section{Biographical Notes.}

By way of introduction, I may be permitted to state some biographical facts that will bear on this discussion. Laura Dewey Bridgman ( $\left.{ }^{1}\right)^{*}$ was born Dec. 21,1829 , in Hanover, New Hampshire, U. S. A. She was the child of Daniel and Harmony Bridgman, who were farming people. The parents( $\left.{ }^{(}\right)$ are described as of sound health, good habits, average height, slenderly built; the father with a small head, the mother with "not a large head"; both rather nervous; the mother activeminded. Their culture was such as might be found in rural districts like their own at that time. Laura inherited the physical peculiarities of her mother, and her health was delicate. During infancy she was subject to convulsions, but at the age of twenty months her health improved, and she is described as active and intelligent. She had learned to speak several words, and knew one or two of the letters of the alphabet, when, being two years $\left({ }^{2}\right) \dagger$ old, she and her two older sisters, forming at that time the family, were attacked with scarlet fever. The two sisters died. Laura was severely ill; both eves and both ears suppurated, and taste and smell were impaired. Sight in the left eye was entirely abolished. With the right eye she appeared to get some sensation from extremely large bright objects, up to her eighth year, but after

* The bracketed figures in the text refer to similar figures in the bibliography, where the authority is given in full. In some cases reference is made to the page of the publication ciced and this is then bracketed in the text with the figures just mentioned.

†'The date of this illness is a matter of some importance. As there is no agreement among the various authors on this point, I have been forced to choose an authority and have naturally taken the dates given by Dr. Howe in his Reports. 
that time became completely blind. Two years passed before she recorered sufficiently to sit up all day. At the age of five years she had regained her strength. Speech was lost with the loss of hearing, and when her education at home was renewed, it was by means of arbitrary tactual signs of the simplest sort. She was tanght to sew, to knit and to braid, and to perform some minor household duties. On Oct. 4th, 1837, she was brought to the Perkins Institution and Massachusetts Asylum for the Blind, and her education was begun by Dr. S. G. Howe, then director of the institution. She was now seven years and ten months of age, and in the defective condition abore described. Dr. Howe $\left({ }^{2-\text { p. }}{ }^{161}\right)$ says of her at this time: "figure well formed; nervous sanguine temperament; a large [no measurements have been preserved] and beautifully shaped head, and the whole system in healthy action."

The process of education commenced with the pasting of the name of a common object on the object, the name being in raised Jetters, such as are used for the blind; then the association of the name and object; then forming the name from the individnal letters; and after a long time the letters themselves were learned. It was when she first recognized that the sign for an object could be constructed from the individual letters, that the meaning of what she was doing dawned upon her. From that time on her education became easier, and, indeed, she had in one sense to be held back in her work, as there was danger that her frail constitution would succumb to the too great interest in her studies. It is important to note that at this time she exhibited the various emotions by gesture and facial expression. She was fond of dress and pleased by attention. The lapse of time within the limits of the day and the occurrence of Sunday were correctly noted by her. In the report for $1839\left({ }^{2-p .172}\right)$ it is said that she can distinguish between a whole and half note of music, and will strike the notes on the piano quite correctly. (How this interesting test was made, is not quite clear.) A test of her sense of taste at this time showed her capable of distinguishing better between different degrees of acidity than between this and sweetness or bitterness. She appeared at the same time to care rather less for eating than most children of her age. 
The sense of smell seems to have been subject to some variations. During the first years of her residence at the institution it was apparently completely wanting, and there was never at any time the slightest tendency to test objects by holding them to the nose. Later (1843) she seemed able to locate the kitchen by the odors coming from it, but this sense does not appear to have ever been of any importance to her. The sense of touch was very acute even for a blind person, and she was sensitive to jar.

Dirt or a rent in her clothing caused her shame. She was familiar with those of her own sex, but distant to men, and was remarkable for her sense of order, neatness and propriety. She seemed capable of discovering the intellectual capacity of those with whom she was thrown, and quickly chose the more intelligent for her companions. Occasionally, too much attention to other scholars, in her presence, aroused jealousy on her part.

She cried only from grief, and the pain from a bodily injury she sought to annul by jumping and excessive muscular motions. So far as could be learned, she did not dream in the terms of her lost senses, and this is what might be expected, since they were lost at so early an age $\left({ }^{3}\right)$.

She made a number of noises. Francis Lieber studied these with some care, with a view to their bearing on the origin of language $\left({ }^{4}\right)$. It appears that Laura had some fifty or more sounds by which she was accustomed to designate people whom she knew. They were all monosyllabic. Besides this she laughed much and lond, was noisy at play, and occasionally made other emotional noises which were suppressed by her teachers. In this respect she was similar to most mutes, so-called, who appear to have a variety of sounds at their command.

In a recent article, Mrs. Lamson( $\left.{ }^{5}\right)$ states that Laura once uttered the word doctor by accident, and her attention being called to this, she subsequently always spoke the word instead of spelling it with her fingers. The same thing happened with the words pie, ship and several others. These facts are taken to indicate that though so defective, she might possibly have been taught to vocalize, as has been done in some more recent cases. She appeared to keep constantly her 
relations in space, and became confused if she lost what might be called "the points of the compass." She was much afraid of animals, and when more than fifteen years of age could hardly be induced to touch a docile house-dog.

When about sixteen she is described as more thoughtful and sedate, though cheerful - a condition which Dr. Howe regards as showing that her age was to be measured by the degree of her mental development rather than by the number of years she had lived. When she was twenty years of age her regular education ceased, and the special reports by Dr. Howe stop at this time.

In 1878 , President G. Stanley Hall( $\left.{ }^{6}\right)$ made a valuable series of tests upon her. At this time she was found completely blind and deaf, though the sense of jar was well enough developed to enable her to recognize the footsteps and sometimes even the voices of her acquaintances, her common statement being that she heard "through her feet." At this time her sense of smell was such that she could distinguish the odors of some more fragrant flowers, but ean-de-Cologne, ammonia and onions were thus recognized only when quite strong. Contrary to what was stated for an earlier period, she was found least sensitive to bitter and acid tastes, and most sensitive to sweet and salt. It was concluded that out of the four defective senses, taste alone was well enough preserved to materially aid in developing her notion of the extermal world. A study of discriminative sensibility for two compass points showed a discrimination in her case, from two to three times as acute as that of a seeing person. To temperature, her sensitiveness was not remarkable, and hence the "facial sense," as it is sometimes called in the blind, was not well-developed in her, though she was said to recognize the approach of persons by the undulations of the air. She was found sensitive to rotation, which made her dizzy and gave her a feeling of nausea.

In the course of her life Laura was the author of "a Jourual, three Autobiographical Sketches, several so-called poems and numerous letters." The Journal covers a period of about ten years. Dr. E. C. Sanford $\left({ }^{7}\right)$, who has made a 
stndy of her writings, sums up her mental development as thus indicated, by the statement that "she was eccentric, not defective; she lacked certain data of thought, but not, in a very marked way, the power to use what data she had."

She died at the Perkins Institution, where she had spent almost her entire life, on the 24th of May, 1889, being in her sixtieth year.

Laura excited wide interest because, for the first time in her case, several experiments were tried and questions tested, with unprecedented results. Her case was used for research in matters pedagogical, psychological and theological. But these are passed over, as they lie ontside our present scope.

Her defect is often regarded as almost nnique. As a matter of fact, if the deficiency of smell and taste is counted with that of sight and hearing, there appear to be few cases like hers; but so small is the educational value of the first two named, that she may be fairly classed with the blind deafmutes, in which, for the most part, the state of smell and taste is not recorded. As Prof. Edwards A. Park says in the introduction to Mrs. Lamson's book $\left({ }^{1}\right)$, there are some fifteen cases recorded of persons who have lived as blind deaf-mutes. Dr. Howe formed his plan for the instruction of Lanra from the study of Julia Brace, who was a blind deaf-mute. There were several similar cases at the Perkins Institution during Laura's lifetime, and there are two young girls in that institution now who are defective in the same way. Special descriptions of one or more cases have been given by Mareschal $\left({ }^{8}\right)$, Fowler $\left({ }^{9}\right)$, Burdach $\left({ }^{10}\right)$, Alessi $\left({ }^{11}\right)$, Sichel $\left({ }^{12}\right)$, Fuller $\left({ }^{13}\right)$ and Borg $\left({ }^{14}\right)$; and Mrs. Lamson, in the current number of the "American Annals of the Deaf," $\left({ }^{5}\right)$ mentions a Norwegian girl, Ragnhild Kaata, who is blind and deaf, but having been taught to articulate, can no longer be described as mute. In the same article is mentioned a school in Sweden where five blind deaf-mutes are being instructed. Finally, I may call attention to the fact that in the Censns of 1871 for Great Britain there are 111 returns for blind deaf-mutes $\left({ }^{15}\right)$, while in the 10th Census of the United States, in the analysis of 
statistics relating to the defective, dependent and delinquent classes by Wines $\left({ }^{16}\right)$, there are returned:

$\begin{array}{lr}\text { Blind deaf-mutes, } & 256 . \\ \text { Blind deaf-mutes, also idiotic, } & 217 . \\ \text { Blind deaf-mutes, also insane, } & 30 .\end{array}$

The literature on this subject would probably be found to be extensive if carefully gathered, and the statistics, if taken from all sources, would show a very considerable number of individuals in this class. It is my purpose, however, only to call attention in a general way to this point, as bearing on our subject. Taking the Census of 1880 for the United States, Laura's case could only be compared with the simply blind deaf-mutes-256 in number-and it would need a careful analysis of this group in turn, to show how many cases were strictly comparable with hers. There is good reason to think, however, that a number of such would be found.

I do not know that we are in a position to say from sound data what the effect of loss of the senses-as in Laura's case -is on the mental integrity of the individual, but certainly the proportion of blind deaf-mutes who are also mentally defective is very large. At the same time there is reason to think that the large number of those who are idiotic were either congenitally defective (the idiocy and the other defects having a cause in common), or that they became defective shortly after birth, and were neglected by those in charge of them. Two points came out in a striking manner in looking over these cases as presented in the literature just cited. The first is, the small amount of mental pabulum which serves to keep the action of the mind normal; and second, the late stage (measured in jears) at which instruction may be begun with fair hope of success, the nervous mechanism apparently retaining for an unusually long time the impressionability which in the normal person belongs to early childhood.

\section{Physical Data and Report of Autopsy.}

On her entrance into the Perkins Institution, some physical measurements were taken, which were unfortunately lost. At eleven years of age her height was 4 ft. 4.7 in. (1.33 M.). Her head measured 20.8 in. (52.8 cm.) in circumference, 
along a line passing over the prominences of the frontal and parietal bones. Above this line the head rose 1.1 in. (2.8 cm.), and was broad and full. From the orifice of one ear to the other, the (shortest) distance was 4 in. $(10.1 \mathrm{~cm}$.$) , and from$ the occipital spine (protuberance?) to the root of the nose, it was (shortest distance) 7 in. (17.7 cm.). The forehead was said to have grown perceptibly larger during the two years preceding $\left({ }^{2-p .131}\right)$. These are the only data that I have been able to find. As nearly as I can learn from those best acquainted with her at the Perkins Institution, her height at maturity was 5 ft. 3 in. (1.596 M.), and her weight, with clothing-98 lbs. avoirdupois (44.45 kilos).

During her residence at the institution, she appears to have had no. serious illness up to the time of the one which proved fatal, although often in poor health as the result of over-exertion in her study or from emotional excitement, as for example that caused by the death of Dr. Howe, to whom she was deeply attached. Her final illness lasted about three weeks, and she sank gradually to a painless death-before, it is said, advancing jears had perceptibly impaired those faculties which she exercised. The autopsy was performed eight hours after death, by Dr. E. S. Boland, of South Boston, in the presence of several gentlemen. The cause of death is stated as lobar pneumonia. Aside from the lungs, the other viscera appeared bealthy save the left kidney, which was slightly atrophied. The encephalon was removed in the dur $a$ with the eyes attached, and the petrous portions of the temporal bones and part of the ethmoid were also taken out. The cranium is described as symmetrical and of good shape and size; bones thin; diploë slightly marked; but little subdural fluid; the encephalon fitting the cranial cavity closely; dura normal in appearance. For the above facts I am directly indebted to Dr. E. S. Boland. The encephalon was not weighed at this time, nor was any further examination permitted. For the next seventeen hours it was kept in a moderately cool place, but not in any fluid. At the end of this time it came into the hands of Prof. W. F. Whitney, who very kindly took charge of it. The specimen was now in such a condition that it was deemed best to cut it in various directions, in order to permit 
the hardening fluid to penetrate. Four transverse incisions were made, the first being about $3.5 \mathrm{~cm}$. from the frontal end, and the other three at equal intervals behind it. The depth was such as to open the lateral ventricles in either hemisphere without injuring the callosum or basal ganglia. Along the mesal surface of each hemisphere a longitudinal cut was made, extending about the length of the callosum and laying open the lateral ventricle on each side. The entire material was then put into several litres of Miiller's fluid plus one-sixth its volume of $95 \%$ alcohol. This fluid was changed some four or five times in the period between May 25th and July 10th, at which time the specimen came into my possession. The eyes were then separated from the encephalon, and they with the portions of the bones, were treated by themselves. The encephalon was hardened for some three months more in $2 \frac{1}{2} \%$ potassium bichromate; kept for a long time in a dilute solution of the same; finally washed out, hardened in $95 \%$ alcohol, and preserved in $80 \%$ alcohol. The majority of the measurements were made while it was in the $2 \frac{1}{2} \%$ or dilute potassium bichromate.

\section{Photographs and Models.}

In studying the encephalon, it was necessary to make those observations which required least dissection first, and so proceed that the different portions should retain their normal connections as long as possible. The results, however, under any head, will be given without reference to the order in which they were obtained. As the complete examination required ultimately a dissection of the encephalon, with consequent loss of form, I first had it carefully photographed, the encephalon being taken from six points of view, and then the mesal surface of each hemisphere taken alone. The entire exposed surface, with the exception of that covered by the cerebellum, is thus represented, and this latter surface was sketched. It would be extremely desirable to have these various riews adequately represented, but since the means for so doing are not at present at my command, I have preferred to await some future opportunity rather than to represent them now by some method of doubtful value. 
It was further extremely desirable to have an accurate model of the encephalon. The character of the specimen, the cuts in it and the method of preservation were all against any device for taking a direct cast of it. I was, therefore most fortunate in securing the co-operation of Mr. J. H. Emerton, of Boston, whose skill in modelling such objects is well known. He made an accurate clay model of the specimen; from this a glue mould was taken, and a number of plaster casts were at once made from this mould, before it had time to undergo any distortion, the original clay model being preserved for comparison. The results are entirely satisfactory, and we have now what is equivalent to a good cast of this specimen. In making the model, the cuts in the hemispheres were not represented, and thus the general appearance was improved without any material loss in accuracy.

\section{Encelopes and Vessels.}

Within the limits of this paper I shall have to deal exclusively with questions relating to the gross anatomy of the specimen.

Dura: Sinuses filled with blood. Normal in appearance. It was incomplete at several points on the ventral aspect of the hemispheres and the cerebellum was completely exposed, the tentorium and falx being both present. This somewhat defective membrane, including tentorium and falx, weighed, after hardening by the method above described, washing out in water, and being pressed between filter papers, 54.4 grms. No data for comparison have thus far been found.

Pia: The vessels were filled with blood. To all appearance it was normal. The adherence to the occipital regions appeared uncommonly strong, even making allowance for the close adherence which is normal for this region. The pia from the entire encephalon with the choroid plexuses, but without the basal blood-vessels, was treated like the dur $a$ and found to weigh $25.1 \mathrm{grms}$. The quantity of the pia obtained was estimated at about .8 of the total. That supposition being correct, the total pia would weigh 31.4 grms.

What the influence of the hardening process is on the weights of the membranes, dura and pia, is not known, but 
it is presumptively slight. Giacomini $\left({ }^{17}\right)$ has made observations on the weight of the pia and cerebro-spinal fluid, which I give. It is to be remembered that we have no means of knowing the quantity of the fluid in our case, though the autopsy report states that there was apparently little at that time. Confining himself to the cerebral hemispheres, which were weighed separately, Giacomini found in 30 normal brains the weight of pia and residual cerebro-spinal fluid (the bulk of the fluid having escaped on the hemisection of the cerebrum, and having been then collected) to be from 5 to $5.5 \%$ of the weight of the hemispheres. Where the vessels of the pia were congested, the percentage might rise to 6 or $6.5 \%$. According to Calori, quoted by Giacomini, the weight of the pia, blood and cerebro-spinal fluid for the whole encephalon is $14 \%$ of the entire weight. This figure seems to Giacomini too high. Huschke $\left({ }^{18}\right)$ calculates that removal of the pia and choroidal plexuses from the cerebral hemispheres alone diminishes their weight by $50-60$ grms. (This diminution is plainly in part due to loss of fluid consequent on remoral of the pia). Bischoff $\left({ }^{19}\right)$ gives $25-40$ grms. for the pia of the cerebral hemispheres alone. Bastian $\left({ }^{20}\right)$ gives $21-28$ grms. for the pia of the entire encephalon. Where the brain is sliced and allowed to drain for $1-2$ hours, according to the method of Thurnam $\left({ }^{21}\right)$, there is, according to Bastian, an additional loss of 28-56 grms. Bischoff $\left({ }^{19}\right)$ gives further figures from Weisbach, Hagen and Marshall, which I have not been able to verify, and therefore omit.

There is here hardly sufficient data on either hand for the purposes of comparison, but the assertion may be fairly made that the pia in our case shows no marked peculiarity. Unfortunately, the conditions do not permit us to follow Giacomini's ( ${ }^{17}$ ) suggestion, and infer from the weight of the pia its relative thickness.

Volume of Encephalon.

On Aug. 13, 1889, while the specimen was still in 21\% potassium bichromate, an effort was made to obtain the volume. The encephalon (deprived of $p i \alpha$ ) was put in a large jar filled with water. On the water floated a cork, in the centre of which a long pin was stuck vertically. A ruler 
laid across the top of the jar formed a line to the level of which the top of the pin rose when water was poured into the jar. The encephalon being in the jar, water was then added until the head of the pin was level with the edge of the ruler. The encephalon was next removed, with all precaution as to drainage, etc., and the quantity of water was measured which had to be added to that in the jar in order to bring the pinhead to the same level. Two determinations were thus made :

$$
\begin{aligned}
\underset{66}{\operatorname{Determination}} 1 \text { gave voiume } & =1385 \text { c.c. } \\
2 & =\overline{1381 \text { c.c. }} \\
\text { Mean, } & =\overline{1383 \text { c.c. }}
\end{aligned}
$$

This figure, 1383 c.c., I have taken to represent the volume under the conditions stated.

The cuts in the specimen were such that there is good reason to think that the lateral ventricles were filled by the fluid in which it was immersed. The method, I am aware, was rough, but was the best at my command at that time. The most important correction to be made is that for the change of volume of the specimen due to the process of hardening to which it had been subjected. On this point some experiments have been made, which are not yet ready for publication. I shall, however, use the facts obtained without further proof, trusting that I may soon be able to give evidence of their correctness. To save any repetition, it may be here stated that the experiments just mentioned relate to the volume, weight and specific gravity of the encephalon, and will be introduced nnder their proper headings without further remark.

If an encephalon is treated like that of Laura (from six to twelve hours after death), the conditions for its preservation in the mean time having been good, it will show an increase equal to about $25 \%$ of the initial volume. This, however, takes place only when the specimen is fairly fresh. When it is not fresh, but still hardens slowly and incompletely, the increase may be about $2 \%$ of the initial volume. In our case it is a fair estimate that one-third of the initial mass of the encephalon is hardened so as to have undergone an increase of but $2 \%$ in volume, while the other two-thirds may 
be considered to have undergone the full enlargement of $25 \%$. Making use of the above percentage for correction, the volume observed wonld be $\frac{88}{75}$ of the initial volume, or

$$
\frac{1383 \times 75}{88}=1178 \text { c.c. }=\text { initial volume. }
$$

The value of this fignre is simply that of the best approximation which I can now make.

\section{Weight.}

At the same time that the volume was taken the specimen was weighed. The weight thus obtained (on balances weighing to $0.1 \mathrm{grm}$.) was $1389.5 \mathrm{grms}$., the pia being completely removed. The hardening of the specimen had caused it to increase in weight about $22 \%$ for those parts which were well hardened. The same conditions determine the amount of this increase in weight that determine the increase in volume, and when the specimen hardens imperfectly the increase in weight is a trifle less than $2 \%$, but may be called $2 \%$ for the present purpose. Supposing, as before, that two-thirds of the initial brain-mass have increased $22 \%$ in weight, and one-third $2 \%$, we have, 1389.5 grms. $=\frac{173}{150}$ of the initial weight, or

$$
\frac{1389.5 \times 150}{173}
$$

Any criticism which can be applied to the volume can also be applied to the weight as thus deduced.

The initial specific gravity of this encephalon or any portion of it is not known, but if we deduce it from the calcnlated weight and volume, it is 1.022 . This is a smaller figure than Bischoff $\left({ }^{19}\right)$ found. For female brains, his figures are from 1.0305 to 1.0478 . The determination of the weight in this case is, in my opinion, less subject to error than the determination of the volume. If we consider a brain of this weight to have either of the extreme specific gravities given by Bischoff or one represented by their mean, we have for a brain weighing 1204 grms.,

$$
\begin{aligned}
& \text { sp. gr. } 1.0305 \text { giving a volume }=1168 \text { c.c. } \\
& \text { " " } 1.0391 \text { " " " }=1158 \text { c.c. } \\
& \text { " " } 1.0478 \text { " " }
\end{aligned}
$$


Thus furnishing figures for the volume which are 10, 20, and 29 c. c. below those first calculated.

Further manipulation of these figures would be of little value. It is concluded, however, that the probable weight of Laura's brain was somewhat over 1200 grms., and that the probable volume was about $1160 \mathrm{c}$. c.

The mean weight for the English and European female encephalon is variously given. Bischoff $\left({ }^{19}\right), 1244.5$ grms.; Tiedemann, 1275 grms.; and Huschke, 1272 grms. Schwalbe $\left({ }^{22}\right)$ gives 1245 grms., as deduced from a composite table of weights. This table further shows that out of the 339 cases which it includes, 283 have a weight between 1100 and 1420 grms., and the majority (two-thirds) of these in turn have a weight between 1160 and 1330 grms. Our specimen, therefore, falls within these last limits, but somewhat below the mean, 1245 grms. The figure which we have obtained will not warrant any discussion of the weight in relation to other conditions of age, body-weight and height. It may nevertheless be pointed out that our specimen had probably not undergone any important loss of weight due to advancing age, and that furthermore it is possible that the figures which have led to the generalization that at about sixty years the encephalon begins to lose in weight, may perhaps, as has been suggested, be as well explained by some relation not yet investigated, between brain weight and longerity.

Of the subdivisions of the encephalon, the cerebellum alone was weighed separately. It was separated from its connections by cutting through the peduncles as close to the hemispheres as was practicable. The portion thus removed weighed $163 \mathrm{grms}$. The increase in weight due to hardening is about $27 \%$ for the cerebellum, which would make the initial weight 128 grms. Taking the weight of the entire encephalon as 1204 grms., then the cerebellum is $10.63 \%$ of the entire weight. This percentage is exactly that found by Weisbach and $0.17 \%$ lower than that found by Meynert, as quoted by Schwalbe $\left({ }^{22}\right)$. It serves to show that there was nothing very peculiar in the weight relations of the cerebellum to the rest of the encephalon in this case. The 
other weights which are usually recorded could not be taken, because further dissection of the brain was impracticable in view of the other observations to be made on it.

\section{Linear Measurements.}

On Nov. 4, 1889, the following measurements were made: Greatest length of left hemisphere,

$178 \mathrm{~mm}$.

$$
\text { " " right "6 }
$$

The masimum width of eerebrum,

The maximum height of cerebrum, $180 \mathrm{~mm} . *$ $153 \mathrm{~mm}$.

The longest perpendicular distance, taken on the mesal $129 \mathrm{~mm}$. aspect of each hemisphere, from the line measuring the length of the hemispheres to the dorsal surface, is in this case the same for both hemispheres,

The encephalon being in the normal position, the distance between a perpendicular plane just touching the tips of the temporal lobes and one just touching the tips of the frontal lobes was found to be

$57 \mathrm{~mm}$.

Schwalbe's $\left({ }^{22}\right)$ figures for similar dimensions in the female brain are, greatest length in the majority of cases, from 150 to $160 \mathrm{~mm}$., the limits being 142-189 $\mathrm{mm}$. (Huschke). The mean breadth is given at $140 \mathrm{~mm}$., whereas the height is given at $125 \mathrm{~mm}$. For the longest perpendicular as above described, and the distance from the tip of the temporal to the tip of the frontal lobes, I find no data that are comparable. For comparison on the last measurement, I have used three male brains which were hardened in bichromate and alcohol in the usnal manner, and which are nearly the same length as our sperimen, (from 2 to $11 \mathrm{~mm}$. longer). In these the temporo-frontal distance, if I may so call it, was respectively 47,41 and $51 \mathrm{~mm}$., as compared with $57 \mathrm{~mm}$. in Laura.

Of course, the swelling of the encephalon due to hardening has increased all three diameters, and so the figures given for Laura cannot be compared with those from Schwalbe until some correction has been made in them. Such correction I am at present unable to make. Assuming, howerer, that the enlargement along the several diameters is proportional to their initial length, we can make the calculation for the

* Where similar measurements for the two halves of the brain are given, the larger figure is in heavier type. It is hoped that this device will render the comparison of the two sides easier. 
cerebral index, the mean length being taken as $179 \mathrm{~mm}$., and breadth $153 \mathrm{~mm}$. The so-called cerebral index, obtained by dividing the latter by the former, equals $85+$, showing the cerebrum to be markedly brachycephalic. The excessive temporo-frontal distance appears plainly to be due to deficient development of the temporal lobes.

\section{General Description of the Encephalon.}

In order to give some data for the control of the foregoing measurements, a general description of the specimen will be useful. To the medulla was attached a piece of the cord which extended $17 \mathrm{~mm}$. from the superficial caudal termination of the decussation of the pyramids. This length was about that usually obtained where the cord is cut through the foramen magnum. The shape of the specimen was well preserved, owing to its having been hardened in the dura. The angle between the stem and cerebrum was approximately normal, and the relation of the cerebellum and hemispheres therefore but little disturbed. The hemispheres overlapped the cerebellum slightly. The vessels forming the circle of Willis were certainly not large. Of the internal carotids the right was the larger, but only slightly so, and the posterior communicating arteries were small, even in proportion to the other vessels.

In passing now to the several subdivisions, no effort will be made to give a complete description, for the nature of the specimen is not such as to demand that, and all exact measurements will be left until the parts are studied histologically.

Medulla and Pons.-The nerves from this region were identified, except the spinal accessory, which could not be found, having been probably pulled away in remoral of the specimen. Here, of course, it is the glossoplaryngeus, the acusticus and the abducens associated respectively with the sense of taste, of hearing, and the external rectus muscle of the eye-ball, that are of special interest. These appeared somewhat reduced in size, though all the cranial nerves were small. On the ventral aspect of this region, neither the olivary bodies nor the pyramids were prominent. The anterior 
median sulcus between the pyramids was well marked, as was the ventral depression on the pons. On the lateral aspect, the corpora restiformia appear well developed. On the dorsal aspect, the floor of the fourth ventricle was seen to be clearly marked. There was a well developed ligula and obex. The nuclei of the columnce graciles made evident swellings in the course of the dorsal columns of the cord, those of the column of Burdach being less marked. On the floor of the ventricle, the alce cinerece and trigona hypoglossi were very evident. The strice acusticce or medullares were particularly clear. The point is of interest, since the strice are looked upon as part of the auditory path in this region. A more detailed description of them will be given later.

Cerebellum.-As we have seen, the cerebellum has thus far offered no peculiarity. The peduncular connections were as usual, and a sagittal section shows the arbor vitce with the characteristic sub-divisions. In the general conformation, there was nothing to excite remark.

Mid-brain.-The oculo-motor nerves were, perhaps, a trifle small. The trochlearis was not found. On the ventrolateral surface, a search for tractus peduncularis transversus of $\mathrm{v}$. Gudden $\left({ }^{23}\right)$, which appears to have some connection with risual apparatus, was unsuccessful. However, it must be remembered that this tract is not always superficial in normal individuals, and therefore failure to detect it is not proof that it has degenerated. On the dorsal aspect, the frenulum was well marked. The posterior pair of the corpora quadrigemina was rather small, but well rounded and both alike. The median groove, the transverse groove separating them from the anterior pair, and the brachia, were all well marked. The anterior pair of the corpora quadrigemina were much flattened towards the middle line. Brachia not evident.

As the result of the cuts necessarily made to allow the entrance of the hardening fluid, and the failure of this region to harden, subsequent dissection has yielded but small results. Of the condition of the corpora geniculata on the right side, nothing can be said. On the left side the corpus geniculatum internum can alone be described, and this was comparatively large and prominent. 
Inter-brain.-On the left side of the specimen the pulvinar had been preserved, and there it was reduced in all dimensions, and but little arched; on the other side it had broken away and conld not be described. The caudal portion of the third ventricle was large. There was a well developed median and posterior commissure. The general lack of development in this inter-thalamic region is not shared in by the pineal gland and its connections, the habenulce and tigona habemula, which were disproportionately enlarged-an enlargement which is probably due to the removal of pressure from the surrounding structures. Turning now to the ventral surface, the corpora mamillaria and, it may be added, the fomix, were normal. About the pituitary body, there was nothing peculiar, but the infundibulum is prolonged ventrad to an unusual degree, and is bounded on either side by the greatly shrunken optic tracts. The relations of the anterior commissure in view of its connection with the olfactory centres would have been interesting, but the specimen did not show this commissure, owing to imperfect preservation.

Before proceeding to the callosum and the hemispheres, it may be well to consider what we should expect to find in these portions. There is no suggestion in this case that would lead us to anticipate appearances such as are recorded for microcephalic, criminal, or low-type brains belonging to the least civilized races. Neither is the case to be associated with those in which the defect or arrest of development was dne to canses originating within the central nervous system. There was not the slightest indication of abnormal mental action, and therefore the brain would not be expected to resemble that of the insane, if for the moment we admit that the brains of the insane show gross peculiarities. What we have is the brain of a normal person who lost at about two years of age the senses of sight, hearing, smell and taste, through injury to the peripheral sense-organs, but who remained mentally balanced throughout a long life, though under conditions which would favor mental derangement, had the tendency to it existed. This loss would have but a moderate power to destroy what was already formed in the brain, though it would do so to some extent. 
The chief effect would be to retard the further development of those portions which represented the lost senses, but even here the hereditary laws of growth wonld act to some extent independently of the modifying conditions which existed in such a case.

As a point of departure, then, it would be interesting to know what was the state of development of an average female brain at the commencement of the third year of life. If we take 1245 grms. as the average weight of the female encephalon, we find that at the commencement of the third year or end of the second, the average weight is about 920 grms. for females. [See Boyd's tables quoted by Schwalbe $\left({ }^{22}\right)$, and Bischoff's $\left({ }^{19}\right)$ table of five observations, made up from those of Huschke and Sims. The figures quoted by Vierordt $\left({ }^{24}\right)$ are not available, because no distinction of sex is made, and, as is well known, such a distinction exists at birth and even in the fœetus.] If 920 grms. is the true figure, then at this age the weight of the encephalon is abont three-fourths that of the adult. As the specific gravity is somewhat less, its volume is proportionately a trifle greater.

On the relations of the nerve-cells and fibres, not much can be said that is satisfactory. Whether we have the elements all formed at birth, and they undergo simply an increase in size during the subsequent processes of growth, so-called, or whether we have new elements formed after birth, is a question for the decision of which the evidence is as yet scanty. Schiller $\left({ }^{25}\right)$, at Forel's suggestion, determined with due precantions the number of nerve-fibers in the oculo-motorize of kittens at birth, and cats at the end of the first year, and found practically the same number in both cases. In this animal and this nerve the number of fibers, then, does not increase after birth. In man, however, the period of helplessness and development after birth is comparatively long, and Below $\left({ }^{26}\right)$ has found in animals that the cortical cells are less developed in those born helpless than in those born in a more mature state. Incompleteness in the development of the central nerve-cells wonld favor the idea that they might still undergo multiplication after birth. As a matter of fact, the development of the cortical cells in the human fœtus is ineomplete 
at birth (Obersteiner ${ }^{27-p .367}$ ), and the development of medullated fibers far more incomplete. The medullation of fibers is continually going on during the early years of life, and there is evidence that it is for the most part completed about the eighth year. For those who hold that practically the number of elements is fixed at birth, the increase in the size of existing elements, and especially the medullation of the fibers, are the causes of the enlargement of the encephalon. If such is the case, however, and Galton's $\left({ }^{28}\right)$ measurements on the heads of Cambridge undergraduates mean what he takes them to mean, $i$. e., brain growth, then the process of medullation or enlargement, or both, must continue in some cases up to the twenty-fifth year.

If we turn now to the sulci and gyri, we find all the important ones present at birth $\left[\right.$ Ecker $\left({ }^{99}\right)$, Rüdinger $\left.\left({ }^{43}\right)\right]$. At that time, the cerebral surface is marked in a typical manner, and according to Ecker the asymmetries which occur in the sulci are caused by the later derelopment of accessory sulci. What the history of these accessory sulci may be, has not, I believe, been studied, and how far they may be developed during the first two years of life, is therefore an open question; but a priori one would imagine that the earliest years of life would be the time when they would appear. Be that as it may, it seems highly probable that the relations of the primary and secondary sulci are fixed to a large extent at birth, and that subsequent development has but a slight influence in altering these relations.

In the child at birth, and during the first years of life, the relative development of the several lobes of the brain is not the same as in the adult. Designating the lobes as occipital, temporal, insular, parietal and frontal, Bischoff $\left({ }^{19}\right)$ states that it is the last two which develope most in later years, and of these the parietal undergoes the greatest enlargement; but the observations on this point are few.

Applying the above conclusions to our case, we may describe Laura's brain at the age of two years as having about three fourths of its adult weight, the cells of the cortex being fairly developed, whereas the medullation 
of the fibers was incomplete to a considerable degree. The primary and secondary sulci were all present, and probably some of the accessory sulci also; and the parietal and frontal lobes were less developed than the should be in the adult. If the callosum is commissural for the different portions of the cerebral cortex, we might expect it to accompany the cortex in development. In the absence, so far as I am aware, of explicit observations on this point, we may assume the callosum well developed at this age.

On such a brain as we have described, what would be the effect of a lesion, like that which occurred in the case of Laura? The nerves and their primary centres would show degeneration, and later some atrophy, then after the lapse of time, arrest of development, in so far as they were incompletely developed at the date of the injury. In the cortical regions, so far as they might be affected, we should probably expect some arrest of development which would show itself on gross examination, and certainly some histological indications of arrest and possibly degeneration. Further, as one result of the limitation in mental activity due to the great defect in the senses, a general appearance of immaturity might be anticipated, while if certain lobes were affected more than others, a disproportion in development as compared with the normal would result. It seemed advisable to make some analysis of the case at this point, in order that no ungrounded expectation of striking anomalies might be cherished, and it will be the chief purpose of the following pages to show in how far actual observations bear out the views above advanced.

Callosum.-The callosum was well developed. On the surface exposed by a sagittal section dividing the two hemispheres, the distance of a straight line between the extreme points was $82 \mathrm{~mm}$., while a line following the dorsal curve and joining the same points, is $87 \mathrm{~mm}$. long. The height or thickness, as one chooses to call it, always measured vertically (the hemispheres being in the normal position) is $22 \mathrm{~mm}$. at the rostral end, $12 \mathrm{~mm}$. in the middle, and $15 \mathrm{~mm}$. at the splenial end. The area of surface exposed by the section was $1172 \mathrm{sq}$. $\mathrm{mm}$. The linear measurements exceed somewhat those given by 
Krause $\left({ }^{30-1 ; d .2, ~ p . ~} 965\right)$, especially those for the thickness, but I am not sure that mine were taken in the same way as his were; and furthermore, his apply to the fresh specimen, while this was swollen by hardening. Comparison with other specimens hardened in potassium bichromate, shows these figures nevertheless to be large. From gross examination, therefore, the callosum appears to have developed completely.

Cerebral hemispheres.-On looking at the hemispheres, the general shape appears normal, but they are somewhat flattened at the occipital pole. The temporal lobe is comparatively small, the tip being thin, and on the orbital surface of each hemisphere at the cephalic end is a marked conical elevation of the general surfaces with the apex directed ventrad. This elevation appears on either side of the median line, just in front of the point where the sulcus olfactorius terminates. As the formation is not usually described, and is only faintly suggested in most brains, it is probably an anomaly due, in this case, to the failure of the orbital plates of the frontal bone to develop in the usual manner, thus leaving more of a depression in the bone at this point than ordinarily occurs. To this depression the brain has accommodated itself, with the result of producing the appearance described. When viewed from above, the general effect was quite similar to the typical female brain, as depicted by Wagner $\left({ }^{31}\right)$, the chief difference being that our specimen was not quite so pointed in the frontal region as Wagner's plate of the female brain, and had the gyri in the occipital region in less relief. The gyri were for the most part widely separated from one another, especially in the frontal and parietal lobes whereas in the occipital they tended to be close together. In general, the gyri were large, but little interrupted and moderately sinuous, and the insula was more exposed on the left than on the right side. The typical arrangement of the gyri was easily followed, and the two hemispheres quite symmetrical in their markings. The symmetry of the hemispheres, the continuity and size of the gyri, may be taken as indicating an average or perhaps less than average development in these respects. Such a statement has, however, so little foundation that is measurable and exact, that it will be best to leave it in the form of a 
mere suggestion. There is some departure from symmetry in the two hemispheres, where, on the mesal surface of the occipital region, the ventro-caudal portion is smaller in the right hemisphere. This is shown in an exaggerated way in Plate II, Fig. 4.

As illustrating the general development of this specimen, I introcluce here several measurements which were made while the brain was in potassium bichromate.

Taking the smalker angle which the fissura centralis makes with the middle line, following the method of Eberstaller $\left({ }^{32}\right)$, it was found to be,

For left hemisphere, $65^{\circ}$.

For right hemisphere, $61^{\circ}$.

This is smaller than is usually stated. Wilder $\left({ }^{33}\right)$ gires $67^{\circ}$ as an average, and Eberstaller $70^{\circ}-75$.

If we take the entire length of the mesal edge of the hemispheres measuring from the trigonum olfaciorium to the occipital pole, and then the distance from the trigonum olfactorium to the point where the fissura centralis reaches the mesal surface, we obtain the following figures:

$\begin{array}{ll}\text { Left hemisphere, entire distance, } & 334 \mathrm{~mm} \text {. } \\ \text { Right 6" } & 331 \mathrm{~mm} \text {. } \\ \text { Left hemisphere, distance to fissura centralis, } & 214.5 \mathrm{~mm} \text {. } \\ \text { Right } 6 \text { ": } & 216 \mathrm{~mm} \text {. }\end{array}$

This, reckoned in per cent. of the entire distance, gives the last distance or extent of frontal lobe along this line, as

Left hemisphere, $\quad 64+6$.

Right hemisphere, $65+\%$.

Eberstaller $\left({ }^{32}\right)$ gives for the female brain, $66 \%$. Our figures, therefore, approximate closely to his average. Measuring the fissura Sylvii on each side from the point where it gives off the anterior rami to the point where it gives off the ramus posterior ascendens, it was found,

For the left hemisphere, $\quad 53 \mathrm{~mm}$.

For the right "6 $52 \mathrm{~mm}$.

This makes it shorter than the average figures for females found by Eberstaller $\left({ }^{32}\right)$, which was $56.5 \mathrm{~mm}$.

Among these figures, one set (namely that for the position of the mesal end of the fissura centralis) is in 
percentage, and that agrees fairly well with the results of other authors. It may be presumed, then, that in hardening the encephalon has not undergone much distortion. If that is true, then the small angle of the fissura centralis with the middle line is probably a true relation. Despite the enlargement of the specimen, the length of the fissura Sylvii as meas: ured is under the average, but the relations of the two sides are as Eberstaller found that is, the left is the longer.

The condition of the ventricles was not easily made out, owing to the state of the specimen and the cuts in it, which somewhat disturbed the connections here. The lateral ventricles were certainly not large. The descending cormua were well developed, but the right posterior cormu terminated $47 \mathrm{~mm}$. in front of the occipital pole. In the left hemisphere it reaches to within $42 \mathrm{~mm}$. of the occipital pole, and there is a well developed calcar which was not observed on the right side.

Description of the Surface of the Hemispheres.

As was stated earlier, it is not ny purpose to describe in detail the cerebral surface in this case,-as good plates wonld give a far better idea than could be obtained from the text,so that on this occasion I shall be content with some outline figures and a description of those regions which may be regarded as important. The four representations of the specimen were drawn from photographs by means of a pantograph. From these drawings the plates were made by one of the photo-engraving processes. In the figures those sulci which are more constant are put in with a heavy line, whereas the others are in light lines. In the case of the fissure of Sylvius an approximate presentation of the amount of separation of the gyri has been attempted. In the description I shall follow Eberstaller $\left({ }^{32,34}\right)$ in most points and also adopt his nomenclature.

Frontal Region.-In Figures I and II, the sulcus frontalis medius, $f 3$, is clearly marked, thus giving the four frontal gyri, (by sub-division of the gyrus firontalis medius,) which the more recent authors are agreed is the normal condition of the frontal lobe. [Eberstaller $\left({ }^{32}\right)$, Wilder $\left({ }^{33}\right)$, 
Giacomini( $\left({ }^{17}\right)$.] To be noticed on the left side is the union of the sulcus fiontalis inferior, $f 2$, with the sulcus frontomarginalis, fm 3 , which appears somewhat nuusual. Further, on the same side the ramus anterior horizontalis fissurce Sylvii, S 3, runs into the sulcus fronto-marginalis, fm 1 , but at the junction there is a vadum or shallow, (see Wilder, ${ }^{33}$ ) which clearly marks the usual limits of this ramus. Aside from these points the fissuration of both frontal lobes is quite typical. Directing attention to the gyrus frontalis inferior we find it well defined laterally and frontally, but as is usual, poorly defined on the orbital surface. In its entirety that of the left does not differ much from that of the right hemisphere, but there are some differences in detail. Dividing the opercular portions into the pars orbitalis ventrad of $S 3$; pars triangularis between $S 3$ and $S 2$; pars ascendens between $S 2$ and $d$ : and the pars basilaris between $d$ and pci, we find the pars basitaris much less well dereloped on the left side, being especially deficient in its ventral portions. The pars ascendens is deficient throughont on the left side while the pars triangularis is somewhat better developed on this side than on the right. A comparison of the orbital areas is not practicable in this case. It should be added that, on the left side not only is the exposed surface of the pars basilaris and pars ascendens smaller, but both these are sunken below the surrounding gyri; the former completely and the latter in its ventral portion, the frontal edge of the gyrus centralis anterior forming a slight operculum over the pars basilaris.

It is our purpose of course to determine whether these features of the left side can be properly brought into connection with the very limited power of articulate speerh possessed by Laura. There is good ground for the view that in right handed persons it is the portion of the gyrus fiontalis inferior of the left side between the ramus anterior ascendens fissurce Sylvii, S2, and the sulcus prcecentratis inferior, pci, that is the centre for articulate speech. So far as known Laura was right handed. According to Eberstaller ( $\left.{ }^{32-\text { p. }}{ }^{104}\right)$, the pars basitaris may often be sunken, but in such cases, where the brain is normal, the pars ascendens overlaps and more or 
less conceals it. In this case no such overlapping occurs. Several authors have called attention to the value of the comparison of the two hemispheres of the same brain where a lesion was suspected on one side, and judged by that test we certainly have defective development of this gyrus on the left side. A variation, however, which seems to me of considerable importance, is the direction of the sulcus diagonalis, $d$. One characteristic of this sulcus is that in the normal brain its dorsal end lies further caudad than the ventral end. On the left side in Laura this direction of the sulcus is reversed, the ventral end being further caudad and to all appearance it occupies this anomalous position because the ventral portion of the pars basilaris has failed to develop. On the right side it has the normal direction.

In this connection the exposure of the insula is significant. I estimate this exposure for Laura:

$$
\begin{array}{lr}
\text { On the left side, } & 128 \mathrm{sq} . \mathrm{mm} \text {. } \\
\text { On the right side, } & 46 \mathrm{sq} . \mathrm{mm} \text {. }
\end{array}
$$

That is, the surface of the insula exposed on the left side is nearly three times that exposed on the right. In looking at the collection of brains in the museum of Cornell University-a collection which has been gathered by Prof. B. G. Wilder,I found no exposure of the insula which approached even that on the right side in Laura, save in the left hemisphere of a negro (catalogue number, 322), in which the exposure was somewhat less than on the right hemisphere in our case. Of course the absolute relations of the specimens have at present no value since the Cornell brains were hardened in alcohol and therefore had undergone some shrinkage. It may, however, be permissable to conclude that on both sides the exposure of the insula in Laura was large, and that on the left side it was much larger than on the right.

Exposure of the insula may be considered in general as characteristic of incomplete development (Rüdinger $^{35}$ ). According to this test, then, there is here a general lack of development which is most marked on the left side. This exposure is due, however, only in part to the small size of the gyrus frontalis inferior which contains the presumptive speech centre, and to which we have hitherto 
specially attended. Rüdinger( $\left.{ }^{35-p .45}\right)$ describes for mutes that have lost the power of speech as the result of deafness and who are otherwise normal, certain slight abnormalities of the speech-centres - but seems surprised that they are not more marked. Without entering into any detail it is evident that the variations in his cases and in that of Laura are similar, and Zuckerkandl $\left({ }^{26}\right)$ also notes as defects in the development of the speech-centre some that we do not find here, but among those that we do find, he mentions the depression below the general surface of the pars ascendens and basilaris, the hiding of them by surrounding gyri, which thus form an operculum at this point, the exposure of the insuld and failure of the tip of the temporal lobe to attain its full size. Zuckerkandl $\left({ }^{36}\right)$ has also something to say with regard to compensatory development on the assumption that such compensation may be physiological as well as morphological. Whereas the pars ascendens and basilaris ate less well developed in the left hemisphere in Laura, if the pars triangularis of the left side is compared with that of the right it is found to be somewhat larger. It might be urged that this better development of the pars triangularis indicated that it had taken on some of the functions of the undeveloped portion. At the moment I am aware of no positive evidence in favor of such a transfer of function and hence do not consider the objection important. Closely associated with this region is the insula, but the discussion of that will be deferred until we consider the cortical derelopment of the brain. From what has been said, then, I conclude that the centre for articulate speech in this case shows some defect, which is most naturally explained as arrest of development. The nature of this arrest will be brought up when we come to the histology of the region.

Occipital Region.-We next turn to the occipital region which is represented in Figs. III and IV. The occipital lobe, and specially the cuneus, in man, appears to be the cortical centre for vision, - but just what the limits of the occipital lobe are, and how much of this area is specialized as a visual centre, are not precisely determined. Ecker's( $\left.{ }^{3 i}\right)$ description of the occipital lobe has not been found satisfactory by later an- 
thors and several attempts have been made to improve on his account. Here I follow Eberstaller's description( ${ }^{34-\times 0.18}$ ). According to him the occipital lobe is best considered as that portion of the hemisphere enclosed between the fissura calcarina ( $c a)$, the sulcus parieto-occipitalis ( $p . o$.), the sulcus occipitalis anterior (occ. ant.) and the sulcus occipitalis lateralis (occ.lat.). The sulcus occipitalis anterior is the homologue of the "ape fissure" of the anthors. The gyrus between the mesal end of the sulcus occipitatis anterior and the sulcus parietooccipitalis is the gyrus amectans superior, while that between the lateral end of the sulcus occipitalis anterior and the sulcus occipitalis lateratis is the gymus annectans inferior. The complete enclosure of the area must be to some extent artificial, but I shall make it by joining the several sulci with one another at the points where they come nearest together, using the two ends of the sulcus occipitalis anterior and the candal end of the fissura calcarina as points from which to start the limiting lines. Of the accessory sulci within this area I have at the moment nothing to say.

The left hemisphere, Fig. III, shows a typical arrangement of the sulci bounding this lobe. On the right side the arrangement is similar, but the sulcus parieto-occipitalis does not show on the dorsal surface and hence there is nothing to match that sulcus on the left side. On the right, also, the whole occipital region is smaller as shown by the principle outlines, and just laterad of the most caudal end of the sulcus occipitalis anterior is a small group of very shallow sulci which appear hardly deeper than vascular grooves, but which section of the region shows to be true sulci.

The smaller size of the region on the right side and the peculiar sulci just mentioned are the principal points which suggest defective development, as the failure of the sulcus parieto-occipitalis to appear on the dorsal surface is not so uncommon in normal individuals. At the same time the fact that this same sulcus is well developed on the left side while it is poorly developed on the right is suggestive when taken in connection with the defects already noted. The gyri of this region are all rather narrow and closely pressed together, thus rendering the intra-lobar sulci inconspicuous. Eberstaller 
(34-Yo.19) notes that the length of the are from the occipital pole to the point where the sulcus parieto-occipitalis cuts the edge of the mantel is to the entire arc, $i$. e., to the trigonum olfactorium (see p. 23), as 1 to 6 . Measured on the left side in Laura it is 1 to 6.1 , and on the right it is 1 to 6 . This for our purpose is not so significant as the arc between the caudal end of the fissura calcarina and the point where the sulcus parieto-occipitalis cuts the edge of the mantel, which is,

$\begin{array}{ll}\text { On the left side, } & 50 \mathrm{~mm} . \\ \text { On the right side, } & \mathbf{2 9} \mathrm{mm} .\end{array}$

Showing the great reduction in that measurement of the cuneus on the right side. Further, whereas the arc of the preecuneus and that of the cuneus are about the same length on the left side-a condition of things which is normal,-on the right side that of the procuneus is much longer than that of the cuneus. These relations are shown in Fig. IV, where, as can be seen, one cause of the reduction in size of the cuneus is its apparent displacement dorsad of the fissura calcarina. In the left cuneus I find nothing peculiar to describe. In the right side the sulcus parieto-occipitalis may be considered to branch just below the letter $p$. The ramus marked p.o. runs dorsad towards the edge of the mantel, bnt never reaches the dorsal surface, as the bounding gyrus has its concavity ventrad and its convexity dorsad. The other branch, running almost vertically in Fig. IV, appears to unite with the sulcus which, lying cephalad to the sulcus parieto-occipitalis, represents that described by Eberstaller( ${ }^{24-N o .18}$ ) as a branch of the interparietal, and by Wilder $\left({ }^{38}\right)$ as the cephalic stipe of his fissura paroccipitalis. The union is apparent only, and is caused by the extension candad, in the form of an operculum, of the pracuneal wall that bounds these sulci. On removing this operculum, the sulcus parieto-occipitatis is seen to be represented by the sulcus marked $p . o$. alone and to have undergone something of a bend with the concavity caudad, at the point of apparent branching, but the relations with the fissura calcarina are normal. The appearance here is somewhat further complicated by a considerable development of the accessory sulci on the mesal surface. So far as we have gone, therefore, the right cuneus is less well developed than 
the left. It will be recalled that we also found the posterior cornu of the left side in better condition than on the right. From these facts it appears that the right occipital lobe shows several anomalies which when all are taken together indicate that the arrest of development has been more marked on this side. It will be remembered that up to her seventh year Lanra was somewhat sensitive to light in her right eye while she was completely blind in the left. That sensitiveness meant the preservation of a certain portion of the retina in the right eye for some five years longer than in the left. The conservative value for the nerve centres of even such weak stimuli has long been recognized, and it is but natural therefore that the occipital lobe chiefly connected with the right eye should be better preserved than the other whose development was presumptively arrested earlier and during the years most important for growth.

Temporal Lobe.-This is disproportionately small and alike on both sides. The failure to develop appears to affect most of all the tip. In Lama's case I have not discovered anything that seemed to deserve study as an anomaly, so far as the gross anatomy of this region is concerned, and I can present nothing on the cortical centre for hearing, on the assumption that that centre is in or about the first and second temporal gyri [Horsley and Sehäfer $\left({ }^{40}\right)$, Starr $\left.\left({ }^{41}\right)\right]$. It may be that the defects in the sense of smell and taste have left their mark on the uncinate gyrus and its neighborhood, if Ferrier's $\left({ }^{39}\right)$ localization is accepted; but it must be remembered that neither of these senses was entirely wanting, although the former was very defective. I should hesitate, however, to adduce any direct evidence from our ease.

While searching for defeets it is only fair to keep in mind that the eentres for those senses and activities which Laura did retain might have undergone an unusual development. Nevertheless, her finger dexterity in talking would not, I should think, call for unusual control from the cortex and the refinement of touch in her case appears to have been limited to the hands and face. The portion corresponding to the finger and thumb area (see Mills ${ }^{42-p, 230}$ ) is fairly devel- 
oped on the left side and not quite so well on the right, but there is nothing in the gross appearance that is remarkable. Since the interesting work of France $\left({ }^{53}\right)$ on the gyrus formicatus and the association of this with dermal sensibility in monkeys, I was led to examine this region with such care as the poor condition of this part of the specimen would permit, but with negative results.

\section{Measurements of Cortical Areas.}

Every now and then during the present century various investigators have made the attempt to get at the quantity of gray matter in the cerebral cortex, both in man and some of the animals. It has thus far proved impossible to obtain a figure for this portion of the brain which would have the accuracy, for example, of those we possess for its weight, but several approximations have been made which are of some value. The questions which such an examination was designed to answer have not always been briefly formulated and it will be as well to state at once what we expect from it in this case. We wish to know whether those portions of the cortex, which in Laura we suspect are defective and which belong to one hemisphere, will prove to have a less area, when the two hemispheres are compared with one another. We wish to know further whether the total area of the cortex is, in our case, less than the total area of the cortex in a normal brain with which that of Laura might be compared. In the statements just made the term area has been alone used, but of course if we knew at the same time the average thickness of the cortex, then the masses of the cortex might as easily be compared as the areas. These measurements are for the most part neglected in the usual description of specimens, as it takes some time and trouble to make them, and the results are perhaps not proportionate to the expenditure of energy necessary for this. Nevertheless when we get them all together there is quite an array of figures to be found in the literature.

With a view to rendering these results intelligible I shall briefly present some of the objects and conclusions of investigators in this line. R. Wagner $\left({ }^{31}\right)$ made a number of direct 
measurements of the area of the convex (as distinguished from the mesal) surface of specimens in the famous Göttingen collection, which contained among others the brains of Gauss, Fuchs and Dirichlet. He was followed by his son, H. Wagner $\left({ }^{44}\right)$, who measured not only the entire exposed surface but also the length and depth of the sulci, from which the sunken surface, i.e., the portion forming the walls of the sulei, could be calculated, and from these two results the total area of the cortex was obtained. In carrying this task to completion $\mathrm{H}$. Wagner established several relations between portions of the cortex which subsequent investigation has tended to confirm. The main problems which the Wagners had in mind were: first, whether individuals of superior intelligence had the frontal lobes unusually developed; and second, whether, if the individuals were arranged in series according to intelligence, the figures for the areas of the cortex of the respective brains would follow the same order. To the first question the answer was negative; to the seeond, apparently positive. At the same time the brains of the more intelligent individuals in their series were in general heavier $i . e$. larger than those of the less intelligent and their table might as well be interpreted to mean that in general the larger brains have the larger cortical areas. From the data given by H. Wagner $\left({ }^{44}\right)$ I form the following table to illustrate this last point:-

$\begin{array}{lcc}\text { Weight of Cerebral } & \begin{array}{c}\text { After Hardening } \\ \text { in Alcohol. }\end{array} \\ \text { Hauss, } & 1492 \text { grm. } & 957 \text { grm. } \\ \text { Fuchs, } & 1499 \text { grm. } & 895 \text { grm. } \\ \text { Frau, } & 1185 \text { grm. } & 8 \text { rrm grm. } \\ \text { Krebs, } & 1273 \text { grm. } & 761 \text { grm. }\end{array}$

Total Area of Cortex.

219588. sq. mm. 221005. sq. mm. 204115. sq. mm. 187672. sq. mm.

It may be noted in passing that Table VIII of H. Wagner $\left({ }^{44}\right)$ is the one that appears in the text books where the figures for the area of the cortex are given. The total area in the original table is expressed as the sum of the areas of the frontal, parietal, occipital and temporal lobes. As a matter of fact it is the sum of these plus the area of the insula (Stammlappen), but the figures for the insula have been omitted in the printing of the original table. It thus happens that the figures representing the total area are somewhat larger than the sum of those for the separate lobes as given 
in the table. This omission in the original has been perpetuated by the text-books, but so far as I know attention has not previously been directed to it.

Most directly in the line of Wagner's work is that of Jen$\operatorname{sen}\left({ }^{45}\right)$ who measured the area of the cortex on six brains of the insane with a view to finding whether they exhibited any peculiarities in this respect. His results were negative.

There are two points in this connection which I desire to emphasize. First, the authors who have undertaken this sort of work have at the same time realized that the thickness, structure and nutrition of the cortex were factors entirely left out of account, and probably of the greatest importance; and second, we have thus far complete measurements only on brains hardened in alcohol in which a decrease in weight of $27 \%-40 \%$ has taken place and consequently no results are at hand to determine by this method the area of the cortex in the fresh normal brain.

Vogt $\left({ }^{46}\right)$ in his study of microcephalics has given the areas of the exposed surface of the brains. These measurements, however, were taken not on the specimens, but on the casts of the cranial cavity. Of the other methods that of Baillarger $\left({ }^{47}\right)$ is the most direct, though not the most satisfactory. $\mathrm{He}$ separated the cortical surface in the fresh specimen by dissecting out the white matter from the hemispheres. This made it possible to unfold the cortex and thus get at the area by direct measurement. His figure for the total cortical area of the hemispheres is $170000 \mathrm{sq}$. mm. which he thinks may be correct within $7 \%$ for his cases. Besides these there are methods which may be designated respectively as the geometrical, physical and chemical. In a certain sense the measurements of the Wagners and Jensen were geometrical as the cortical surface sunken in the sulci was calculated from the observed length and depth of the sulci. Calori $\left({ }^{48}\right)$ reduced the exposed surface of the hemispheres to geometrical forms and measured them in that shape, using the device alread $y$ described for getting the area of the sunken cortex. Giacomini is of the opinion that Calori's method is less exact than that of the Wagners and Jensen. The specimens had been hardened in alcohol. His problem was the varia- 
tion in the total area according to the shape of the head. The results which Calori has obtained from a very large number, 41, of Italian brains, measured by his method, are indicated by the following average figures:

$\begin{array}{lll}\text { Male: } & \text { Brachycephalic, } & 243773 \mathrm{sq} \cdot \mathrm{mm} . \\ \text { Male: } & \text { Dolicocephalic, } & 230212 \mathrm{sq} \cdot \mathrm{mm} . \\ \text { Female: } & \text { Brachycephalic, } & 211701 \mathrm{sq} \cdot \mathrm{mm} . \\ \text { Female: } & \text { Dolicocephalic, } & 198210 \mathrm{sq} \cdot \mathrm{mm} .\end{array}$

The physical method of getting at similar results is based on the weight of the entire brain, its specific gravity and the specific gravity of the gray and white matter that compose it. This method has been introduced by Danilewsky $\left({ }^{49}\right)$. The result is the percentage of gray and white matter in a given specimen. If now a certain proportion of the gray matter is assumed to belong to the cortex we can obtain the mass of the cortex and in turn assuming a certain average thickness for the same we can calculate the area. Omitting all detail, Danilewsky $\left({ }^{49}\right)$ found:

For encephalon weighing $1240 \mathrm{grm}$., total cortical surface, $158800 \mathrm{sq} . \mathrm{mm}$. " "6 " 1324 " " " " 169200 " "

As will be seen these figures fall below any that have thus far been given.

In the chemical method, so called, the percentage of water is determined instead of the specific gravity and from data thus obtained the mass or area of the cortex can be determined. More or less complete data for the percentage of water in the gray and white matter of the brain have been furnished by Bourgoin $\left({ }^{50}\right)$, Desprez $\left({ }^{51}\right)$ and Forster $\left({ }^{52}\right)$. Giacomini takes the view that of the last two methods the chemical one is the more exact. At his suggestion DeRegibus( $\left.{ }^{17-p .276}\right)$, examined several brains and obtained the following figures for the area of the cortex :

$$
\begin{aligned}
& \text { 1. Single hemisphere, } \\
& \text { 2. Both hemispheres, } \\
& \text { 3. 6 } \\
& \text { 4. 6 }
\end{aligned}
$$

$128000 \mathrm{sq} . \mathrm{mm}$. $278940 \mathrm{sq} . \mathrm{mm}$. $245160 \mathrm{sq} \cdot \mathrm{mm}$. $217472 \mathrm{sq}$. $\mathrm{mm}$.

The original weights of the brains are not given.

The figures obtained by Baillarger $\left({ }^{47}\right)$ and by those authors who have used the physical and chemical methods apply to the fresh brain, having its normal size; whereas all the other figures apply to brains shrunken by alcohol. At the moment 
we have no means of making the corrections required, but it would be fair to expect that measurement on the fresh brain would show a larger area than those on alcoholic brains. If that is a true inference, then it is not a little curious that of these authors just mentioned only DeRegibus presents figures which are at all comparable with those of the Wagners, Jensen and Calori, the figures from the other observers being smaller.

I pass now to the measurements of our own specimen. The questions to be answered have already been stated: 1st. To determine any differences between the areas of special regions in the two hemispheres. 2nd. The total area of the cortex.

Method of Making Measurements. Investigators have covered the exposed surface of the cortex with squared paper, tin foil, gold-leaf or something of the sort, and then by computing the number of these squares required to cover a given region have calculated the area. In this instance I moistened thin sheets of gelatine until they were flexible; these were then laid on the surface and the outlines of the exposed portions of the gyri traced on them by means of India ink. The area of a region having thus been transferred to the gelatine it was removed, a copy of it taken on tracing paper and numbered. The same area was enclosed by a line on the plaster cast and given the same number, thus each region was recorded. The gelatine sheet was placed over a piece of standard paper ruled in squares $2 \mathrm{~mm}$. on each side. Under a lens magnifying 6 diameters the number of squares enclosed by the outline was enumerated and reduced to millimeters. The method proved quite practicable and accurate. In getting the area from the gelatine sheet measurements were made to square millimeters.

The length of the sulci was taken with compasses where that was permissible, but usually with a strip of tin foil marked in centimeters. The fractions of a centimeter were taken with compasses and read on a millimeter scale. The depth of the sulci was taken with a fine hard rubber probe, a trifle enlarged at the tip so that it had there a diameter of $1.3 \mathrm{~mm}$. On this a button of pith which slipped easily served to mark the dis- 
tance to which the probe was inserted, and this distance was read off on a millimeter scale. The majority of the sulci were sounded every centimeter, short ones at lesser intervals. The calculations of the sunken surface were made on the assumption that the lines representing the length and depth formed with one another rectangular figures. Jensen's $\left({ }^{45}\right)$ argument for considering these figures zonal segments, on the convex surface at least, was at the time unknown to me, but I think that the error introduced by the method used has in our case largely balanced out, since the direct measurement of the depth of the sulci was constantly too small. The figures were not summed until all the data were collected and they have not been manipulated in any way save as I shall in a moment state. The sums thus obtained are as shown in Table I.

TABLE I.

Total Surface, Sunken and Exposed. (Not corrected.)

LEFT.

Insula,

Frontal lobe,

Occipital lobe,

Residual portions,
RIGHT.

$2026.5 \mathrm{sq} . \mathrm{mm}$.

29584. sq. $\mathrm{mm}$.

3604.8 sq. mm.

47452. sq. mm.

$82667.3 \mathrm{sq} . \mathrm{mm}$.

\section{Absolute difference $=\quad 1398.4$ sq. mm.}

In percentage $=1.8 \%$

As will be seen the result shows the total cortical surface nearly alike in both hemispheres.

By " exposed surface" is meant that portion which does not contribute to the walls of the sulci ; by "sunken surface" that which does thus contribute. The portion of the insula and the operculum which would, under this definition, be called exposed is nevertheless counted as part of the sunken surface from its position, both in the calculations for the surface of the frontal lobe and for the entire hemisphere. In the tables for the insula alone a distinction is made between the sunken surface, as defined, and the other portion, which to avoid ambiguity is there called "convex surface." The total figure for the sunken surface of the frontal lobe or a hemisphere contains, then, the not-sunken or convex surface of the insula and also the operculum which, by the way, 
showed no sulci so far as it was in contact with the insula. As neither of these contribute to form the walls of sulci they are subtracted from the total "sunken surface" before the average depth of the sulci is calculated. Further, in getting the average depth of the sulci, proper correction is made for those instances where the sulcus had been considered to have but one wall, as in the case of the callosal and the cephalic portions of the Sylvian fissures.

The Sylvian fissure is considered to start at the lateral end of the vallecula Sylvii. The limitation of the insula is by the sulcus circularis (Schwalbe). The frontal lobe is limited by the fissura Sylvii, the fissura centratis, and the fissura subfrontalis (Eberstaller). The limitations of the occipital lobe have been previously described as formed by the sulcus parieto-occipitalis, fissura calcarina, sulcus occipitalis lateralis, and sulcus occipitalis anterior.

Finally with regard to the corrections in the figures obtained by direct measurement. Such correction has been made for the depth of the sulci only. This affects in the results, of course, the average depth of the sulci, the area of the sunken surface and the total area. The correction has been made by adding $25 \%$ to the observed depth of the sulci, that is, the observed depths were considered to represent $75 \%$ of their real value, and were increased so as to represent $100 \%$.

A word of explanation is here needed. The facilities for getting the true depth of the sulci in a brain hardened in potassium bichromate are much less than in the case where the hardening has been effected by alcohol. Sulci in our case could not be opened up without fear of injury to the specimen and the resistance by which one inferred that the bottom of the sulcus had been reached was often caused by the approximation of the walls at some distance above the bottom. This error was neglected, however, until the measurements were complete, on the assumption that it would be the same for both sides. The figures obtained, Table I, justified this assumption and what we have to say concerning the relative development of the hemispheres and their sub-divisions can be equally as well based on the original as on the corrected figures; but when 
we desire to compare the total area in our case with that found by other investigators as well as the relations of the exposed and sunken surface, it is absolutely necessary to use the corrected figures. The correction was obtained by measuring sulci in sections of the hemispheres and noting the difference between the true depth and the depth as obtained by the probe. This difference approximated on an average $25 \%$, being a trifle over that figure. It is with regret that I introduce this modification of the results, but certain it is that without the correction the absolute figures would have fallen far below the truth. One point more; we are dealing here with a brain that has swollen in hardening. What the total amount of variation in the area of surface thus produced is, I cannot say, but I see no reason to think that the relations of regions at the surface of the brain have been altered. The portions which did not harden and therefore did not swell were the ental ones, but the cortex throughout was exposed to the action of the fluid in much the same way and does not, I believe, show any distortion that is due to irregularities in the preservation.

\section{Insula.}

I may be permitted to state here that the descriptions of the various regions were written before the following figures relating to them had been tabulated, and that in comparing the figures with the previous description I am comparing independent observations.

Defective development of the centre for articulate speech in the left hemisphere has been already described. When defective development occurs here the insula is often reported as sharing in the defect. The following, Table II, shows the relations for the insula. This table, as well as all those that follow, is corrected in the manner above mentioned.

TABLE II.

Insula. (Corrected.)

Greatest length,

Greatest width,

Convex surface,

Sunken surface,

Total length of sulci,

Average depth of sulci,

\section{LEFT.}

55. $\mathrm{mm}$.

$30 . \mathrm{mm}$.

1458. sq. mm.

363. sq. mm.

88. $\mathrm{mm}$.

$2.0 \mathrm{~mm}$.
Right.

66. mm.

33. $\mathrm{mm}$.

$1625.5 \mathrm{sq} . \mathrm{mm}$.

548. sq. mm.

83. $\mathrm{mm}$.

$3.3 \mathrm{~mm}$. 
It appears from this that the left insula is less well developed than the right in every way except the length of the sulci, in which it is slightly superior.

\section{Frontal Lobe.}

Next in order we take the frontal lobe as above defined.

The frontal lobe is bounded by sulci, and these stand in the table as limiting sulci. One half the sunken surface which lines these sulci is designated as the limiting sunken surface; the other half of course belongs to the lobes bounding the frontal lobe. The area bounded by these limiting sulci is the included area. In this case our interest is in the included area.

TABLE III.

Frontal Lobe. (Corrected.)

LEFT.

11320. sq. mm. $5920.4 \mathrm{sq} . \mathrm{mm}$. $15818.4 \mathrm{sq} . \mathrm{mm}$.

Limiting sunken surface, Included sunken surface,

Length of limiting sulci, Length of included sulci,

Average depth of limiting sulci, $13.0 \mathrm{~mm}$.

Average depth of included sulci, $7.4 \mathrm{~mm}$.
Riget.

12326. sq. mm. $5020.2 \mathrm{sq} . \mathrm{mm}$ 17994. sq. mm.

411. $\mathrm{mm}$.

1117. $\mathrm{mm}$.

$12.1 \mathrm{~mm}$.

8. $\mathrm{mm}$.

Considering the included area and the figures relating to it, we find the left lobe inferior to the right in every point; to this inferiority the suspected gyrus frontalis inferior is assumed to contribute largely. It would seem simpler to compare measurements of this gyrus on both sides, but the difficulty of bounding it cephalo-ventrally has deterred me from trying to make the comparison. The deficiency in the figures relating to the limiting portions on the right side is in part due to the less elaborate development of the fissura subfirontalis (Eberstaller)- the sulcus calloso-marginalis of Ecker.

\section{Occipital Lobe.}

In the earlier description it was brought out that the right occipital lobe and especially the right cuneus were poorly developed. Table IV shows the results of measurements. 
TABLE IV.

Occipital Lobe. (Corrected.)

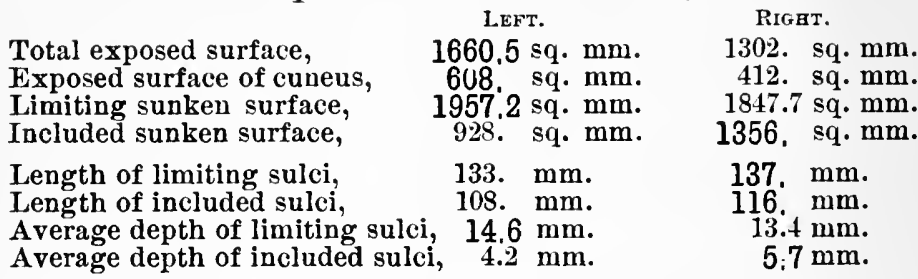

Here again the measurements support to some extent the previous observations. The total exposed surface, and the exposed surface of the cuneus are both less on the right side. But when we come to compare the included sunken surfaces on the two sides the right is superior, and if we sum the total exposed and sunken surface for the two sides we find it:

2588.5 sq. mm. 2658, sq. mm.

That is, it results to the advantage of the right side. The disturbance then which caused the peculiarities of the right lobe did not materially alter the cortical development on the two sides. This would, for one thing lead us to regard the cuneus where the difference between the two sides is striking with especial care. As the table shows, the exposed surface of the cuneus on the left side is the greater. If we add to each exposed surface the sunken surface for this special region, i. e., cuneus, we get the following:

Exposed surface, cuneus, Sunken surface, cuneus,

Total surface, cuneus,
I.EFT.

$602 \mathrm{sq} . \mathrm{mm}$. $376 \mathrm{sq} . \mathrm{mm}$.

$984 \mathrm{sq} . \mathrm{mm}$.
Right.

$412 \mathrm{sq}$. $\mathrm{mm}$.

$428 \mathrm{sq} . \mathrm{mm}$.

$840 \mathrm{sq} . \mathrm{mm}$.

This indicates the total cuneal surface as smaller for the more irregular right side, which is what we might expect if the visual centre is here located. For the rest of the occipital lobe there appears to have been that compensatory growth by which the portions about the cuneus developed more generously as the cuneus, itself somewhat arrested, offered less resistance to their expansion.

\section{Residual Portion.}

What remains after the insula, frontal and occipital lobes have been considered, I call the "residual portion." In itself 
it has no special interest for us at the moment. The figures are given in Table $\mathrm{V}$.

\section{TABLE V. \\ Residual Portion. (Corrected.)}

Total exposed surface,

Limiting sunken surface, Included sunken surface,

Length of limiting sulci, Length of included sulci,

Average depth of limiting sulci, Average depth of included sulci,

\section{LEFT.} 18842. sq. mm. $7877.6 \mathrm{sq}$. $\mathrm{mm}$. $35074.9 \mathrm{sq} . \mathrm{mm}$. 588. $\mathrm{mm}$. 1619. $\mathrm{mm}$.

\section{$13.3 \mathrm{~mm}$.} $10.8 \mathrm{~mm}$.
RIGHT.

19037.2 sq. mm.

6867.9 sq. $\mathrm{mm}$.

31022. sq. mm.

548. mm.

1613. mm.

$12.4 \mathrm{~mm}$.

10. $\mathrm{mm}$.

Having thus presented the data for all portions of the hemispheres it remains to cast them in the form of tables so that, as far as possible, they may be compared with the results of others, and we may thus determine something of the relative cortical development in this case. Table VI gives the total exposed surface according to the limitations previously stated.

TABLE VI.

Total Exposed Surface.

Insula,

Frontal lobe,

Occipital lobe,

Residual portion,

Total,

Absolute difference,

Percentage difference,
LEFT.

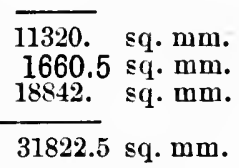

RIQHT.

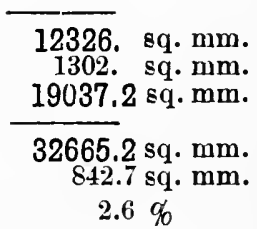

Table VII gives in the same way the total sunken surface.

TABLE VII.

Total Sunken Surface. (Corrected.)

LEFT.

RIGHT.

- Insula,

Frontal lobe,

Occipital lobe,

Residual portion,

$1851.0 \mathrm{sq}$. mm. 21738.8 sq. $\mathrm{mm}$.

$2885.2 \mathrm{sq}$. $\mathrm{mm}$. $42952.5 \mathrm{sq}$. $\mathrm{mm}$.

$69427.5 \mathrm{sq} . \mathrm{mm}$. $3246.2 \mathrm{sq}$. $\mathrm{mm}$.

Absolute difference, Percentage difference,
$2173.5 \mathrm{sq} \cdot \mathrm{mm}$. $23014.2 \mathrm{sq} . \mathrm{mm}$. $3203.7 \mathrm{sq}$. mm. 37889.9 sq. mm.

$66181.3 \mathrm{sq} . \mathrm{mm}$.

* It will be recalled that for our purpose the insula is not considered to have an exposed surface. 
TABLE VIII.

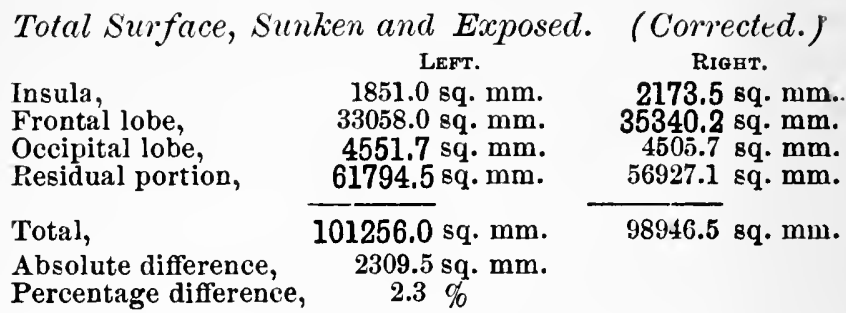

This Table VIII gives the total figures which I consider final for this specimen. To prevent any possible misunderstanding I may state again that Table I, which gives the original figures before they were corrected, is presented to show on what basis the corrections were to be made. And though it is possible that the two tables may be confused, I hope by this explicit statement to prevent such a complication, and make it plain that Table VIII only is the one to be used in comparison with the figures obtained by other authors.

In connection with Table VIII, I have to call attention to. the figures for the total surface of the insula and frontal lobes. of the left side which still remain smaller, whereas the occipital lobe is slightly larger on the left side. On the wholethe area of the left hemisphere is greater, and I associate that with the fuller development of the caudal portions of this hemisphere. (See Fig. III.)

The length of sulci is shown in Table IX, and as will beseen the left hemisphere is a trifle inferior in this measurement. The limiting sulci are of course counted but once, so that if their length is given for the frontal and occipital lobes then the residual portion is to be credited with the included sulci only.

TABLE IX.

$$
\text { Total Length of Sulci. }
$$

Insula,

Frontal lobe, limiting sulci,

Frontal lobe, included sulci,

Occipital lobe, limiting sulci,

Occipital lobe, included sulci,

Residual portion, included sulci,

$\begin{array}{r}\text { LEFT. } \\ 88 \mathrm{~mm} \text {. } \\ 449 \mathrm{~mm} . \\ 1051 \mathrm{~mm} . \\ 133 \mathrm{~mm} . \\ 108 \mathrm{~mm} \text {. } \\ 1619 \mathrm{~mm} \text {. } \\ \hline 3448 \mathrm{~mm} .\end{array}$

$88 \mathrm{~mm}$.

$449 \mathrm{~mm}$.

$1051 \mathrm{~mm}$.

$133 \mathrm{~mm}$.

$108 \mathrm{~mm}$.

$3448 \mathrm{~mm}$.
RIGH'T.

$83 \mathrm{~mm}$.

$411 \mathrm{~mm}$.

$1117 \mathrm{~mm}$.

$137 \mathrm{~mm}$.

$116 \mathrm{~mm}$.

$1613 \mathrm{~mm}$.

$3477 \mathrm{~mm}$. 
Table $\mathrm{X}$ exhibits the average depth of the sulci for each hemisphere. The average depth of the sulci is obtained in the following manner: From the total sunken surface as previously given, the areas of the operculum and convex surface of the insula are subtracted. The areas for the sulcus callosi and the portion of the gyrus frontalis inferior which forms the dorsal wall of the fissura Sylvii, which have not been doubled in estimating the sunken surface, are added to this remainder. The sum is then divided by two, thus giving the area of one side of all the sulci. This divided by the total length of sulci gives the average depth. This process is carried out in Table X.

\section{TABLE $\mathrm{X}$.}

\section{Average Depth of Sulci. (Corrected.)}

\section{LEFT. RIGHT.}

Total sunken surface,

Less sum of opercular and convex insular surfaces, $\}$

$69427.5 \mathrm{sq} . \mathrm{mm}$.

2426.0

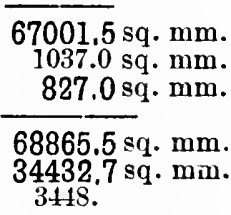

$9.9 \mathrm{~mm}$.
$66181.3 \mathrm{sq} . \mathrm{mm}$.

\section{3.}

$63518.3 \mathrm{sq} . \mathrm{mm}$. $1037.0 \mathrm{sq} . \mathrm{mm}$. $400.0 \mathrm{sq} . \mathrm{mm}$.

$64955.3 \mathrm{sq} . \mathrm{mm}$. $32477.6 \mathrm{sq} . \mathrm{mm}$. 3477.

$9.3 \mathrm{~mm}$.

Gives average depth of Sulci

The table explains itself I think without further comment, except the difference between the figures for the dorsal wall of the fissura Syleii on the two sides, which is due to the fact that the method of measurement was not the same in both cases.

Before we make comparison of those figures which apply to the entire hemispheres, several other numerical relations may be noted. The surface of the frontal lobe in per cent. of the total surface is found to be :

$\begin{array}{lcc} & \text { LEFT. } & \text { RIGHT. } \\ \text { Total surface, } & 1 \text { CO } & 100 \\ \text { Frontal lobe, total surface, } & 32.5 & 35.8\end{array}$

We may also express the relations of the exposed and sunken surface in the two hemispheres:

* Our limits of the frontal lobe enclose a smaller region than those of the other authors who have given figures. 


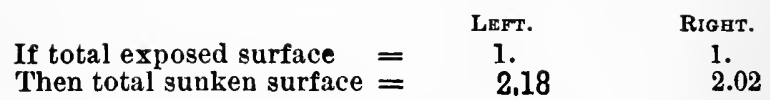

This relation of the exposed to the sunken surface is that which has been found by others, namely, the sunken surface is on the average very slightly more than twice the exposed surface.

Finally $H$. Wagner( $\left.{ }^{44}\right)$ devised a formula by which the exposed surface of the brain could be calculated from its several diameters. Applying this formula to our specimen we find by calculation a figure which is some $25 \%$ larger than that obtained by observation. Evidently the swelling of the brain and the consequent gaping of the sulci renders this formula inapplicable in our case.

It remains now to determine what peculiarities these figures obtained from our specimen show when compared with the figures from other authors, always keeping in mind that the latter figures used for comparison were obtained from shrunken specimens, whereas ours is swollen. We shall use for comparison the data furnished by $\mathrm{H}$. Wagner $\left({ }^{44}\right)$, Jensen $\left({ }^{45}\right)$ and Calori $\left({ }^{48}\right)$. From the first the figures for the "woman" are used. From the second those for "Rockel," female, insane, and from the last those for brachycephalic females, three in number.

TABle XI. Total Surface.

Weight of Fresh Encephalon. LEFT. Right. SUM.

1204 grm. Laura, $\quad$ 101256. sq.mm. $98946.5 \mathrm{sq} . \mathrm{mm} .200202 .5 \mathrm{sq} . \mathrm{mm}$. *1304 grm. Woman, 102742, sq. mm. 102373. sq. mm. $205115.0 \mathrm{sq} . \mathrm{mm}$. 1065 grm. Rockel (female, insane), 74615, sq. mm. 74523. sq. mm. 149138.0 sq. mm. $1236 \mathrm{grm}$. ) Brachycephalic 245260. sq. mm.

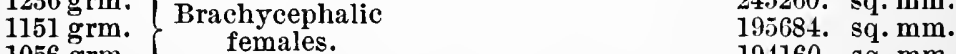
1056 grm. $\int$ females.

The total figure for Laura, though her brain is swollen, is somewhat under that found by Wagner, and also under the average taken from the two brains of Calori with which it may be fairly compared, but above that of Jensen. The

* Figures for area corrected from $H$. Wagner's $\left({ }^{44}\right)$ table. As I understand Wagner, the fresh weight of this brain, which he gives as $1185 \mathrm{grm}$., applies to the hemispheres alone. 1304 is the estimated weight of the entire encephalon to which these hemispheres belonged. 
small brain weight and the mental condition of the patient in Jensen's case must however be considered. I see here no greater variation than occurs in the full tables of these authors. We may conclude therefore that the total area of Laura's brain, if at all peculiar, was small for its weight. Comparison for total length of sulci and their average depth can be made only with the first two, as Calori does not give. his figures on this point.

TABLE XII. Total Length of Sulci and Average Depth.
Name.
LEFT.

Length. Av. Depth. Length. Av. Depth. Length. Av. Depth. Laura, 3448. mm. $9.9 \mathrm{~mm} .3477 . \mathrm{mm}$. $9.1 \mathrm{~mm} .6625 . \mathrm{mm}$. $9.5 \mathrm{~mm}$. Woman, 3349. mm. $9.88 \mathrm{~mm}$. $3189 . \mathrm{mm}$. $10.48 \mathrm{~mm} .6538 . \mathrm{mm} .10 .14 \mathrm{~mm}$. Rockel, 2870. mm. - $\quad 2834 . \mathrm{mm}$. - $\quad 5704 . \mathrm{mm} .9 .08 \mathrm{~mm}$.

It appears that, whereas the length of the sulci is greater in Laura than in those with whom she is compared, the average depth in less than that of the woman and more than that of Rockel. At the same time both length and depth are well within the limits found by these authors for other brains.

The relative development of the frontal lobe is something to which a certain historical value, at least, attaches. The frontal lobe as we define it is somewhat smaller than that of Wagner and Jensen as they include that portion of the gyrus fornicatus which extends candad as far as the procuneus. If we include this region so as to make our results comparable with theirs we have the figures given in the next table.

TABLE XIII.

Relative Development of Frontal Lobe, given in Percentage of the Total Surface.

LEFT. Right. Average for Both

$\begin{array}{llcc}\text { Laura, } & 36.8 & 39.9 & \text { Hemispheres. } \\ \text { Woman, } & 40 . & 41.9 & 38.3 \\ \text { Pockel, } & 38.3 & 40.9 & 39.6\end{array}$

When the comparison is made in this way Laura is seen to be slightly inferior to the other two. An examination of the tables shows this to depend mainly on the smaller average depth of the sulci. The inferiority of the left side is manifested here again. In general then we may say that so far as these measurements are concerned, Laura's brain differs from other brains with which it may be compared to 
no remarkable degree, and the difference can in part at least, be explained by the failure of certain portions of the brain to develop completely. The determination of the mass of the cortex must await the measurement of its thickness, and that together with other observations is reserved for a second article. 


\section{ANATOMICAL OBSERVATIONS ON THE BRAIN AND SEVERAL SENSE-ORGANS OF THE BLIND \\ DEAF-MUTE, LAURA DEWEY BRIDGMAN.}

Henry H. Donaldon, Ph. D.

II.

I.- On the thichness and structure of the cerebral cortex. Plates III and IV.

In a previous paper (AM. Journ. of Psychology, Vol. III, No. 3, Sept., 1890.) I have described some of the macroscopic features of the brain in question. I there stated the results of the measurements of the extent of the cortex (loc. cit. p. 336) as follows :

$\begin{array}{ll}\text { Extent of cortex, right hemisphere } & =98946.5 \square \mathrm{mm} . \\ \text { Extent of cortex, left hemisphere } & =101256.0 \square \mathrm{mm} . \\ \text { Total extent of cortex } & =200202.5 \square \mathrm{mm} .\end{array}$

It has been recognized by all those who have studied the extent of the the cortex, that unless supplemented by observations on the thickness and character of the same, the figures for extent did not give a good ground for further inference. Jensen $\left({ }^{45}\right)$ is, however, the only investigator who has up to this time made his studies thus complete.

It is, therefore, my purpose to report the results of the examination of the cortex of Laura Bridgman together with such conclusions as may be drawn from the results.

I.-The thickness of the cerebral cortex in general.

By way of preface I made a little excursion into the literature of the cortex to determine what was considered to be the normal thickness of that layer. It is highly probable that some of the work on this subject has escaped my notice, but what was found is tabulated (Table I.) with the purpose of showing how fully the various authors have stated the manner in which they obtained their results and what correc. tions had to be made, in certain cases, in order to have the results fairly comparable. 


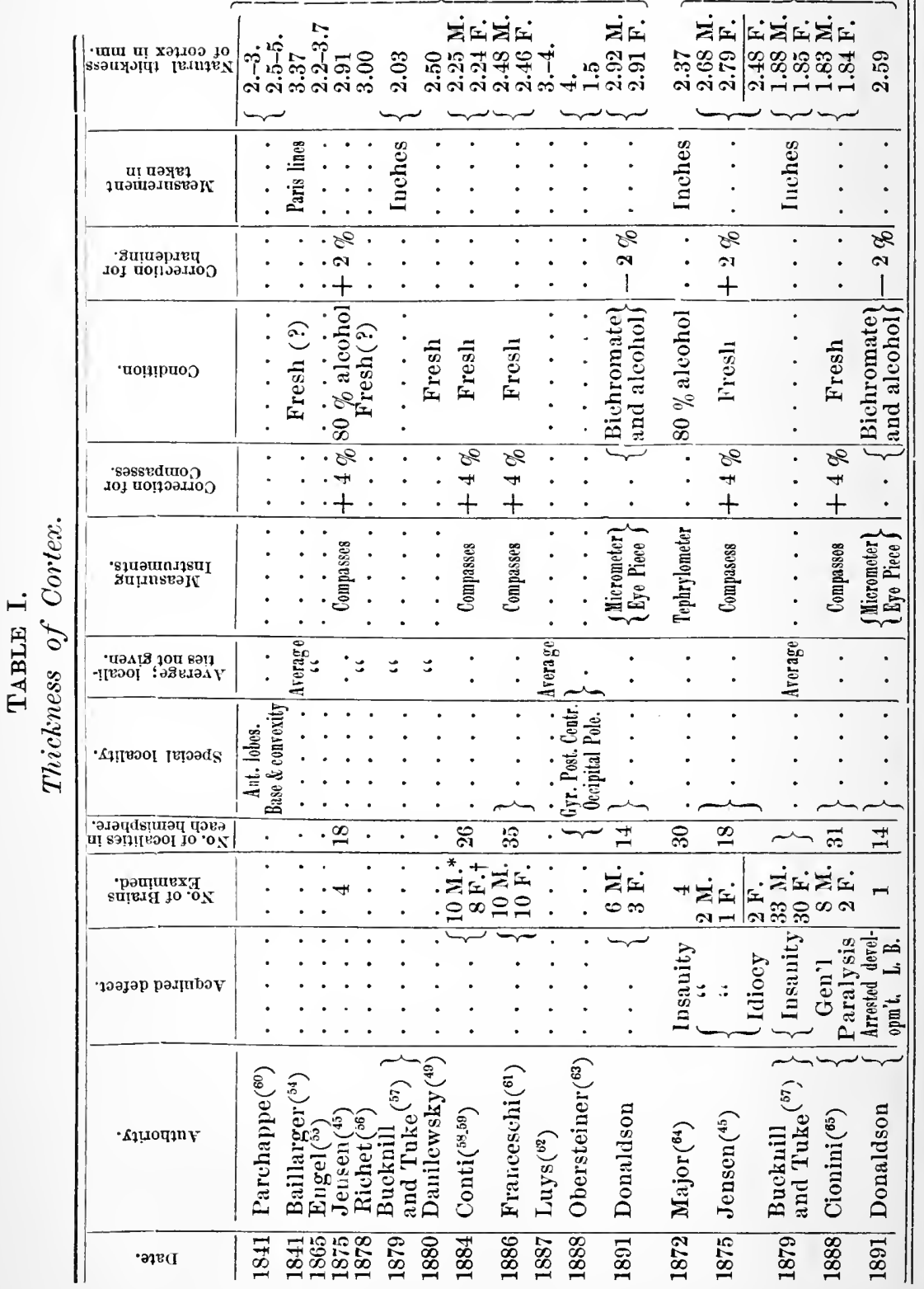


The authorities are arranged in chronological order, and in two groups : the first group containing the figures which apply to the cortex of normal persons, and the second the figures that apply to defectives. In this latter group I have only the measurements that apply to individuals with an acquired defect, as contrasted with those congenitally defective. The literature bearing on the cortex in these last has been brought together by Marchand $\left({ }^{66}\right)$, and, though the facts are very interesting, they do not bear on our present problem and are therefore excluded.

The headings of the columns in Table I. will explain themselves, I trust, and the Table may be examined now without further explanation.

Omitting my own results, there are but six authors whose figures are of interest to us now. The manner in which the final figures in these cases have been obtained requires some explanation.

We desire to know the thickness of the cortex in its natural state, but the hardening reagents used for preserving the brain alter the thickness. In another place, I expect to make some general statements with regard to the weight and volume of nervous tissues as influenced by hardening reagents. Therefore I may state here only the results obtained, viz., that alcohol of $80 \%$ causes a decrease of $2 \%$ in the thickness of the cortex, while the bichromate and alcohol treatment (potassium bichromate $2 \frac{1}{2} \%$ plus $\frac{1}{6}$ its volume of $95 \%$ alcohol for 6 to 8 weeks ; washing in water for 24 hours; alcohol $95 \%$ for 2 days, and final preservation in $80 \%$ alcohol) causes an increase of $2 \%$. As will be seen these corrections have been applied in Table I. Further, the manner of making the measurements has a very decided influence on the results. Direct experiment showed that the same localities measured with the compasses gave a thickness $4 \%$ less than when measured with a micrometer eye-piece under the microscope. There is no doubt in my mind that the microscopic method is the more accurate, hence I have cor rected all the measurements made with compasses by the percentage above found.

There still remains the important question of the handling 
of the figures for thickness after they are obtained. In general, the summit of a gyrus has the thickest cortex and the very bottom of the sulcus, the thinnest. In getting the thickness for any locality on the hemispheres at least two measurements, a maximum and minimum, are taken. Most investigators have measured the gyri at the points where the very thickest and very thinnest cortex was to be found, and for an average taken half the sum of these figures. The thiuning of the cortex at the bottom of the sulci is, so to speak, sudden and excessive and the thinnest point deviates more from the intermediate cortex than does the thickest. Such being the case the resultant figure is somewhat too small. Conti $\left({ }^{59}\right)$, Franceschi $\left({ }^{61}\right)$ and Cionini $\left({ }^{65}\right)$ give full tables and they have measured in the manner above described so that their averages represent one-half of the sum of the thickest and thinnest points in each gyrus. In the brains which I have examined the thickest portion was measured at the summit of the gyrus. The observations for the thinnest was taken at the side, about two-thirds of the distance from summit to sulcus. In making the average advantage was taken of the observation that one-third of the cortex lies at the summits of gyri and two-thirds is sunken in the sulei. The smaller figure was multiplied by 2 , added to the larger figure and the sum divided by 3 . As a consequence of this treatment I believe that my final average for the cortex of any particular gyrus is nearer the truth than it would be if half the sum of the thickest and thinnest points had alone been taken.

The figures which will be most useful to us can now be taken from Table I and presented in Table II, with the purpose of showing whether there is any difference in cortical thickness between males and females, or between the two hemispheres of the same brain; whether defectives correspond with normal persons; and what may be regarded as the normal thickness of the cortex.

Since the figures given in the Table II do not occur in their present form in the original tables of the anthorities there quoted, I should perhaps add a word of explanation on the method by which they have been obtained. 
Jensen $\left({ }^{45}\right)$ gives a condensed statement for the normal brains, and in Table II his figures are simply corrected for the effect of alcohol and the use of compasses in measuring. His tables for the defectives are fuller and permit us to determine the averages for the two hemispheres. These are corrected in the manner above mentioned. In no case did he measure the cortex of the insula. Among the defectives one case which he gives is not entered in the table because it is that of a microcephalic.

Bucknill and Tuke $\left({ }^{55}\right)$ give, without detail, the thickness of the normal cortex as .08 in. In a table of 63 pathological cases entered with great care and fullness, one column is devoted to the thickness of the cortex - also given without detail - in hundredths of an inch. This unit, approximately equal to $.25 \mathrm{~mm}$., is rather large when employed in so delicate a measurement. No statement as to the number, locality or method of their measurements is made. The cases were all adults.

Conti $\left({ }^{59}\right)$ gives full tables. He claims twenty brains in his series. The measurements on two brains - females - are, however, so incomplete that they are not used here, hence he is credited with but eighteen brains in the table. Both hemispheres were not always examined. The total number of hemispheres represented in the table is only twenty-nine, 16 right and 13 left. His cases, principally adults, range in age from sixteen months to eighty years, but there is no evidence that the youngest cases should be excluded. Twenty-six localities in each hemisphere were measured but the cortex for the insula, if measured, is not specially recorded. In the prerolandic and post-rolandic regions only the summits of the gyri and the depths of the sulci were measured. In the rolandic region intermediate measurements on each wall of the gyri were taken. The averages were obtained by summing and dividing the figures as they stand in his tables and then correcting the final results for the use of compasses. The original measurements were made in tenths of a millimeter.

Franceschi( $\left.{ }^{61}\right)$ gives full and very complete tables. He examined the cortex at 35 localities on both hemispheres of twenty brains, principally from adults of advanced age, 10 
males and 10 females. The measurements taken in tenths of a millimeter, and were made at the summits of the gyri and the depths of sulci. The cortex of the insula was included. The figures in Table II. are obtained directly from those of his tables, save that they have been corrected for use of compasses.

Major ${ }^{(4)}$ ) tested the thickness of the cortex at thirty localities on both hemispheres of the brains of four adult insane patients, the sex not given. For each locality he gives only the mean depth using one-fifth of an inch as his unit of measure. This unit is, of course, too large. He measured the insular cortex. His figures for the cortical thickness give the mean depth without detail as to the method of obtaining the mean. The instrument used, the tephrylometer, consisted of a thin walled graduated glass tube. This was pressed into the brain substance at any desired point, then, the upper end being closed by the finger, withdrawn, when a plug of brain substance remained within the tube and on this plug the thickness of the cortex is read off by the aid of the scale etched in the tube. The figures in Table. II are the simple averages of those in his tables without any corrections. Concerning the accuracy of this method of measuring the cortex there are no observations.

Cionini $\left({ }^{65}\right)$ presents his results from the examination of fifteen adult brains, ten males, five females, all cases of general paralysis. The number of localities was 31 , but in other respects the details are similar to those in the case of Conti. It occurs, however, that in five cases, three males and two females, the tables are so incomplete that they cannot be used for averages, and hence only ten cases are represented. The figures in Table II. are obtained as in the case of Conti.

A glance at Table II. shows that in both normals and defectives the average thickness is very slightly, -.01 to $-.04 \mathrm{~mm}$., greater in the males in five out of the six cases (larger number underlined). There is a slightly greater difference between the two hemispheres, which is in favor of the left hemisphere as the figures stand (eight out of thirteen cases). In discussing the absolute thickness of the cortex as reported we have, of course, to throw out the defectives, who are, ipso facto, expected to have a thinner cortex. 


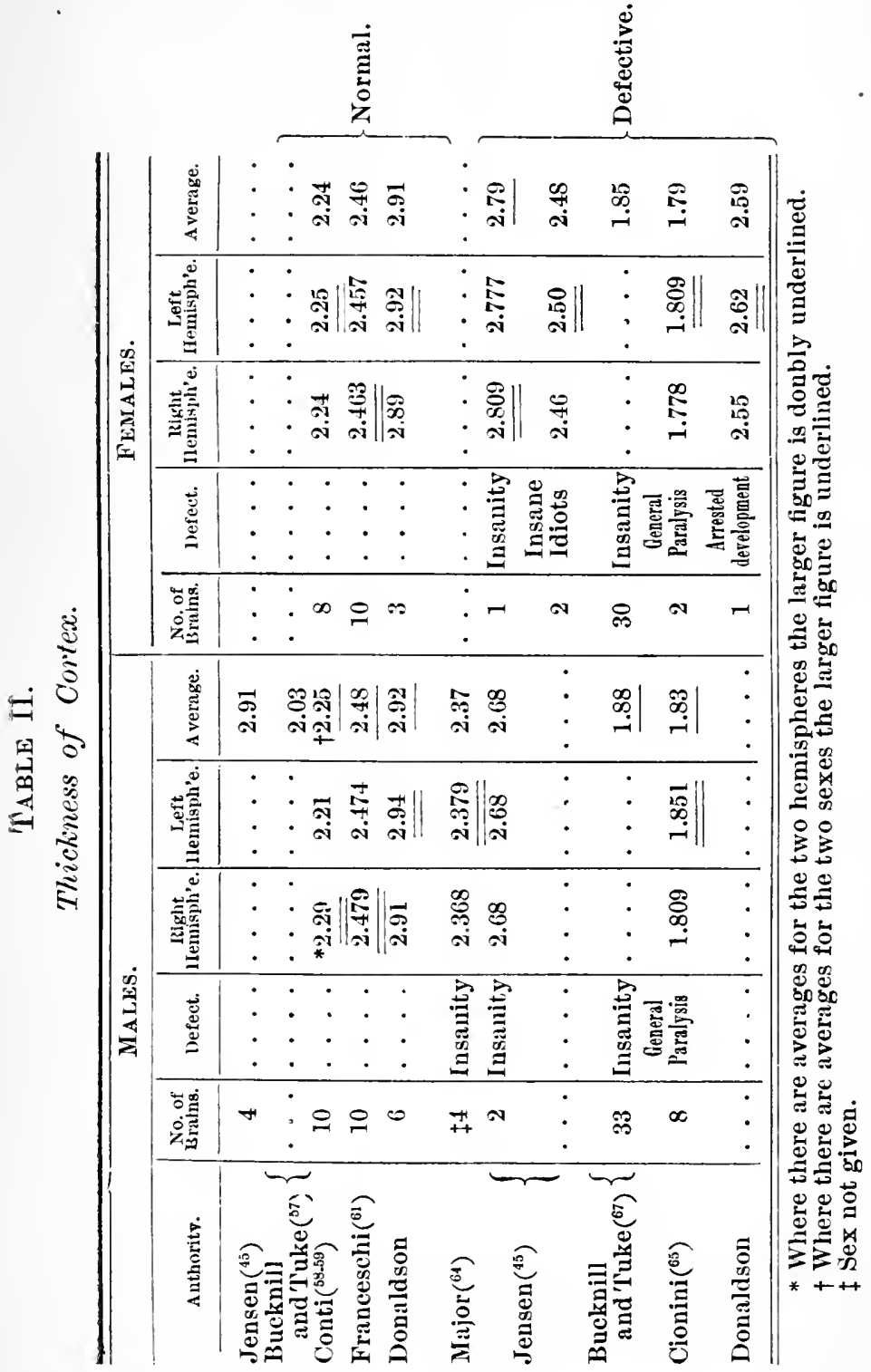


At the moment I have no explanation to offer of the various figures given for the absolute thickness in normal persons and will simply point out that my figures agree most closely with those of Jensen.

It appears, therefore, that the average thickness for the two sexes is nearly alike, what difference there is being in favor of the males; that the left hemisphere more often has the thicker cortex; that in defectives (not congenital) it is thinner than in normal persons, and that the figures given for the absolute thickness in normal persons are at present irreconcilable. With this I conclude the introductory study of the subject.

II. Comparison of the cortex of Laura Bridgman with that of nine normal brains (six males; three females).

The normal brains were obtained in New York about a year ago, and I am indebted to the courtesy of several medical gentlemen of the city for them. There is no reason to think that any of these specimens were from persons of more than average intelligence, hence on that score they are comparable with the Bridgman brain. They were hardened in the same manner that the latter was (vide p. 9). Samples of cortex were taken in all cases from 14 localities on each hemisphere, each locality being designated by an arbitrary number.

Plate III shows the localities with the numbers used, and is intended to take the place of a written description.

In Table III. I give the cortical areas in which the localities. are situated.

All the samples from the several localities were treated in the same manner, viz.: imbedded in celloidin, cut in sections about $0.1 \mathrm{~mm}$. thick and measured, unstained, under a low magnifying power. It is hardly necessary to add that all the TABLE III.

Locality. Cortical Area for.

1. Speech motor?

2. Speech, motor.

3. Speech?

4. Head and eyes, motor.

5. Arm, motor.

6. Hearing, sensory.

7. $\quad$ ?
Locality. Cortical Area for.

8. Sight, sensory.

$9 . \quad-$ ?

10. Taste and smell, sensory-

11. Sight, sensory.

12. Touch, sensory.

13. Leg, motor.

14. Sight, sensory. 
measurements were concluded before any calculations were begun and that precaution was taken to keep the results unprejudiced.

Figures for the average thickness at each locality having been obtained from all the brains in the manner above described, the localities were arranged in order, from the thickest to the thinnest, and the tables thus formed were plotted as curves. Vide Plate IV.

The principal results are tabulated in Table II (under Donaldson, normals), and in Table IV a further analysis is given. The figures for males and females being separated in Table IV, those for the right and left hemispheres are given in each group and the individuals in each group are ranged according to age. This last arrangement was made to see whether they showed a decrease in cortical thickness with advancing age. Conti $\left({ }^{53}\right)$ reports that the cortex decreases regularly from a maximum at 3 years to a minimum in extreme age. I do not pretend to discuss the question here but simply refer to the table to show that these brains when thus arranged do not exhibit a decrease.

TABLE IV.

Thickness of Cortex in Controls and in Laura Bridgman.

MaLes.

Females.

Arranged aceording to age.

Arranged according to age.

\begin{tabular}{|c|c|c|c|c|c|c|c|}
\hline Age. & $\begin{array}{c}\text { Weight in } \\
\text { grrns. }\end{array}$ & R. $\mathrm{H}$. & L. H. & Age. & $\begin{array}{l}\text { Weight in } \\
\text { grms. }\end{array}$ & R. H. & L. $\mathrm{H}$. \\
\hline $3 \check{5}$ & 1419 & $* 2.81$ & 2.81 & 40 & 1196 & 2.74 & 2.74 \\
\hline 35 & 1443 & $\overline{\overline{2.87}}$ & 3.09 & 45 & 1173 & 2.80 & $\overline{\overline{3.10}}$ \\
\hline 39 & 1393 & 2.77 & 2.86 & Adult & 1312 & 3.12 & 3.02 \\
\hline 45 & 1367 & 2.90 & $\overline{2.93}$ & & & & \\
\hline 57 & 1464 & 2.96 & $\overline{\overline{2.91}}$ & & & & \\
\hline \multirow[t]{2}{*}{ Adalt } & 1210 & $\overline{3.14}$ & 3.07 & & & & \\
\hline & & 2.91 & $\underline{2.94}$ & & & 2.89 & $\underline{2.92}$ \\
\hline \multicolumn{4}{|c|}{ General Average, 2.92. } & \multicolumn{4}{|c|}{ General Average, 2.90.} \\
\hline \multicolumn{4}{|c|}{ Laura Bridgman, } & 60 & 1204 & 2.55 & 2.62 \\
\hline & & & & \multicolumn{4}{|c|}{ General Average, 2.59} \\
\hline
\end{tabular}

* The underlining has the same significance as in Table II. 
The cortex of the left hemisphere is in five cases the thicker, while that of the right is so in four. The maximum difference between the two hemispheres of the same individual is $.22 \mathrm{~mm}$. (2.87 to 3.09 ). The averages for the males and females are nearly alike, the males being a trifle, $.02 \mathrm{~mm}$., thicker.

If the results for each locality are averaged for all the controls, these averages arranged in a series from the largest to the smallest and this series plotted as a curve, then the curve has the form indicated by the continuous black ink line on Plate IV. In that curve the insula, as pointed out by Major $\left({ }^{64}\right)$, has the thickest cortex. Next follows the convex surface of the hemispheres with little variation, and then the thickness gradually decreases in the mesal, occipital and orbital cortex, in the order named. Table $\mathrm{V}$ gives the figures from which this curve is formed as well as the figures for the two component curves, viz.: that for the males and that for the females.

\section{TABLE V.}

Averages for each locality. All controls, I.

Averages for each locality. Controls, Male, II.

Averages for each locality. Controls, Female, III.

Unit of measure, $1 \mathrm{~mm}$.

\begin{tabular}{|c|c|c|c|c|c|c|c|c|c|c|c|c|c|c|c|c|c|}
\hline \multirow{2}{*}{ Locality. } & & \multicolumn{6}{|c|}{$\begin{array}{l}\text { I. A Average for } \\
\text { all Controls. }\end{array}$} & \multicolumn{5}{|c|}{$\begin{array}{l}\text { II. A verage for } \\
\text { Controls. (6) IIale. }\end{array}$} & \multicolumn{5}{|c|}{$\begin{array}{l}\text { III. Average for } \\
\text { Controls, (3) Female }\end{array}$} \\
\hline & & . & - & 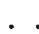 & . $\quad 3.38$ & . & . & . & . & 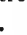 & 3.48 & 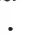 & & & & & 3.33 \\
\hline 7 & . & & & & 3.15 & . & & . & . & • & 3.02 & . & & & . & . & 3.43 \\
\hline 6 & . & & & . & 3.10 & & & . & & . & 3.05 & & & & . & . & 3.18 \\
\hline 4 & . & • & . & . & 3.09 & . & . & . & . & • & 3.12 & . & & & & . & 3.04 \\
\hline 2 & . & & & . & 3.08 & . & & . & . & . & 3.06 & 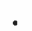 & & & . & . & 3.12 \\
\hline 5 & & & & & 3.08 & . & & $\dot{v}$ & . & . & 3.10 & & & & . & . & 3.04 \\
\hline 10 & . & . & . & . & 3.04 & . & - & . & . & . & 3.03 & & & & . & . & 3.06 \\
\hline 1 & & . & & . & 2.98 & . & • & . & • & 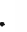 & 2.92 & 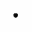 & - & & . & . & 3.06 \\
\hline 13 & & & & & 2.86 & . & & . & . & • & 2.82 & & . & & $\cdot$ & . & 2.94 \\
\hline 12 & & & & . & 2.75 & . & • & . & . & . & 2.83 & & & & . & . & 2.60 \\
\hline 11 & . & . & . & . & 2.65 & . & . . & . & . & . & 2.65 & & & . & $\cdot$ & . & 2.66 \\
\hline 8 & & . & . & . & 2.61 & . & . & . & . & . & 2.67 & & . & & $\cdot$ & . & 2.50 \\
\hline 9 & . & . & & . & 2.53 & . & & & . & . & 2.60 & . & & & . & • & 2.41 \\
\hline 14 & & . & . & . & 2.52 & . & & . & . & . & 2.59 & & . & & . & . & 2.38 \\
\hline & & & & & & ra & $\mathrm{g}$ & & & & .92 & & & & & & 2.91 \\
\hline
\end{tabular}

By these figures I aim to show the normal thickness of the cortex at the given localities.

The figures which form the basis for the curve of the Bridgman brain are given in Table VI. The average thickness of this cortex (see Table IV) is $2.59 \mathrm{~mm}$., which is 0.32 $\mathrm{mm}$. below the average for all the females and $0.15 \mathrm{~mm}$. below that for the female in whom the cortex was thinnest. 
TABLE VI.

I. Averages of the several localities. L. B., right hemisphere.

II. Averages of the several localities. L. B., left hemisphere.

III. Averages of the several localities. L. B., both hemispheres.

LaURa BRIDgman.

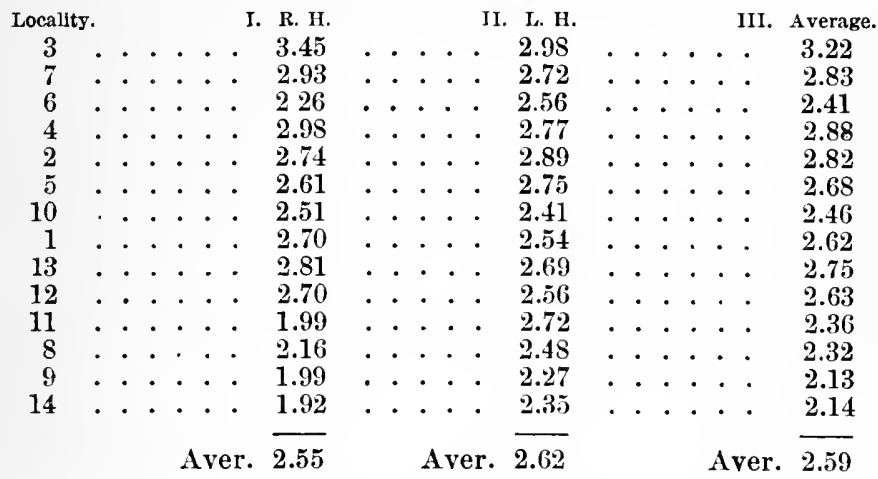

The curves for the Bridgman figures are plotted on Plate IV. That for the left hemisphere is indicated by a broken line (dashes), and that for the right hemisphere by the line of long and short dashes. Attending for the moment to these we observe a remarkable drop at 6 ; from 4 to 12 both curves are generally low with a special depression at 10 , and from 12 to the end they run at different levels.

It will be seen at a glance that these two curves are fairly accordant until locality 11 is reached. Here they are widely divergent, approach somewhat at 8 , again to diverge at 14 .

Taking up the peculiarities of the Bridgman cortex then in the order in which they occur we find the insula (3) thinner on the left side. Both sides very thin at 6 , the auditory area. Locality 2, the area for motor speech, is well developed on both sides. From 4 to 13 the development is poor, specially so at 10 , area for taste and smell. At 12, the area for dermal sensations, the curve is high again, and from that point on commences the remarkable divergence in the curves of the two hemispheres, that for the left side being much higher at 11,8 and 14, all of which are within the visual area.

Referring now to the description which I have previously given (op. cit.) of the macroscopic features of this brain, I may briefly attempt to collate them with the measurements of the cortex. 
The insula (3) on the left side was found less well developed. It has the thinner cortex. Vide Waldschmidt $\left({ }^{67}\right)$.

At the auditory area (6) I could not decide on any macroscopic defect, but have since determmined that the first temporal gyrus at its caudal end, especially on the right side, was abnormally slender. The cortex is decidedly thin on both sides, most markedly so on the right. At the area for motor speech, the left side showed a clear lack of development (depression), but the cortex was not particularly thin for this brain.

At 10, the area for taste and smell, there was a general lack of development, exhibited by the entire temporal lobe. This is easily explained by the slow growth of this portion of the brain, a growth which was quite incomplete at the period when Laura was taken ill ( 2 years). The glossopharyngeal nerves appeared normal, but the olfactory bulbs and tracts were small, though not so small as in the case of some normal persons. The thinness of the cortex at this point (10) appears therefore as a part of the general arrest in growth.

Passing now to the visual area it was noticed macroscopically that both occipital lobes were blunted, but the right side turned out in every way to be much the more defective and anomalous. Concordantly the cortex of this right side at 11 , 8 , and 14 is much thinner than that of the left.

It must be recalled here that although at the age of two years, Laura became completely blind in her left eye, yet she retained some remnant of vision with her right eye up to her eighth year. This has left its mark on the entire central apparatus for vision. The right optic nerve is larger than the left.

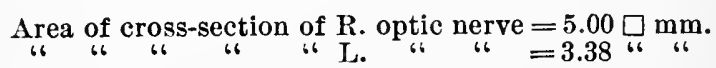

The relation in the tracts is, of course, reversed:

Area of cross-section of R. optic tract $=3.13 \square \mathrm{mm}$.

On the one hand then we have loss of vision in left eye at 2 years of age, associated with the smaller optic nerve and tract-a defectively developed right occipital lobe and a thin cortex in the right visual area. On the other hand we have some vision in the right eye up to the eighth year of age, associated with the larger optic nerve and tract, the more normal occipital lobe and the thicker cortex. 
The general thinning of the motor cortex I would explain in part by the absence of the fibres through which the motor areas are normally associated with the sensory areas-here defective -and in part by the smaller size of some of the cell elements and non-development of others, resulting from lack of stimuli. The defects in the visual and auditory area follow directly from the loss of the corresponding sense organs and consequent arrest of growth. When the loss is not at first complete a good deal of subsequent development is possible. Why the speech-centre has not a thinner cortex I cannot, at the moment, explain.

In considering the fact that the sensory centers are much more affected than the motor, it should be remembered that aside from the special loss due to arrest and possibly degeneration falling less on the motor than on the sensory centres, there is the physiological difference that each motor centres can be excited by way of any sensory centre, and hence, so long as any senses are left, the motor centres must be stimulated to somedegree, while the destruction of the special senseorgan throws a given sensory centre quite out of function. The physiological conditions in the two cases are therefore quite different and in favor of the development of the motor side.

For reference. I introduce here several tables containing the details of the figures just given.

Table VII. gives the maximum and minimum thickness of the cortex as observed at each locality on Laura Bridgman and the nine controls. The maximum was taken at the summit of the gyrus and the minimum at the side - not at the bottom of the sulcus. The average of the maximum and minimum is obtained by doubling the minimum, adding the result to the maximum and dividing the sum by three. This average figure is given in the third column for each hemisphere. The averages at the foot of the first and second columns are obtained by dividing the sum of these columns by fourteen. All the figures in this table are corrected for hardening, so that they represent the natural thickness of the cortex. The observations for the males and females are separated. 


\begin{tabular}{|c|c|c|c|c|c|}
\hline & & & 崖 & 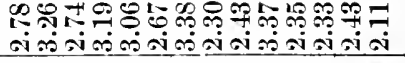 & 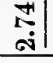 \\
\hline & & $\stackrel{\dot{M}}{\dot{i}}$ & 完 & 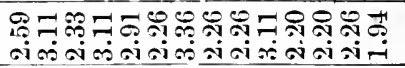 & 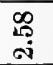 \\
\hline & & & $\dot{\rightleftarrows}$ & 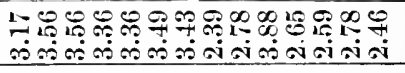 & $\underset{\substack{1 \\
0}}{\infty}$ \\
\hline & H & & 离 & 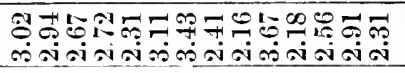 & 交1 \\
\hline & & $\dot{4}$ & 远 & 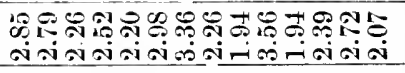 & 峁 \\
\hline & & & 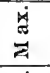 & 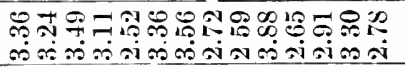 & $\vec{\Leftrightarrow}$ \\
\hline & & & $\frac{\dot{0}}{4}$ & 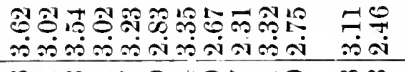 & $\begin{array}{c}0 \\
0 \\
0\end{array} \mid$ \\
\hline & & $\dot{\vec{\Delta}}$ & $\dot{\dot{g}}$ & 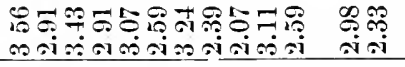 & $\begin{array}{l}\infty \\
\infty \\
\dot{\omega} \\
\dot{N}\end{array}$ \\
\hline & ت & & 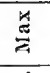 & 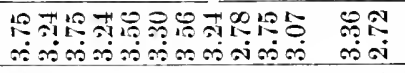 & 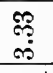 \\
\hline & 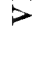 & & $\dot{\vec{\Delta}}$ & 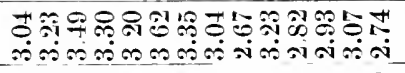 & $\underset{7}{9}$ \\
\hline & & $\dot{\vec{H}}$ & $\dot{\Xi}$ & 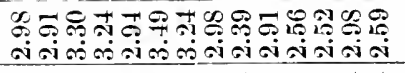 & $\begin{array}{l}\mathscr{g} \\
\stackrel{9}{i} \\
\end{array}$ \\
\hline & & & $\stackrel{\dot{x}}{\dot{a}}$ & 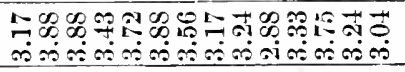 & $\sin _{0}$ \\
\hline 国 & & & $\frac{\dot{0}}{4}$ & 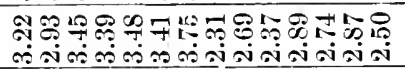 & $\begin{array}{c}8 \\
\dot{\infty}\end{array}$ \\
\hline दो & & $\stackrel{\vec{A}}{\dot{j}}$ & $\dot{g}$ & 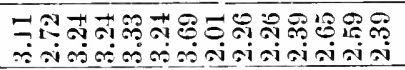 & : \\
\hline & & & $\stackrel{\dot{\alpha}}{\stackrel{\dot{m}}{厶}}$ & 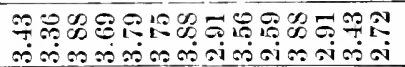 & $\underset{j}{7}$ \\
\hline & - & & 安 & 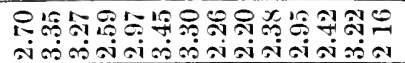 & $\begin{array}{l}\infty \\
\infty \\
\text { ij }\end{array}$ \\
\hline & & $\dot{\vec{m}}$ & $\dot{\Xi}$ & 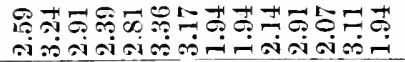 & $\begin{array}{l}1 \\
0 \\
01\end{array}$ \\
\hline & & & $\stackrel{x}{\stackrel{x}{\rightleftarrows}}$ & 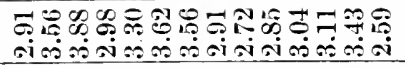 & $\stackrel{\infty}{\infty}$ \\
\hline & & & $\dot{D}_{4}^{\dot{\zeta}}$ & 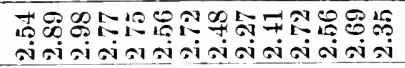 & $\begin{array}{l}\text { S } \\
\text { No }\end{array} \mid$ \\
\hline & & $\dot{\Delta}$ & $\dot{g}$ & 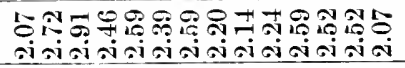 & $\stackrel{\text { as }}{\text { a }}$ \\
\hline & 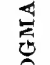 & & $\stackrel{\dot{x}}{\ddot{Z}}$ & 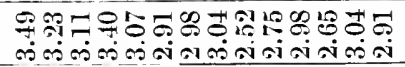 & क्ष. \\
\hline & $\stackrel{\theta}{a}$ & & 岕 & 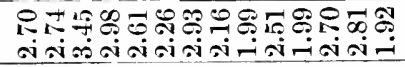 & 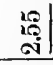 \\
\hline & & $\dot{~ ت ُ ~}$ & $\dot{\Xi}$ & 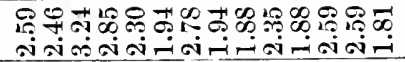 & $\stackrel{\sim}{\infty}$ \\
\hline & $\stackrel{\Xi}{\Xi}$ & & 总 & 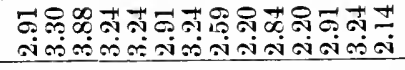 & $\begin{array}{l}\text { \& } \\
\text { ส }\end{array}$ \\
\hline & 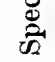 & & & 一N⿻ & 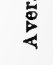 \\
\hline
\end{tabular}


Table VIII. is derived from Table VIr. by arranging the figures for the average thickness of each locality in each hemisphere in vertical columns, and getting the averages of these for the females alone, for the males alone, and for both together.

Table VIII. Controls Only.

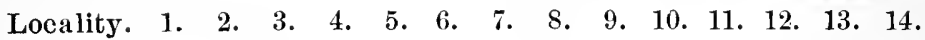

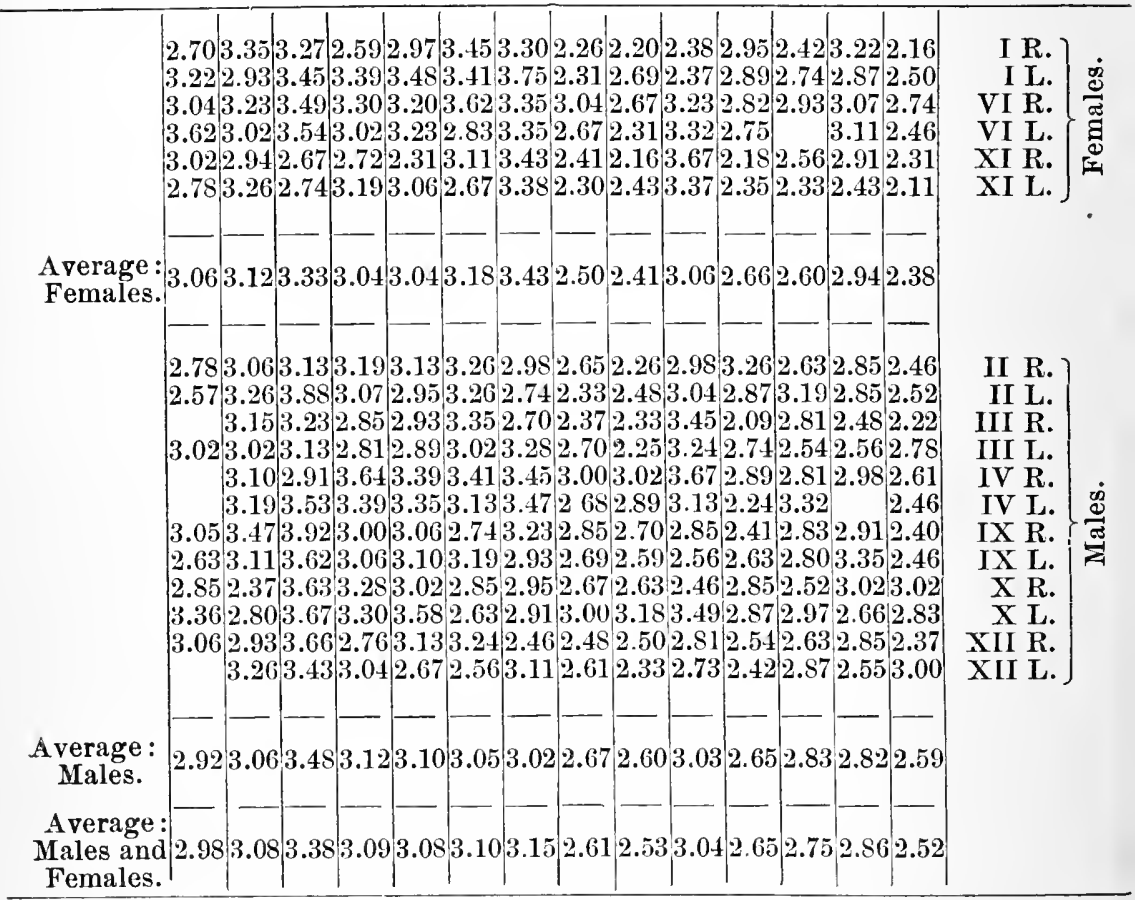

Table IX. gives the difference in the thickness of the cortex in the two hemispheres of those controls in which the difference is greatest. The figures on which this table is based are found in the "average" columns of Table VII. The controls are grouped into males and females and the instance of greatest dlfference found for each group. To be compared with this is the difference in the same localities in the Bridgman brain. The figures for fhe latter show that the differences are much within the extremes of the controls 
except at those localities where the largest difference is to be expected i. e., 3, 8, 11, 14-where they may exceed those of the controls. The roman numeral indicates the number of the specimen and the side which is larger is first designated, so that VI L.-VI R. means that the left hemisphere has the thicker cortex in control VI. It is not without interest in this case that among the females, 9, and among the males, 11 out of the 14 cases have the left cortex the thicker.

\section{TABLE IX.}

Greatest Differences in Cortical Thichness.

\begin{tabular}{|c|c|c|c|c|c|c|}
\hline \multicolumn{3}{|c|}{ Females. } & \multicolumn{2}{|r|}{ MaLEs. } & \multicolumn{2}{|r|}{ L. B. } \\
\hline -oc. & Gr. Diff. & 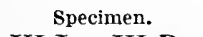 & Gr. Diff. & Sp & Gr. Diff & \\
\hline 1. & .58 & VI L.- & .51 & X L. - X R. & .16 & R. I. \\
\hline 2 . & .4 & I R.-I & .4 & $\mathrm{X}$ L. $-\mathrm{X} R$. & .15 & L. R. \\
\hline 3 & .18 & I L.-I & .75 & II I.-II & .47 & R. I. \\
\hline 4. & .80 & I L.-I & .28 & XII I.-XI & .21 & R. I. \\
\hline 5. & .75 & XI L.-X & .5 & $X I . . X R$. & .14 & L. R. \\
\hline 6. & .79 & VI R.-VI L' & .0 & XII R.-XII I. & .30 & L. R. \\
\hline 7. & .4 & $\mathrm{I}$ & .6 & XII L.-XI & .21 & R. I. \\
\hline 8. & .37 & VI R.-VI L. & .33 & 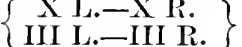 & .32 & L. I \\
\hline 9. & .4 & I $\mathrm{L}$ &.$\tilde{0}$ & $X L_{.}-\mathrm{X} R$. & .28 & \\
\hline 10. & .5 & XI R.-X & 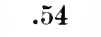 & IV R.-IV L. & .10 & R. L. \\
\hline I. & .17 & XI L.-XI R. & .65 & $\left\{\begin{array}{l}\text { III L.-III R. } \\
\text { IV R.-IV L. }\end{array}\right\}$ & .73 & L. \\
\hline & & & .56 & &. $\mathrm{I}$ & \\
\hline & .48 & XI R.-XI & .4 & IX L.-IX R. & .12 & R. I \\
\hline 14. & .34 & I I.-I R. & .63 & XII L.-XII R. & .43 & L. R. \\
\hline
\end{tabular}

\section{III.-Histological Examination.}

The Bridgman brain was not well enough preserved to admit of a very fine microscopical examination. Some points can be made ont, however, on sections $.02 \mathrm{~mm}$. thick, stained with hæmatoxylin and cosin, or hæmatoxylin and carminic acid, or with Weigert-Pal hæmatoxylin. Whatever general statements are made are always in comparison with the nine controls, from which sections were also cut and similarly stained.

The cells generally in the Bridgman cortex have abundant pigment-the nuclei often somewhat irregular and the nucleoli sometimes single and clear, often multiple and unclear, and, at times, wanting. Where the cortical granules form layers they appear abundant, as a rule, and immature (i. e., without 
angles), as though they had been arrested in their growth. The general impression one gets is, that the large nerve cells are neither so large nor so numerous as in the normal brains. Of cell processes and abundance of fibres one can only say, that there appear less of both in all localities, and hasten to add, that the poor condition of the material makes itself painfully felt at this point.

It seemed worth while, however, to select sections from several localities, especially those in which the cortex of the Bridgman brain appeared thin, and attempt to get some notion of the development of the cell elements at these points.

To arrive at this result $I$ counted the number of cells above a given diameter in a strip of the cortex, comparing the number found in the Bridgman cortex with that in two controls. For results see Table $\mathrm{X}$.

\section{TABLE X.}

To show the average number of cells $12 \mu$ in transverse diameter which occur in $0.01 \square \mathrm{mm}$. of cerebral cortex at the localities named. Sections $.02 \mathrm{~mm}$. thick.

\begin{tabular}{|c|c|c|c|c|c|c|c|c|c|}
\hline \multicolumn{4}{|c|}{ MALE. } & \multicolumn{3}{|c|}{ Female. } & \multicolumn{3}{|c|}{ - } \\
\hline \multicolumn{4}{|c|}{ Control III. } & \multicolumn{3}{|c|}{ Control XI. } & \multicolumn{3}{|c|}{ Laura Bridgman. } \\
\hline Locality. & ${ }^{*} \mathrm{R}$ & † I. & Aver. & $\mathrm{R}$. & L. & Aver. & R. & L. & Aver. \\
\hline Speech, 2 & .85 & 1.10 & 0.975 & 1.06 & 1.16 & 1.11 & .93 & .80 & 0.865 \\
\hline Insula, 3 & 1.15 & 1.04 & 1.10 & 1.15 & 1.03 & $\overline{1.09}$ & 1.00 & 1.07 & 1.035 \\
\hline $\begin{array}{l}\text { Head and } \\
\text { Eyes, } 4\end{array}$ & 1.13 & 1.40 & 1.26 & 1.03 & 1.46 & 1.25 & 1.11 & 1.19 & 1.15 \\
\hline Hearing, 6 & 1.23 & .99 & $\overline{1.11}$ & 1.23 & 1.21 & 1.225 & $.81 \mathrm{c}$ & .92 & 0.865 \\
\hline $\begin{array}{l}\text { Taste and } \\
\text { Smell, } \quad 10\end{array}$ & .82 & 1.12 & 0.97 & 1.34 & .97 & $\underline{\underline{1.155}}$ & .86 & 1.05 & 0.955 \\
\hline Sight, 11 & 1.03 & .99 & 1.01 & 1.08 & .95 & $\overline{\overline{1.015}}$ & $.47 \mathrm{c}$ & 1.01 & 0.74 \\
\hline Sight, 14 & 1.13 & 1.08 & $\underline{\underline{1.105}}$ & .99 & 1.08 & $\overline{\overline{1.03}}$ & $.40 \mathrm{c}$ & .92 & 0.66 \\
\hline Average, & & & 1.075 & & & 1.125 & & & 0.895 \\
\hline
\end{tabular}

* R. = Right hemisphere.

$\dagger \mathrm{L}$. = Left hemisphere. 
To obtain these figures the following method was employed. The specimen was fixed upon a mechanical stage in such a way that the direction of motion was vertical to the cortex. It was examined with a Zeiss apochromatic objective, $4 \mathrm{~mm}$. focus, combined with the compensating eye-piece 6 , tube $160 \mathrm{~mm}$. , thus giving an enlargement of 375 diameters.

The eye-piece carried the micrometer with 50 divisions. With the objective used, each division had a value of $4 \mu$. The whole scale covered therefore 50 times $.004 \mathrm{~mm} .=.2 \mathrm{~mm}$.

Placing the micrometer scale so that it was at right angles to the direction of motion for the specimen, and passing the specimen in review by means of the mechanical stage, a strip of cortex .2 mm. wide could be brought, throughout its entire extent, under the scale. In this manuer the nerve cells were sifted, so to speak, through the micrometer scale, and each one that was $12 \mu$ or more in diameter was picked out and counted.

In selecting the point on the section at which to make this test I always took the spot where the cells were apparentlyto a low power-most abundant, and in all cases everything in the field that could be counted was counted.

The depth of the cortex where the count was made was multiplied by the constant width, .2 mm., and the total number of cells divided by this product, using .01 sq. mm. as the unit. The thickness of the section was always $.02 \mathrm{~mm}$, which being a constant factor may be neglected. By this treatment it comes out that about one cell, $12 \mu$ or more in basal diameter, normally occurs in each $.01 \mathrm{sq}$. $\mathrm{mm}$. of a section $.02 \mathrm{~mm}$. thick.

For comparison with the Bridgman sections I took those from Control III. (Brain weight 1,393 gr., male, average thickness of cortex R. H. 2.77 m., L. H. 2.86 m.), and Control XI. (Brain weight 1,196 gr., female, average thickness of cortex R. H. 2.74 m., L. H. 2.74 m.), (see Table IV.), thus happening to get both the male and female with the thinnest cortex.

Table X. shows that, taking the average of both sides, at no locality in the Bridgman brain are the large nerve cells, as abundant as in the controls. The number in both the controls is nearly the same. 
Taking the matter more in detail the motor areas in Laura do not show as great a poverty of large cells as the sensory areas.

In three instances (marked $\mathrm{c}$ in Table X.), the abundance of cells accords with the thickness of the cortex-i. e., the thicker cortex has the larger number of cells. These instances include the ones in which the Bridgman cortex most clearly deviates from the normals.

As in the measurements of cortical thickness, so in the abundance of cells, the Bridgman brain is clearly deficient at 6, the auditory area and in the right hemisphere at 11 and 14, visual area, while in the left hemisphere some deficiency is to be noted only at 14, thus again bringing out the contrast between the occipital regions on the two sides. Locality 10 has fewer cells than the controls, but the difference is not so marked as in the thickness of the cortex.

In general it may be added that where the number of cells above $12 \mu$. in basal diameter was small, that there the absolute number of large cells appeared smaller, and the very largest cells not so large, as in the controls. In other words, small number and small size of large cells appeared to be associated, though I have no figures to present on the point. If, howeve', my impression is correct, then Table X. only in part represents the difference in the development of the cortical cells of Laura as compared with the controls.

\section{Summary.}

\section{I.-General.}

1. No figures can be given for the average thickness of the fresh normal cortex. The various investigators differ widely in their results. My own results agree most closely with those of Jensen.

2. Persons with an acquired defect of the central nervous system have a thinner cortex than normal persons.

3. Females have a slightly thinner cortex than males. Difference less than $1 \%$.

4. The right hemisphere (normally) has a cortex a few percent less thick than the left. Maximum difference $7 \%$. 


\section{II.-Special.}

1. The cortex of Laura Bridgman was abnormally thin, having but $89 \%$ of the thickness of the controls. If we suppose that in its other dimensions the cortex was similarly reduced in development, i. e. by $11 \%$ in each linear measurement, then its normal extent would have been 246,808 sq. $\mathrm{mm}$. instead of $200,202.5 \mathrm{sq}$. mm. as found. This estimate is similar to some of those by the Italian observers, Calori $\left({ }^{48}\right)$ and De Regibus ( $\left.{ }^{17-p .}{ }^{276}\right)$.

2. The right hemisphere had on the average the thinner cortex-specially to be associated with the defective visual area.

3. The thinning in the motor areas was not so well marked as in the areas for the defective senses.

4. Cortex of motor speech centre was not thin.

5. Cortex of area for dermal sensations was well developed.

6. Auditory areas (6) on both sides and visual area on right side $(11,8,14)$ remarkably thin.

7. Area for taste and smell (10) thin-associated with the generally undeveloped state of the temporal lobe.

$$
\text { III.-Histological. }
$$

1. The cortex of Laura Bridgman contained an abnormally small number of large nerve cells-i. e., cells $12 \mu$. or more in transverse basal diameter.

2. There were fewer nerve cells in the samples from the right, than in those from the left hemisphere.

3. The deficiency of nerve cells was not so well marked in the motor as in the sensory areas.

4. In the centre for motor speech (2) the number of nerve cells was abnormally small.

5. Number of nerve cells very small in the auditory areas (6), both sides, and in the visual area $(11,8,14)$ on the right side.

6. Some diminution in the number of cells at (10), area for taste and smell. Region generally undeveloped.

7. The small number of cells was associated with small size of the largest cells. 
The persistence of vision, though in a very defective form, is still of great importance to the full development of the visual cortex-e. g., right eye and left visual area in Laura.

Orservations on the Olfactory Region.

A hbert C. Getchell, M. D., Worcester.

Description of the Specimen.

The specimen submitted for examination was a portion of the ethmoid bone, extending from the anterior base of the crista galli to the sphenoid bone, a small part of the sphenoid being included in it. It contained nearly all the perpendicular plate of the ethmoid. At the sphenoidal end the lateral surfaces were devoid of mncous membrane; towards the frontal end the surfaces were quite covered with the remains of membrane in a ragged condition. The right superior turbinated bone presented a smooth surface marked with grooves. Between it and the perpendicular plate was mucous membrane. Little of the left superior turbinated bone remained, and that which did was rough and without grooves. The entire specimen measured from the extreme frontal to the sphenoidal end, $3 \mathrm{~cm}$; from the apex of the crista to the farthest point on the perpendicular plate, $2.2 \mathrm{~cm}$; laterally its greatest measurement was through the horizontal plate of the ethmoid, $.5 \mathrm{~cm}$. This line represented the base of two triangles; the apex of one being the tip of the crista, that of the other the farthest point on the perpendicular plate of the ethmoid.

The specimen had been hardened in Müller's fluid, and decalcified in a saturated solution of picric acid, the process being completed in a $1 \%$ solution of hydrochloric acid. It was imbedded in celloidin, and most of the sections were stained with Delafield's hæmatoxylin and eosine. Four additional stains were used for nerves, viz.: Upson's carminic acid, Schæfer's nigrosine, hæmatoxylin und carminic acid, and Pal's hæmatoxylin.

Results of the Microscopic Examination.

For the purpose of comparison, I obtained a specimen 
similar to the one under consideration. This was a portion of the ethmoid bone taken from an elderly man who had been a patient at the Worcester Insane Asylum, and had died there. The presumption would be that this specimen conld not be taken as a type of the normal, for it is difficult to suppose that one could pass the greater part of a long life in this climate without having had more or less nasal catarrh. The specimen was, however, healthy in its gross appearance: that is, it was symmetrical, both superior turbinated bones were present; their surfaces were shiny and grooved; the mucous membrane was generally and uniformly distributed between the perpendicular plate and the superior turbinated bones. The next point to consider was its microscopic appearance, and here arose the question, What is our standard for the normal? The work in this region has been done mainly upon the lower animals, and while the results obtained are in the main applicable to the olfactory region of the higher animals, including man, obviously it would be of great assistance to have well-conducted studies upon the olfactory region of man. In an investigation upon the olfactory region of a case of leukæmia Hermann Suchannek $\left({ }^{84}\right)$ has touched upon this topic. He has figured a microscopic section of the olfactory region of a man 40 years old, with a normal sense of smell. The picture agrees with the usual description of this region. It represents a section consisting of a regular row of epithelial cells, resting upon a basement membrane, beneath which are many Bowman's glands, a few blood vessels and nerves, with Jittle intertubular connective tissue. Unfortunately no measurements are given, either of the entire mucous membrane or the epithelium. My specimen presented a different appearance. The epithelial layer preserved for the most part its normal characteristics of a regular row of columnar cells resting upon a row of round cells, the epithelial cells being well formed and distinct. In many places, however, the surface was not so well defined, but was breaking into crowded irregular masses of granular matter, while the subjacent layer of round cells had disappeared, and its place was taken by a mass of round cells, which penetrated deeply the underlying tissue. In these localities the surface layer of cells was thrown 
into folds which projected above the surface, and also ramified into the mucous membrane, like glands. There was a general increase of connective tissue. The thickness of the entire mucous membrane varied from $.16 \mathrm{~mm}$. to $.88 \mathrm{~mm}$. Those localities that measured $.16 \mathrm{~mm}$., taking as a standard the usual description and the figure of Suchannek, were fairly normal. The epithelium of these regions was particularly healthy. The epithelial layer varied from $30 /$ to $98 \mu$ in thickness (Kölliker quoted by Schwalbe ${ }^{85}$ ) gives $40^{\mu}$ to $98^{\mu}$ as the normal thickness). It was thinnest at the extreme vault of the olfactory fissure.

In the Bridgman sections the thickness of the mucous membrane entire varied from $.16 \mathrm{~mm}$. to $.64 \mathrm{~mm}$., and the thickness of the epithelial layer from $4 \delta^{\mu}$ to $90^{\mu}$. Taking $.16 \mathrm{~mm}$. as the thickness of the normal mucous membrane, I found those areas of the mucous membrane that were of this thickness, far from normal. The surface of the epithelial layer was covered with thin granular matter, and the surface line was very irregular. The cells took the stain poorly, showing that they were degenerating into mucus. In many places the cell bodies had entirely disappeared, leaving a mere outline of their former structures. The row of round cells had disappeared and its place was taken by a mass of cells, now pushing up into the epithelial layer, now invading the membrana limitans. In the sub-epithelial tissue there was a dense deposit of connective tissue. In no part of the specimen was the epithelium healthy. At some points the mucous membrane was entirely devoid of epithelial cells; at others, there was the row of round cells, now single, now two or three deep. In some places these cells were becoming polygonal in shape; again over them was a crowded confused mass of irregular cells breaking away. In some places there were breaks of continuity in the line of epithelial cells, otherwise fairly regular in their size and distribution. There were also places where the surface of the mucous membrane was thrown into elevations. There was generally a large increase of connective tissue, which, in some areas, had replaced everything else. In other areas was abundant infiltration of small, round cells. Bowman's glands were very irregularly distributed and varied 
much in their character. They presented all gradations from a ring of fairly healthy polygonal cells to a confused mass of granular matter.

The mucous membrane on the right of the septum was much healthier than that on the left. Its thickness was uniform, though in some places there was an increased deposit of connective tissue. The curve into the vault of the olfactory fissure was uninterrupted and regular throughout this side of the specimen. The epithelial cells, though individually undergoing degeneration, were fairly regular in outline. Bowman's glands were numerous in the frontal part of the specimen, but toward the sphenoidal end they had disappeared. Throughout this area were nerves and blood-vessels, with greatly thickened walls. The left side of the specimen presented a very different picture. In the frontal fifth of the olfactory fissure was crowded a mass of connective tissue, in which were nerves, blood-ressels, glands, covered ventrad with degenerated epithelium. Still ventrad to this, the perpendicular plate was devoid of mucous membrane, as was also that part of the superior turbinated bone which remained; the greater part of this bone was either in small fragments or had entirely disappeared. The remaining four-fifths of this side of the specimen was occupied by a fibrous tumor, which was, as it were, in a closed cavity, the mucous membrane of the septum having firmly united with that of the superior turbinated bone, giving in the sections the appearance of a ring lined with epithelium, enclosing the tumor. The tumor sprang from the septum and projected into the superior meatus. Its length from its frontal to its sphenoidal end, estimated by the number of sections in which it was found, was upwards of $1.5 \mathrm{~cm}$. It was irregularly polygonal in shape, and measured at its frontal end $1.12 \mathrm{~mm}$. in height (that is, from the septum to the apex of the tumor) and $1.05 \mathrm{~mm}$. in breadth, while at its sphenoidal end the corresponding measurements were 2.50 $\mathrm{mm}$. and $1.44 \mathrm{~mm}$. Its character changed from the frontal to the sphenoidal end. In the frontal region it was made up of a central column of dense connective tissne, which supported nerves, blood vessels, Bowman's glands, the whole being covered with a layer of epithelium as healthy as that in any part 
of the specimen. At the sphenoidal end the central column was divided by a fissure, Bowman's glands had disappeared, and the whole tumor was filled with spaces of irregular shape, many of them full of blood corpuscles. Blood vessels remained, but there were few nerves and the greater part of the tumor was devoid of epithelium.

\section{The Nerves.}

There were two varieties of nerves in the specimen, a branch of the ophthalmic division of the fifth which passes into the nose through the fissure at the base of the crista galli, and the olfactory nerves. The branch of the fifth, a medullated nerve, was in the main normal. The axis cylinders stood ont sharply throughout the greater part of the sections. In some areas, however, they had lost this distinctness and showed signs of beginning degeneration. But the change was no greater than might be expected in a woman of Laura's age.

Before entering upon the description of the olfactory nerves of this specimen, it will be well to discuss briefly the normal and pathological anatomy of the olfactory nerve in general.

The generally accepted view of the non-medullated nerve, of which the olfactory is a type, is that it is made up of the so-called Remak's fibres. Each of these consists of an axis cylinder, a neurilemma, and between the two a nucleated nerve corpuscle from place to place. This fibre has a striated appearance due, according to Max Schultze, to the fibrillæ of the nerve, which are distinguished from the axis cylinders of a medullated nerve in that they individually have no medullary sheath. Boveri $\left.{ }^{86}\right)$, on the other hand, has made a careful study of this subject, and concludes that the fibrillæ of Max Schultze are really nerve fibres, each having a medullated sheath. This sheath does not, however, belong exclusively to each nerve. It sustains the same relation to the contiguous nerve fibres that the cell wall of a honey-comb does to the cells. A number of these nerves are surrounded by an envelope of connective tissue, in which are here and there stellate connective tissue corpuscles. There are also within the investing sheath, among the nerves, connective 
tissue corpuscles, with stellate rays which can be traced very far, even to the enclosing sheath.

The olfactory nerves are subject to certain definite pathological conditions. In the first place, they may be congenitally absent. Injury to the head may cause rupture to the nerves as they pass through the cribriform plate. Excessive stimulation may temporarily or permanently destroy their excitability. Tumors in the brain or cerebral hemorrhage may by pressure cause disease of the olfactory nerves. There may be atrophy of the bulb or nerves, or they may be affected by the degenerative changes of old age. Simple neuritis is a very rare affection (Althaus) $\left.{ }^{87}\right)$. Chronic neuritis, due to syphilis, however, is not uncommon. The nerve may become involved in local inflammatory changes in connection with meningitis. Bosworth $\left({ }^{88}\right)$ is of the opinion that a very frequent cause of anosmia from diseases of the olfactory nerves is due to the influence of local inflammatory changes. Thus in acute rhinitis, anosmia persists many days after the inflammatory process undergoes resolution. In severer disease of the nose, where the local inflammatory action persists longer, or is of a severer type, the anosmia lasts much longer, long after the inflammatory action has subsided.

To return to our specimen. The nerves were numerous and were easily distinguished by moderate powers of the microscope (320 diameters.) To get some definite idea of the distribution of the nerves in the different parts of the specimen I selected five slides and counted the nerves on them. One of these sections was from the frontal end, one from the sphenoidal, the other three at regular intervals between them. I also made a count of the nerves of the control specimen under similar conditions, with the following results, (The slide numbered one in each case, was from the frontal end).

Bridgman.

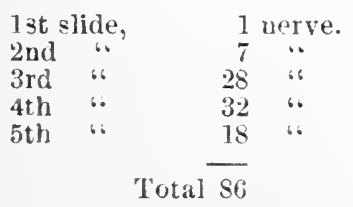

Control.

$\begin{array}{lrrr}\text { 1st slide, } & & 4 & \text { nerves. } \\ \text { 2nd } & 66 & 20 & 6 \\ \text { 31d } & 6 & 10 & 6 \\ \text { 4th } & 6 & 8 & 6 \\ \text { 5th } & 6 & 15 & 6 \\ & & & \\ & & & \end{array}$


This enumeration is of interest in that it shows the distribution of the nerves in the different parts of the specimens, but it gives no reliable information as to the relative number of nerves in the two specimens. It is a difficult matter, even under favorable conditions, to stain the olfactory nerves so as to show the nerve fibres. In neither of these specimens was I able to show the olfactory nerves with the special stains for nerve tissue. The only stain that brought them out at all was the hæmatoxylin and eosine, which did it by virtue of its differentiating the connective tissue. We shall see that this latter was greatly increased in the Bridgman specimen, and it is evident that because of this many more nerves would be detected than in the healthier specimen.

In the Bridgman slides, the nerves were surrounded by a ring of connective tissue which was very thick. Within this ring was a uniformly granular field broken up into smaller areas, and more or less studded with deeply stained dots. With a $\frac{1}{12}$ oil immersion objective, these dots were seen to be stellate connective tissue corpuscles. The areas alluded to above corresponded to the portions of the nerve bounded by the connective tissue envelope in Boveri's sections. Here, as with his sections, the connective tissue corpuscles were upon and within the sheaths. Rather the connective tissue corpuscles of the sheath were where the sheath should be, that place being represented in our sections by a vacant space. As this apparent shrinking was quite general throughout the specimen, I attributed it to the action of reagents. With this power, the nerve presented a regularly mottled appearance, very similar to a section of a frog's olfactory nerve as figured by Boveri, and representing according to his views the cut ends of the nerve fibres. The nerve in its essential elements, therefore, was normal. The connective tissue elements, however, were largely increased.

\section{General Considerations.}

It will be interesting now, to gather together the available facts relating to Lanra's sense of smell, and the general condition of her nasal mucous membrane during life, and to find, if we can, in the condition of this membrane an explanation of her symptoms. 
As an infant she was delicate, being subject to severe convulsions. But later her health improved, and when two years old she is described as being more active and intelligent than ordinary children. At two she had scarlet fever with such severity that for seven weeks she was unable to swallow solid food. Both eyes and ears were affected, suppurating freely $\left({ }^{1-p} 2\right)$. When seven years old she was seen by Dr. R. D. Mussey, Professor of Anatomy and Surgery at Dartmouth College, and in a letter dated April 14, 1837, he thus alludes to her sense of smell : "Her sense of smell is thought by her mother to be less acute than other children, as she very seldom applies any odorons substance to her nose: it is not improbable that this sense may have been impaired by the fever"'(1-VIII). In this year, 1837, she entered the Perkins Institution and we find in Dr. Howe's report this note $\left({ }^{2-155}\right)$ : "For all purposes of use she is without smell, and takes no notice of the odor of a rose, or the smell of cologne water, when held quite near her, though acrid and pungent odors seem to affect the olfactory nerve." April 6, 1842, Miss Swift, Laura's teacher, made this note $\left({ }^{1-\text { p. } 107}\right)$ : "Dr. Howe came into the room, while she was having a lesson, peeling an orange. She stopped in the midst of a sentence to say, 'I smell an orange.' We can see a decided improvement in her sense of smell since last year, but she has never noticed any perfume so quickly or at so great a distance before." June 19, 1844, we find this note $\left({ }^{1-0.257}\right)$ : "This is the first season she has ever perceived the smell of a rose or pink, and she now puts all flowers to her nose and is disappointed if they have no perfume. In a letter to Mrs. Howe, dated June 25, 1844, Laura herself says $\left({ }^{1-\mathrm{p} .} 258\right)$, "I can smell roses much better than I did two years ago, and it gives me much pleasure in smelling roses."

I find but few observations upon the general condition of her nose. Dec. 14, 1843, Miss Swift made this note $\left({ }^{1-p .}{ }^{215}\right)$ : "She has always been a sufferer from a severe catarrhal affection, and as this shows signs of improvement, we hope for a corresponding one in both smell and taste." In 1878 Dr. G. Stanley Hall, in the course of a series of observations upon her several faculties, examined her nose with this result $\left({ }^{6}\right)$ : 
"There is no deformity or scarification observable without or from a cursory examination within the nose, and the yellow pigment of the Schneiderian membrane can be seen by a very simple apparatus." Dr. Hall made further this very interesting observation. He described her sleeping with long regular breathing, the teeth slightly apart and the tongue pressed against them and almost between them.

I have received the following letter from Miss Della Bennett, who has been a teacher in the Perkins Institution since 1876 :

"Laura Bridgman lived for several years in the same family with myself, and I have conferred with the matron of the cottage, and can answer most of your questions definitely. There was copious discharge from her nose, so much so that she was wont to say, 'My poor nose!' Her handkerchief was in frequent demand, and she used many. Her breath was never offensive. She always breathed through her nose, a habit which she formed when quite young, and her breathing was often accompanied with a gentle whistling sound. I have seen her asleep in the daytime and her month was closed, but I cannot tell about the night. She did remove mucus from her throat, and occasionally had a sore throat."

From these notes one gathers that at the age of two, Laura suffered from a severe inflammation of the naso-pharynx, which doubtless extended to her nose: that after her illness she was quite destitute of the sense of smell, entirely so when at the age of eight she entered the Perkins Institution : that at the age of fifteen she could detect with certainty and pleasure moderately pronounced odors: that she had a severe nasal catarrh which lasted her entire life, although it decreased somewhat in severity: furthermore that there was no deformity without or within the nose that conld be seen by one not accustomed to examine these parts.

We now come to the consideration of the canse of Laura's anosmia and her partial recovery from it. We have seen that the olfactory nerves were capable of performing their function, and according to Dr. Donaldson (vide ante) there was no central lesion that would cause anosmia. We must therefore seek for the cause in the periphery of the nervous 
apparatus. The two chief peripheral causes of anosmia are obstruction to the inspired air due to deformity of the nose, hypertrophy of the turbinated bodies, nasal polypi or tumors, and atrophic disease. That there was not atrophic disease is shown by the absence of bad odor, by the partial return of the sense of smell, and by the result of our examination of the specimen. Furthermore, according to Bosworth, catarrhal affections caused by febrile diseases and prominently scarlet ferer, are characterized by hypertrophic changes $\left({ }^{85-n \cdot 157}\right)$. It is quite improbable that Laura had any deformity of the nose or hypertrophic disease in the respiratory part of the nose, which would interfere very materially with the access of the inspired air to the olfactory region, and it is in this latter region, therefore, that we must look for the cause of her anosmia. We have found in the left superior meatus an adequate canse for a complete absence of the sense of smell for that area, in the extensive disease there which resulted in a thorough disorganization of the mucous membrane in a part of the olfactory fissure, while the rest was excluded from all contact with the inspired air by the firm union of the mucous membrane of the septum with that of the left superior turbinated body. In the right superior meatus, on the other hand, conditions were more favorable for the proper performance of function. It is here that Laura must have smelled, and the questions now to be settled are, how could this area have been rendered incapable of performing its function, and how could this function have been resumed.

Catarrhal inflammation of the nasal mucous membrane is the usual accompaniment of scarlet fever, except in the mildest cases, and is associated with an irritating discharge from the nose (Smith) $\left({ }^{89}\right)$. The inflammatory process in these cases does not involve more than the epithelial layers. But in severe disease the deeper tissues of the mucous membrane are affected. There is a copious proliferation of cells in the deeper layers, with fibrinous infiltration even to the extent of compressing the ressels and making portions of the tissue gangrenous (Henock) $\left({ }^{90}\right)$. There may even result necrosis of the bones (Thomas) $\left({ }^{91}\right)$. There may be recovery even though the disease be severe, or it may result in chronic disease with 
more or less profuse discharge and extensive inflammatory infiltration, or there may be an osteitis of all the bones which enter into the composition of the nasal cavities (Allen) $\left({ }^{92}\right)$.

That Laura's nasal mucous membrane was profoundly affected by the fever there seems no doubt, and it is easy to conceive how the active cell proliferation and swelling of the mucous membrane caused by the catarrhal process would have so affected the delicate termination of the olfactory nerves that they would be entirely incapable of functioning. But as time went on we know her catarrh grew better and we rightfully infer that the inflammatory processes in the mucous membrane subsided, to an extent, though they never entirely ceased. We have seen that the structures of the nose were a good deal damaged, yet they were not entirely useless. In the right superior meatus especially, there were spots of membrane in a fairly healthy condition. A question of interest here presents itself-would the olfactory nerves after so long a period of inactivity prescrve their power of responding to stimuli? The following case reported by Allen $\left({ }^{92}\right)$ proves that this is possible. The patient was a married woman. She had never breathed through her nose and had never experienced the perception of an odor. There was found to be a complete bony occlusion of the posterior nares. This was broken through and on the sixth day after the operation she began to smell and in a short time became familiar with the common odors and flavors. The odoriferous air was not kept from Laura's olfactory nerves by bony obstruction, but it was kept from them by what acted as efficiently for a long time, namely, masses of rapidly proliferating cells, and the mucus and débris of a diseased mucous membrane. When this process subsided it again became possible, in those areas where the ephithelium still remained sufficiently healthy, as it did in places, for the terminal filaments of the nerves to receive and convey their proper stimuli. There may have been a further cause for the anosmia. When discussing the pathology of the olfactory nerve, we alluded to Bosworth's view that anosmia was due in some cases to the local action of the surrounding inflammation upon the nerve itself. As I understand the matter he bases this view solely upon clinical experience, and attempts no explanation of the tardy return of the sense of 
smell after the subsidence of the inflammation. We have in our sections a possible explanation of this peculiarity. The connective tissue of the nerve was increased in amount, while the nerve tissue proper was apparently normal. Interesting questions suggest themselves in this connection. Does the development of this tissue impair the functioning power of the nerve, and does a nerve so affected resume its normal activity more slowly than the surrounding tissue? At present, so far as I know, there is not sufficient anatomical data upon which one could even discuss these topics.

\section{Summary.}

I. The ethmoid bone and the mucous membrane covering it had suffered from inflammatory disease, which particularly affected the left side. 2. This disease resulted in an excessive production of connective tissue, and in one area, the left superior meatus, there had been formed a fibrous tumor. The epithelium was generally and considerably diseased. The nerves contained an excess of connective tissue, but were otherwise normal. 3. When two years old, Laura had scarlet fever, which left her anosmic and with severe nasal catarrh. She partially recovered from both these conditions. 4. The anosmia was due to the occlusion of the left olfactory area by the union of the mucous membrane of the septum with that of the superior turbinated body, and also to the action of the inflamed mucous membrane upon the nerves of the right olfactory region. Partial recovery resulted from subsidence of this inflammation.

\section{II.-The Visual Apparatus.}

When Laura recovered from her illness it appeared that she was totally blind in her left eye but could see somewhat with the right. The remnant of vision in her right eye continued up to the eigthth year of her life.

From that time on she was absolutely blind in both eyes.

In 1878 Dr. O. F. Wadsworth, of Boston, tested her for vision and found her totally blind ( ) and at the same time reported on the appearance of the eyes as follows :

"On both sides the lids are sunken, partly on account of lack of the normal amount of orbital fatty tissue, partly on account of the small size of the eyeballs. They remain constantly closed. The right conjunctival sac is much smaller 
than normal, somewhat irregular, and presents an appearance such as is seen after severe and long-continued inflammation. The right eye appears about one half the normal size. It is wholly enclosed by the sclerotic, except over a space at the centre, some two millimetres in diameter, where a less opaque tissue, on which a few blood-vessels are visible, represents the altered remnant of the cornea. The left conjuctival sac is somewhat larger than the right, and more regular, though still small. The left globe also is a little larger than the right, and its opaque altered cornea is some four millimetres in horizontal and two millimetres in vertical diameter. There was constant irregular oscillation of the globes [nystagmus] whenever they were exposed to view by raising the lids, and the oscillation evidently continued even after the lids were closed."

At the autopsy the eyes were removed with the surrounding tissue and put unopened into the Müller's fluid and alcohol. The hardening was completed in alcohol.

Both bulbs were enclosed by orbital fat. All the muscles the of bulbs were present, though small, and the external appearance of the bulbs corresponded with Dr. Wadsworth's description given in 1878. After hardening, the right eye had a transverse diameter of $15 \mathrm{~mm}$. and an antero-posterior diameter of $10.5 \mathrm{~mm}$. Similar measurements of the left eye gave 17.5 and $11 . \mathrm{mm}$. showing the left to be decidedly the larger. The condition of phthisis bulbi existed for both eyes. There was a faint indication of the anterior chamber. The locality of leus and vitreous contained abundant calcareous deposits in small masses and the choroidal pigment was very abundant. Sections through the point of entrance of the optic nerve showed no trace of the retina or normal nerrous elements at this point. Both eyes were similar in the appearance just mentioned. As has been stated the optic nerves were small :

Right optic nerve, area of cross-section near chiasma, $5.00 \mathrm{sq.} \mathrm{mm.}$

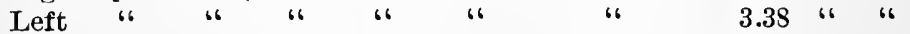

The connective tissue was vastly increased in both nerves but one also saw the characteristic cross sections of axiscylinders with their medullary sheaths. The fibres were both 
large and small. It is worth noting that these fibres were abundant in the left nerve but much less so in the right, although the : right was the larger nerve. The chiasma was much flattened dorso-ventrally. The optic tracts were small and flattened. Their area was taken about $10 . \mathrm{mm}$. behind the chiasma. The relations of size were of course reversed at this point and the left tract was the larger :

$\begin{array}{lll}\text { Right optic tract near chiasma, } & 3.13 \text { sq. mm. } \\ \text { Left " " } & \text { " }\end{array}$

From these measurements the only conclusion that can be drawn is that a large part of the fibres decussated. In the tracts, which were not very well hardened, the fibres visible in cross-section of the corresponding optic nerves were also to be found. Throughout the nerves and tracts, but more abundant in the latter, there were numerous droplets or spherical homogeneous masses, as a rule about $12 \mu$ in diameter, and staining with fuchsin and carmine. Lying at the periphery of both nerves and tracts these bodies would appear to correspond with corpora anylacea, with some of the descriptions of which, however, they do not exactly agree. Further than the tracts it was not practicable to carry the histological examination of the optic path way.

The corpora geniculata externa were too imperfect for description. The pulvinar and the anterior pair of the corpora quadrigemina were both slightly less prominent than in the normal brains. The cortex was the next locality studied and the results there obtained have already been given.

The first point calling for remark is that the eye in which vision was longest retained ultimately had the smaller bulb and at the same time it was associated with the larger optic nerve and tract. The nerve and tract, however, though larger showed fewer nerve fibres that were clearly marked. It should perhaps be noticed in this connection that this smaller bulb had also the smaller (right) oculo-motor nerve in connection with it.

From these facts it would appear that although in general the right eye was more seriously affected yet some portion of the retina remained undamaged for a long time-up to the 
eighth year. During this period the optic nerve, the tract and the cortex underwent considerable development so that the subsequent degeneration of the right nerve was accompanied by far less atrophy than that of the left side. On the left side the disturbance in the eyeball was in general less severe and though vision was abolished very early, there was left some condition which favored the better preservation of those nerve fibres which did not at an early period undergo degeneration and absorption. I had expected to find complete degeneration of both optic nerves such as had been described by Purtscher. $\left({ }^{80}\right)$

On the bases of these specimens, I should hardly like to enter into the forms of degeneration possible to the optic nerves but if a double set of fibres in the optic-the two sets developing and conducting in opposite directions-be accepted, then these nerves found intact in this case might be considered as belonging to that set the centre for which was central and which conducted peripherally. v. Monakow ( ${ }^{81,}{ }^{82}$ )

In this instance then the disturbance in the cortex is probably to be looked upon much more as due to an arrest of growth following the removal of the normal stimuli, than to a continuation of the degeneration into the hemispheres.

\section{III.-The Auditory Apparatus.}

From the time of her illness to her death there is good evidence that Laura was entirely deaf. At the same time she had a good sense of direction and of equilibrium and was sensitive to rotation. Hall $\left({ }^{6}\right)$. The equilibrium and auditory functions of the eighth nerve are therefore to be separated in this case.

An examination of the ears was made in 1878 by Dr. Clarence J. Blake who reported as follows: $\left(^{6}\right)$

"Both external ears normal. The right external auditory canal normal in size and contour, and the skin lining the passage healthy and showing no marks of previous inflammation-processes. The right membrana tympani was entirely destroyed with the exception of a narrow rim, the remains of the inferior and posterior portions of the membrane, from which a thin cicatrical tissue extended inward to the promontorium over the stapes and fenestra rotunda. The malleus 
and incus had disappeared. The mucous membrane of the tympanic cavity presented a normal appearance, with the exception of one spot on the promontorium covered with a thin crust of dried secretion about two millimetres in diameter. A band of thin cicatrical tissue also extended across the anterior portion of the tympanic cavity. The left external auditory eanal was filled with dark brownish cerumen, on removal of which the passage was found to terminate, at a depth of two centimetres, in a diaphragm of secondary granulation-tissue, concave, very firm, and resisting gentle pressure with a probe, except at the central or thinner portions, where it could be slightly depressed. Its outer covering was continuous with the dermoid lining of the canal."

After death, the petrous bones were put in Dr. Blake's hands and the report on them, made by Dr. W. S. Bryant, of Boston, is the following:

The Examination of Laura Bridgman's Petrous Bones.

The Right Petrous Bone.

A deep groove for the superior petrosal sinus is seen. The external auditory canal is terminated by a concave curtain of fibrous tissue resting on the promontory. There is no evidence left of the former position of membrana tympani except at the floor of the canal, where there is a slight indication of the sulcus tympanicus. The tympanic cavity is considerably constricted by hyperostoses. The oval and round windows are ossified across and the promontory is very rough, leaving only a small space inferiorly and posteriorly. The inferior anterior wall of the tympanum is very thin and there are two pin-hole perforations into the carotid canal.

The Eustachian tube is impervious; its tympanic end being closed by bone and just beyoud this there is an accumulation of cheesy matter also enclosed by bone. There are no air spaces within the tympanum for all the bone cells are filled with tissue, although in the highest part of the petrous bone there is a cell which connects with the tympanum. There is no evidence of mastoid cells or antrum. (I did not see the mastoid process).

The chorda tympani muscle is very much atrophied and its tendon is attached to cicatricial tissue. The stapedius 
was very much atrophied and its canal narrowed. The tendon still protrudes from the tubercle.

Anteriorly and externally the osseous wall of the aqueduct of Fallopius is wanting. No trace of the ossicles could be found. The inner ear appears normal.

Dr. H. F. Sears kindly examined the terminations of the auditory nerve and organ of Corti and found the terminal ganglion cells intact.

The Left Petrous Bone.

The groove for the superior petrosal sinus is unisually deep. A diaphragm of dense fibrous tissue especially thick and firm on the surface and coneave outwards forms the end of the conical external auditory meatus $8 \mathrm{~mm}$. exterual to the base of the styloid process.

The floor of the osseous meatus is defective externally and is pierced internally and anteriorly by a foramen $1 \mathrm{~mm}$. in diameter, in the fissure of Glacier.

External to the fibrous diaphragm there is a diaphragm formed by hyperostosis of the walls of the canal which obstructs the passage except near the centre and slightly external to the normal position of the membrana tympani, where there is an opening $2 \times 4 \mathrm{~mm}$.

The hyperostosis extends into the tympanum filling the greater part of it, but leaving a space external to the fenestræ and below the promontory, also a considerable space in the external anterior and superior part of the petrous bone.

There are no air spaces between the place of closure of the meatus and the pharyngeal end of the osseous Eustachian tube. All the bone cells are filled with soft tissue and the osseous Eustachian tube is not seen. No remains of the membrana tympani could be found.

Before I saw the specimen the tympanum had been opened and some of its contents taken out; all of this was lost except the head and neck of the malleus with the base of the long process, all enclosed in fibrous tissue.

The relations of the fenestra ovalis and the attachment of the tensor tympani muscle had also been destroyed. The chorda tympani nerve was found intact. The tendon of the stapedius muscle was protruding from its tubercle. 
The aqueduct of Fallopius and its contents are intact. The round window is closed by dense fibrous tissue. Both the round and oval windows are small, less than one-half of normal size.

Dr. H. F. Sears kindly examined the nerves and muscles and found the tensor tympani considerably and the stapedius slightly atrophied. He also found numerous ganglion cells in the cochlea.

The original report of Dr. Bryant ends here. In answer to a further question, however, he states that nothing pathological could be definitely made out in either the cochleas or semi-circular canals. As the original preservation of the specimens had been in Müller's fluid only, they were not in the best condition for a fine histological examination.

As the case stands the inflammation of the midale ear is the occasion of the deafness. The authorities on the subject state that absolute deafness does not follow disease of the middle ear alone. So that there is something here to be explained. I consider that the cochlea must have been thrown out of function on both sides since the tuning fork placed on the skull gave no auditory sensations-and this, to my mind, outbalances the negative result of the histological examination.

The auditory nerves were studied only by means of the stumps attached to the medulla; the right auditory had an area of $4.26 \mathrm{sq} . \mathrm{mm}$. in cross section. The left of $3.17 \mathrm{sq} . \mathrm{mm}$. Both samples were taken within about $3 \mathrm{~mm}$. of their attachment to the medulla. (For the method see the article in this same number on "The size of several cranial nerves in man as indicated by their cross-section.") Roughly their area was about two thirds of that of the similar nerves from the brain of a normal male in whom the cranial nerves were all very large. There is no reason then to think that in Laura the nerves were remarkably small. The figure for the area of the larger, right nerve, is somewhat too high owing to the obliquity of section and some distortion, so that they were really more nearly equal than these figures would indicate. The connective tissue in the nerve trunks is normal. The 
nerve fibre show well marked sheaths and axis cylinders. If degeneration has occurred in these nerves the indications of it have long since disappeared. The nerve fibres found would be designated as normal. The bundles of larger fibres, presumptively connected with the semi-circular canals, contain particularly well preserved fibres.

In the medulla both roots and all three nuclei can be clearly identified on both sides.

The fibres in the medulla stain by Weigert's method and the cells with carmine, as well as could be expected from the condition of the specimen. If there is any abnormality it is that the auditory fibres do not take the Weigert's stain particularly well and that the cells of the accessory nucleus in the medulla are few and poorly developed. The striae acusticae were well developed and on gross examination-when the floor of the fourth ventricle was viewed from above-there were visible two bundles on the right side and three on the left which could be counted as belonging to the striae, while just cephalad to these was a well marked bundle on each side of the middle line, corresponding with the structure described as the conductor sonorus (Klangstab) and supposed to form part of the centripetal pathway for the auditory impulses.

On comparison with a number of normal specimens the caudal pair of the quadrigemina exhibited no marked peculiarity. They were small, but no smaller than in the case of some normals. The corpora geniculata interna did not appear small in Laura upon gross examination but this appearance I am inclined to attribute to the failure of the surrounding regions to fully develop, thus causing the corp. gen. int. to stand out with unusual clearness.

The next point examined in the auditory pathway was the cerebral cortex and the results there found have already been stated.

I wish to add in this place that in the description of the surface of the brain previously given Iwas not willing to admit any superficial abnormality in the region of the first temporal gyrus at its caudal end. Since writing that description I have made further comparisons with normal brains and have obtained evidence of lack of development in the cortex of this 
region in the case of Laura. At present then I look on the slenderness of this gyrus, especially on the right side, where the cortex is most affected, as an expression of the incomplete development of the region. Mills $\left({ }^{42,68}\right)$, Starr $\left({ }^{41}\right)$, Manouvrier $\left({ }^{83}\right)$.

At first sight the small disturbance-to the naked eye at least-existing between the middle ear and the cortex is striking. Histological investigation up to the centres in the medulla yields a similar negative result. Between the medulla and cortex the condition of the specimen did not warrant a histological study.

In the scattered literature relating to the examination of the ear and brain in deaf-mutes, a condition where there is little or no apparent abnormality of the inner ear, the auditory nerve or the medulla, associated with disease of the middle ear, deafness and (sometimes) atrophy of the cortical auditory centres, is occasionally described: Bremer $\left({ }^{69}\right)$, Larsen \& Mygind $\left({ }^{70}\right)$, Moos $\left({ }^{71}\right)$, Mygind $\left({ }^{72}\right)$, Obersteiner $\left({ }^{73}\right)$, Moos and Steinbrügge $\left({ }^{74,75,76}\right)$. I believe that in future cases, like that of Laura, a more detailed examination than it was possible to make in her case will show disease of the membraneous cochlea or the nerves between it and the spiral ganglion of the cochlea. Such a case has been reported by Moos and Steinbrügge $\left({ }^{79}\right)$.

As long, of course, as the cells of the spiral ganglion are intact, just so long will the auditory fibres associated with them-and this must represent a very large portion of the cochlear division of the auditory-remain morphologically intact. Following the pathway to the cortex we find no point at which marked changes occur until we reach the cortex itself. The disturbance here is most probably due to the early and long continued lack of normal excitation, for the cortical cells in the sensory areas are peculiarly dependent for their proper development on the special sense with which they are associated.

The evidence from stimulation of the cortex and from the histology of the medulla goes to show that the association between the auditory nerve and the cortical centre for hearing is to some extent at least, a crossed one. If this were so, then 
the smaller, left nerve, would associate itself with the thinner, right cortex. This relation exists in the case of Laura, but it remains for further investigation to show its significance. Strümpell $\left({ }^{78}\right)$.

As regards the semicircular canals it may be added that they were not found diseased. Their nerve was in good condition, and sensibility to rotation, sense of direction, etc., were present. Of course the relation of this part of the inner ear to the middle ear is less intimate than that of the cochlea, and this in part may account for the normal preservation of the canals. That both portions of the labyrinth need not be conjointly affected is shown by James $\left({ }^{79}\right)$, in his study of the sense of dizziness in deaf-mutes, where this sense was found totally lacking in only 186 out of the 519 cases examined.

$$
\text { IV.-The Cranial Nerves. }
$$

It is desirable to bring together the various facts regarding the cranial nerves in Laura's case. After what has been said in the foregoing pages, and the discussion of their area by $\mathrm{Mr}$. Bolton and myself ( vide p. 224 ), this can be briefly done. Table XI. gives the various points in a condensed form.

\section{TABLE XJ.}

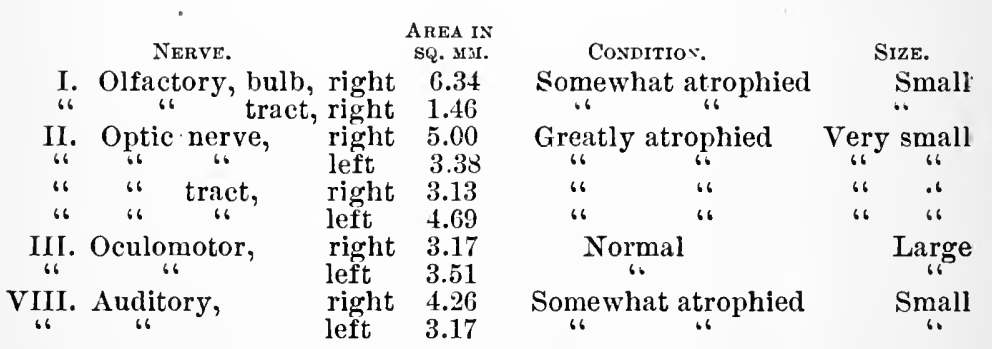

The sixth nerve-abducens-contained only normal fibres and appeared healthy, but the measurements on the two sides were so different that I suspect some strands were lost, and hence do not give the figures for the area.

The only nerve in the Table which has not been discussed is the olfactory. The bulb was flattened and the glomeruli could not be identified. The ganglion cell layer was there, and contained some well formed cells. The other layers were poorly preserved. The vessel walls were thickened. There was some excess of connective tissue and an abundance of 
hyaline bodies-corpora amylacea (?). Distinctly degenerated fibres could not be made out in the tract, but the vessels, connective tissue, corpora amylacea, were found as in the bulb. Grossly the left tract and bulbs were like the right, but by accident the former was lost before it had been examined histologically.

Whether there was anything peculiar in the glossopharyngeal fibres, I am unable to say. The portion within the medulla was normal.

The medulla which was examined from the level of the pyramid to the middle of the pons, by means of sections, showed no abnormality save in the neighborhood of the accessory nucleus of the auditory nerve, where the cells appeared small, reduced in numbers and highly pigmented.

The pia of the hemispheres had a normal abundance of nuclei in it, even over the occipital region-and the blood vessels were normal in size and thickness of their walls. The cerebellum was also normal.

\section{V.-Conclusion.}

From these fragmentary observations, which leave so many points connected with this special case still undecided, it will be advantageous to construct some sort of general picture.

The anatomical condition was that of a normal brain in which the olfactory bulbs and nerves, the optic nerves, the auditory nerves, and possibly the glossopharyngeal, had all been more or less destroyed at their peripheral ends. This destruction caused a degeneration-most marked in the optic nerves-which extended towards the centres and involved them indirectly. This condition has left its mark more or less plainly on the whole brain, as indicated by the extent and thickness of the cerebral cortex, and specially by the cortex connected with these deficient sensory nerves. The physiological effect of the peripheral lesions, as I conceive it, was to retard growth in the centres, cortical and subcortical, which were thus involved, and also to interfere with, if not entirely prevent, the formation of the association tracts.

To be sure, this case represents a maximum loss in these defective senses with a minimum amount of central disturbance, thus offering the very best sort of opportunity for education by way of the surviving senses. At the same time, we must 
imagine the hemispheres to have been traversed in every direction by partly or completely closed pathways. The brain was simpler than that of a normal person, and Laura was shut off from those cross-references between her several senses, which usually so facilitate the acquisition of information and the process of thought. Mental association was for her limited to various phases of the dermal sensations and the minor and imperfect senses of taste and smell. Yet from their fundamental and protean character, the dermal senses are perhaps the only ones on which alone the intellect could have lived. We are thus brought back to Sanford's ( ${ }^{7}$ ) conclusion as derived from the study of her writings. "She was eccentric, not defective. She lacked certain data of thought, but not, in a very marked way, the power to use what data she had."

One word more upon the cortex. The deficiency in the motor speech centre is mainly macroscopic, as far as the third frontal gyrus is concerned. The motor centre there had lost some, but not all its associative connections. Histologically, it was slightly deficient. The lesion there was so different from that of the sensory centres that a histological difference ought not, perhaps, to be surprising. The cortex of the sensory centres was not sunken below the surrounding level, though the gyri were slender and flattened. Possibly in this sinking in a motor area and the absence of the same in the sensory areas, we have a suggestive difference in the reactions of the several portions of the cortex.

Finally, the deficiency was not so very great even in those areas, where it was most marked, and the question arises as to what sort of occupation the cells in those areas had, which would thus justify their prolonged existence. If they were thrown entirely out of function it is not easy to see how they conld last so well for nearly sixty years. In some way then they may have taken a slight part in the cerebral activity, but it was so slight that their specific reactions did not rise into consciousness, for though Laura had some light perception up to her eighth year, she apparently had no visual memories, whereas those who have retained full vision up to four and a half or five years of age and then become blind, do usually remember in terms of sight $\left({ }^{8}\right)$. 


\section{BIBLIOGRAPHY.}

RETERENCE

NUMBER. DATE.

1. 1878 .

2. 1890. Fifty-eighth Annual Report of the Trustees of the Perkins Institution and Massachusetts School for the Blind, for the year ending September 30, 1889. Boston. (Appendix C. of the above Report contains the more important Reports by Dr. Howe on Laura D. Bridgman up to the twentieth year of her age.)

3. 1888. Jastrow, J. The Dreams of the Blind. The New Princeton Review. Vol. V, No. 1. Jan., 1888.

4. 1850. Lieber, Fraxcis. A paper on the Vocal Sounds of Laura Bridgman. Smithsonian Contributions to Knowledge, Washington. December, 1850. Same, enlarged edition, in Reminiscences, Addresses and Essays. Philadelphia, 1881. Lippincott \& Co.

5. 1890. Layson, M. S. Ragnhild Kaata. Am. Annals of the Deaf. Vol. XXXV, No. 3; July 1890. Washington.

6. 1879. Hall, G. S. Laura Bridgman. Mind. Vol. IV, 1879. Also, in Aspects of German Culture. Boston. 1881 .

7. 1886. SAKFord, E. C. The Writings of Laura Bridgman. The Overland Monthly. Oct. and Dec., 1886.

8. 1838. Mareschal. Observations sur deux sourds-muets aveugles. Journ. de la Sect. de Med. de la Soc. Acad. du Depart. de la Loire-Infër. Vol. XIV, p. 244-251. Nantes.

9. 1843. FOWLER, R. Some observations on the mental state of the blind, deaf and clumb. Suggested by the case of Jane Sullivan, both blind, deaf, dumb and uneducated. pp. 100. Salisbury.

10. 1845. Burdach, C. Fr. Ueber blinde Taubstumme. Jour. a. Chir. u. Augenh. B. XXXIV, p. 215-234. Berlin.

11. 1862. Alessr. Un aveugle-né, sourd-muet, guéri de la cécité congéniale. Annales d'oculistique. XLVII, p. 112-118. Bruxelles.

12. 1865. Sichel. De la coexistence de la cécité avec la surdité et surtout avec la surdi-mutité. Annales d'oculistique. Vol. LIII, p. 187-196. Bruxelles.

13. 1879. Fuller, A. A. Sophia Augusta Hutson, a blind deaf-mute. Am. Annals of the Deaf and Dumb. Vol. XXIV, pp. 90-100. Washington. 
RhFerence NOMBER.

14. 1879 .

1578

1883.

\section{1884.} XIII. Pt. 21. Washington.

Borg, O. E. Un mémoire sur l'education d'un de ses élèves en même temps aveugle et sourd-muet. Congrès Universal pour l'Amélioration du Sort des Avergles et des Sourds-Muets. p. 126-130. 1 pl. Paris.

Large, A. Article: Deaf and Dumb. Encyc. Erit. IX ed.

Wines, F. H. Statistics relating to the defective, dependent and deliuquent classes. 10th census, U.S. House Misc. Doc. $2 d$ Sess. 47th Cong. 1882-83. Vol.

Giacomini, C. Guida allo studio delle circonvoluzioni cerebrali dell' uomo. 2 d ed. 17 Fig. p. 288. Torino. Loescher.

18. 1854. Huschke, E. Schädel, Hirn und Seele des Menschen und der 'Thiere nach Alter, Geschlecht und Race. S. 194. 6 'laf. Jena.

19. 1880. v. Bischoff, 'TH. L. W. Das Hirngewicht des Menchen. S. 171. Bonn.

20. 1880. Bastian, H. C. 'The Brain as an organ of mind. $8^{\circ}$ London.

21. 1865. Thurnam J. On the weight of the braiu and the circnmstances affecting it. Journ. of Mental Science. Vol. XII, pp. 1-43. London.

22. 1S81. Scrimalbe, G. Lehrbuch der Neurologie. Erlangen.

23. 1889. v. Gudden, B. Gesammelte und hinterlassene Arbeiten. S. 227. 41 'laf. Wiesbaden.

24. 1888. Vierordt, I. Anatomische, physiologische und physikalische Daten und Tabellen. Zum Gebrauche für Mediciner. S. 303. Jena.

25. 1889. Schiller, H. Sur le nombre et le calibre des fibres nerveuses du nerf oculomoteur commun chez le chat nouveau-né et chez le chat adulte. Compt. Rend. Vol. ClX. Paris.

26. 1888. Below, E. Von dem versehiedenen Zustand der Entwickelung der Gauglienzellen bei verschiedenen ueugeborenen Thieren. Verhandl. d. physiolog. Gesellsch. zu Berlin. 3 Feb., 1888. No. 7.

27. 1888. OBERstminer, H. Anleitung beim Studium des Baues der nervösen Centralorgane im gesunden und kranken Zustande. S. 406. 178 Fig. Leipzig und Wien.

28. 1888. GaLton, F. Head growth in students at the University of Cambridge. Read at Anthropological Institute, London, April 24, 1888. Report in Nature. Vol. XXXVIII, May 3, 1888.

29. 1869. ECKER, A. Zur Entwickelungsgeschichte der Furchen $u$. Windungen der Grosshirn-Hemisphären im Fotus des Menchen. 4 'Taf. S. 203-225. Archiv f. Anthropologie. Bd. III. Braunschweig.

30. 1876. Krause, W. Handbuch der menschlichen Anatomie. 2 Bd. Hannover. 
REFERENCE

Number. Date.

31 .

als Seelenorgan. Göttingen.

1860. Erste Abhandlung, 6 Kipftaf. S. 96.

1862. Zweite Abhandlung, 5 Stntaf. S. 105.

32. 1890. Eberstaller, O. Das Stirnhirn. Ein Beitrag zur Anatomie der Oberfläche des Grosshirns. 9 Abb. u. 1 'Taf. S. 142. Wien und Leipzig.

33. 1889. Wilder, B. G. Art. Brain-Gross or Macroscopic Anatomy. Reference Handbook of the Afedical Sciences, edited by A. H. Buck. New York. Vol. VIII, p. 107.

34. 1S84. Eberstaller, O. Zur oberflächen Anatomie der Grosshirn-Hemisphären. Wiener med. Blätter. Nr. $16,18,19,20,21$.

35. 1882. Rübrxaer. Ein Beitrag zur Anatomie des Sprachcentrums. 5 Taf. S. 59. Stuttgart. Separatabdruck aus den "Beiträge zur Biologie." Jubiläumsschrift für Geheimeratl v. Bischoff.

36. 1S83. ZuCKERKANDL, E. Ueber Defecte an der Sprachwindung nebst einigen Bemerkungen zur normalen Anatomie dieses Windungszuges. Wiener med. Jahrb. Jahrg. 1883, S. $443-462$.

37. 1883. ECKER, A. Die Hirnwindungen des Menschen. 2te Auf. S. อ̊. Braunschweig.

38. 1886. WILDER, B. G. The Paroccipital, a newly recognized fissural integer. Reprint from Journal of Nervous and Mental Disease. Vol. XIII., No. 6, June, 1886, p. 15. New York.

39. 1886. Ferrier, D. The Functions of the Brain. 2d Edit. pp. 498 . London.

40. 18S8. Horsler, V., and Schäfer, E. A. A record of experiments upon the functions of the cerebral cortex. Phil. Trans. Roy. Soc. Vol. 179. 1888. p. 7, pl. 1-7. London.

41. 1888. Starr, M. A. Aphasia. Transactions of the Congress of American Physicians and Surgeons, held at Washington, D. C., Sept. 18s8. New Haven.

42. 1888. Mulss, C. K. Cerebral localization in its practical relations, loc. cit. in Reference Number 41.

43. 1877. RüDINGER. Ueber die Unterschiede der Grosshirnwindungen nach dem Geschlecht beim Fotus und neugeborenen mit Beriicksichtigung der angeboreuen Brachycephalie und Dolicocephalie. Beiträge zur Anthropologie i. Urgeschichte Bayerns. Bd. I. 3 Taf. Mïnchen.

44. 1S64. WAGNER, H. Maassbestinmungen der Oberfläche des grossen Gehirns. S. 48. Inaug. Diss. Göttingen.

45. 1875. JENSEN, J. Untersuchungen über die Beziehungen zwischen Grosshirn und Geistesstörung an sechs Gehirneu geisteskranker Individuen. 'Taf. IX-XIV, S. 577-757. Archiv $f$. Psychiatrie. Vol. V. 1875. Berlin. 
ReFRRENCE NUMBR DATE.

46. 1867 .

47. 1872 .

48. $\quad 1870$. p. 428 . 3 pl. $8^{\circ}$. Paris. singes. Genève, 1867. Arch. f. Anthropologie, Bd. II, S. 129-284, 26 Taf. Braunschweig.

BAILlarger, J. Recherches sur l'anatomie, la physiologie et la pathologie du système nerveux.

Calori, L. Del cervello nei due tipi brachicefalo e dolicocefalo italiani. Marzo. 1870. Memoria della Accad. delle Scienze dell' instituto di Bologna. Ser. Seconda. T. X. p. 35.

49. 1880. Danilewsky, B. Die quantitativen Bestimmungeu der grauen und weissen Substanzen im Gehirn. Centralblatt $f$. $d$. medicinischen Wissenschf. No. 14. 1880.

50. 1866. Bourgorn. Recherches chimiques sur le cerveau. Journ. de pharm. et de chimie. 'T. III. 4e Ser. p. 420-432. Paris, 1866.

51. 1867. Desprez, G. Essai sur la composition chimique du cerveau. Paris, 1867.

52. 1S82. Forster. Ein Beitrag zur quantitativen Bestimmung der grauen und weissen Substanz in menschlichen Gehirne; in "Beiträge zur Biologie." Jubiläumschrift fuir Geheimerath v. Bischoff. Stuttgart. 1882.

53. 1889. France, E. P. On the descending degenerations which follow the lesions of the gyrus marginalis and the gyrus fornicatus in monkeys. With an introduction by Prof. Schäfer, F. R. S. Phil. Trans., Vol. 180, (1889) B. pp. 331-334. 3 plates.

54. 1840. BAIllarger. Recherches sur la structure de la couche corticale. Pl. I, II. Mém. de l'Acad. $R$. de Médecine T. VIII. p. 182.

55. 1865. ENGEL, J. Ueber die Oberflăchen des Gehirns; ihre Verschiedenheiten nach Alter, Geschlecht und Nationalităt. Wiener. Med. Wochenschr. Bd. XV. 1865, S. 605.

56. 1878. Richet, C. Structure des circonvolutions cérébrales, in-8. Paris, 1878. Baillière et Cie. pp. 172, pl. 2.

57. 1879. Bucknill and Tuke. Psychological Medicine. 4th Ed. London.

58. 1884. Contr, A. De l'épaisseur de l'écorce du cerveau humain. (No tables.) Internationale Monatsschrift für Anatomie u. Pysiologie. Vol. I. pp. 395.

59. 1884. ConTI, A. Dello spessore della corteccia cerebrale nell uomo. Torino, 1881. Giornale della $R$. Acad. di Medicina di Torino. Fasc. 11-12 Nov.-Dec. 1884. (Full Tables.)

60. 1841. Parchappe. Traité théorique et pratique ile la folie. Paris, $184 \mathrm{l}$.

61. 1886. Franceschi. Sulla varia grossezza della sostanza grigia degli emisferi cerebrali e dei centri psicomotori dell' uomo. Bologna. Bull. d. sc. med. di Bologna. 1886, 6s., XVIII, pp. 153. (Tables.)

62. 1887. LUYS, J. De l'écorce cérébrale. L'encephale. 1887. pp. 16. 

RefERENCE Date.
NuMBer.

63. 1890.

Obersteiner, $H$. The Anatomy of the Central Nervous Organs in health and in disease. 'Trans. by Alex. Hill, M. A., M. D. Philadelphia, 1890.

61. 1872. MaJOR, H. C. A new method of determining the depth of gray matter of the cerebral convolutions. West Riding Lunatic Asylum Hed. Reports, 1872, Vol. II. p. 157.

65- $\quad$ 1S88. Cionini, A. Sullo spessore della corteccia cerebrale negli alienati. I. Paralesi generale progressiva. Rev. sperimant. di Freniatria e di Medicina legale. Vol. XIII, Fasc. IV. 18ss. ('lables.)

66. 1889. MaRchaND, F. Beschreibung dreier MikrocephalenGehirne nebst Vorstudien zur Anatomie der Mikro. cephalie. I. Abtheilung 1889. Nova Acta der Ksl. Leop-Carol. Deutschen Akademie d. Natur-forscher. Bd. LIII. No. 3. II. Abtheilung, Ibid. Bd. LV. No. 3, 1890.

67. 1887. Waldschyid, J. Beitrag zur Anatomie des Taubstummengehirns. Allgem. Zischr. f. Psych. Bd. XLIII. H. 4, 1887 .

68. 1889. MrLls, C. K. Brain specimens chiefly illustrating localization. University Medical Magazine, Philadelphia, November, 1889.

69. 1880. BREMER, V. The pathological results of the examination of deaf mutes, especially in Deumark. Copenhagen, 1850. (Abstract in Archives of Otology, Vol. X. p. 169. 1881.)

70. 1890. Larsen, P. C., und Mrgind, H. Ein Fall von erworbener Taubstummheit mit Sectiou. Arch. $f$. Ohrenhlkde. Bd. XXX, 1890, S. 188-197.

71. 1874. Moos, S. Contribution to the pathology and pathological anatomy of the organ of hearing. Case VII. Archives of Ophthalmology and Otology, Vol. III. p. 171.

72. 1890. MYGIND. H. Uebersicht iiber pathologisch-anatomischen Veränderungen der Gehörorgane 'Taubstummer auf Grundlage vorliegender Sectionsberichte. Avch. f. Ohrenheilkde. Bd. XXX, 1890. S. 76.

73. 1892. OBersterner, H. Anleitung beim Studium des Baues der nervösen Central-organe in gesunden und kranken Zustande. Zweite Auflage. Leipzig uud Wien, 1892. vide S. 389-90.

74. 1882 Moos, S., and STEINBRÜGGE, H. Total absence of both labyrinths of a deaf-mute; with embryological and physiological remarks. Archives of Otology. Vol. XI. 1882 , p. 236.

75. 18s3. Moos, S., and StennbrügGe, H. Histological labyrinthine changes in a case of acquired deafmutism. Archives of Otology. Vol. XII, 1883, p. 304.

76. 1886. Moos, S., and SteinbrüGGe, H. Results of the examination of six petrous bones from three (?) deafmutes. Archives of Otology. Vol. XV, 1886. Nos. 2 and 3. p. 123.

77. 1884. Moos, S., and STEINBR ̈̈GGe, H. The results of the examination of four petrous bones of two deaf-mutes. Archives of Otology. Vol. XIII. 1884, p. 247. 
ReFERENCE Date.
NumbKr.

78. 1882 .

79. 1882 .

80. $\quad 1880$.

S1. 1885. v. Monakow, C. Experimentelle und pathologisehanatomische Untersuchungen iiber die Beziehnngen der sogenannten Sehsphäre zu den infracorticalen Op. tieuscentren und zum N. Opticus. Archiv. f. Psychzatrie. Bd. XVI. H. 1. u. 2.

S2. 1889. v. Monakow, C. Experimentelle und pathologischanatomische Untersuchungen iiber die Opticuscentren und Bahnen. (Nene Folge.) Archiv f. Psychiatrie. B. XX. H. 3.

83. 1889. Manouvmier. Ies premières circonvolutions temporales droite et ganche chez un sourd de l'oreille gauche (Bertillon). Revue Philosophique. 'T. XIV.3. p. 330. Paris.

84. 1890. Suchanseк, H. A case of Leukamia with noteworthy changes of the nasal mucous membrane. Archives of Otology, Vol. XIX.

85. 1887. Schwalise, G. Anatomie der Sinnes-organe. Erlangen.

86. 1885. Boveri, 'T. Beiträge zur Kenntniss der Nerven fasern. Abhandl. d. k. bayer. Akademie d. Wiss. II. cl. XV. Bd. II. Abthe. München.

57. 1881. Altilaus, J. A lecture on the physiology and pathology of the olfactory nerve. The Lancet, 1881, vol. 1 .

88. 1889. Boswonti, F. H. $A$ treatise on the diseases of the nose and throat. Vol. I. New York.

89. 1855. Surtir, J. I. Scarlet Fever : in System of Medicine by American Authors. Pepper, Philadelphia.

90. 1889. Henoch, E. Lectures on Children's Diseases. Vol. II. New Sydenham Society's Publieations. London.

91. 1879. 'Tinomas, I. Cyclopaedia of the Practice of Medicine. von Ziemsen. New York.

92. 1891. Aluen, H. Clinical Signs common to the mouth, nose, throat and ear. The cephalic mucous membrane. University Medical Magazine, March, 1891. Philadelphia.

\section{Corrigenda. I. Article.}

Page 12. The percentage increase in volume is certainly too large. It should be one or two per eent. less than that for weight.

Page 14. Line 8. All the specimens mentioned in this paragraph except the Bridgman, are snpposed to have been weighed with the pia on. To make this specimen comparable then its weight must be increased by the weight of the pia, 31.4 grms. 'This makes the total weight of the Bridgman encephalon, with pia, 1235.4 grms. 
Page 20. Line 13. Topinard's Table (Éléments d'Anthropologie générale, Paris, 1855) in his Anthropology, p. 518 shows the relations between brain weight and age. It is based on 1913 cases of Boyd, and according to it the maximum encephalic weight for females, falls between the ages of 20-30 years; that for males between $30-40$ years; This indicates brain growth up to the age of maximum weight, therefore beyond the twenty-fifth year.

Page 32. Table. The first series of weights stands under the heading "Weight of cerebral hemispheres, fresh." The question arises whether "cerebral hemisphere " should not be replaced by "encephala." I have not seen any account of how much of the encephalon was used in determiuing the fresh weights in this series, but, since these brains were directly compared with those of other observers in which the entire encephalon had been weighed. it is only fair to suppose that they had been treated in the same way. 'This was my opinion until I found a table in R. Wagner's $\left({ }^{31}\right)$ Vorstudien. 2te Abhandlung, 1862, P. 91, in which the weights of the two "hemispheres," of at least three of these brains in the table, are compared with one another. The specimens had been in alcohol the strength of which is not given. Now the sum of the weights of the two "hemispheres" is nearly equal to or more than the weight of the "brains" given by H. Wagner (44) 1864. I therefore used the word "hemisphere" in the above heading as equivalent to hemicerebrum. It would appear that both the Wagners used it as equal to hemieneephalon. In the above mentioned table then the weights given are those for the entire encephalon and not for the cerebrum only.

Page 36. Table I. For absolute difference,

$$
\begin{aligned}
& \text { Read " } \\
& \text { For in percentage, } \\
& \text { Read :" }
\end{aligned}
$$

Iage 42. Table VIII. For total (left), Read"

For absolute difference, $1398.4 \mathrm{sq} . \mathrm{mm}$. 1598.466

$$
1.8 \%
$$$$
1.9 \%
$$

$101256.0 \mathrm{sq}$. mm.

101255.2 66 6

2309.5 " 6

$2308.7 \quad 6 \quad 6$ 


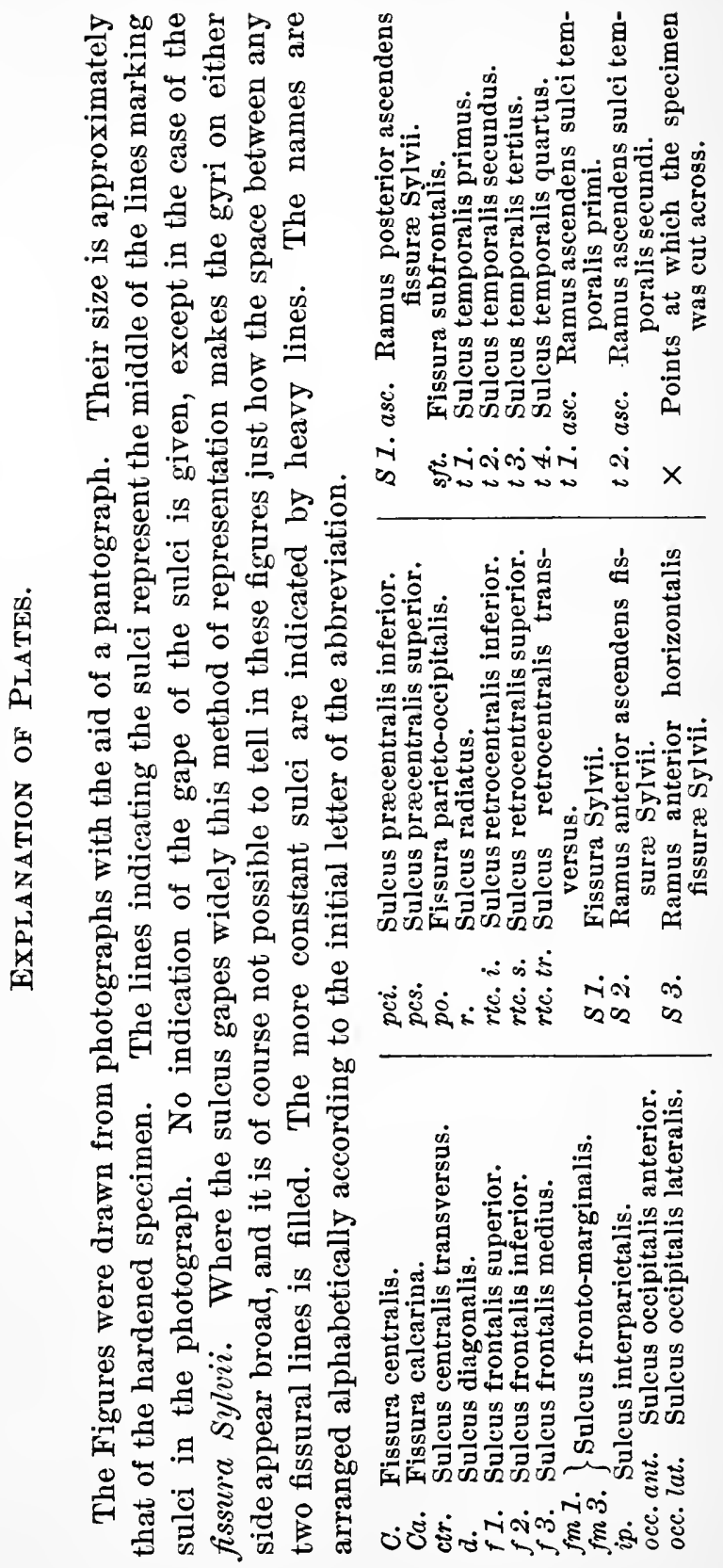




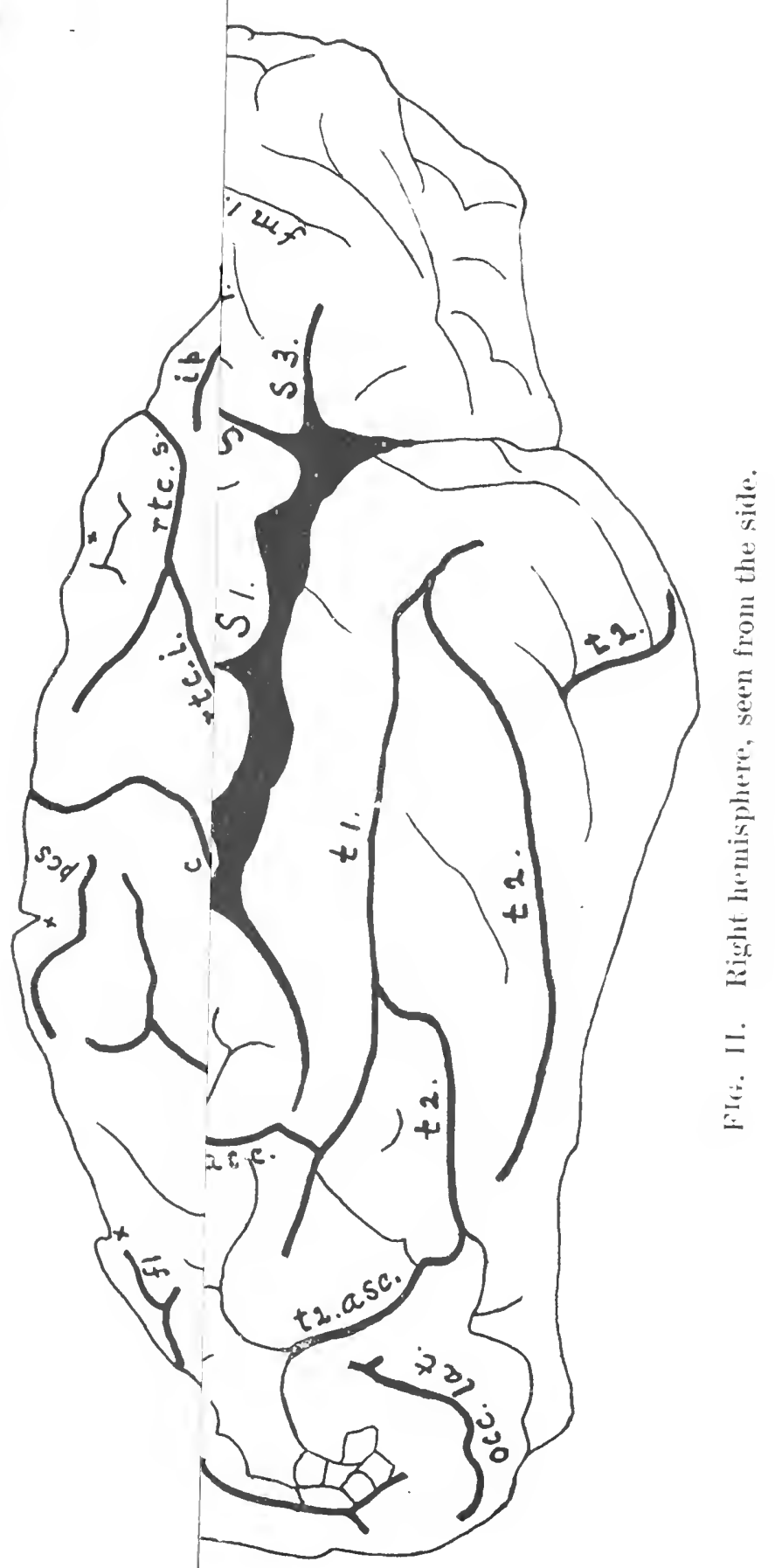




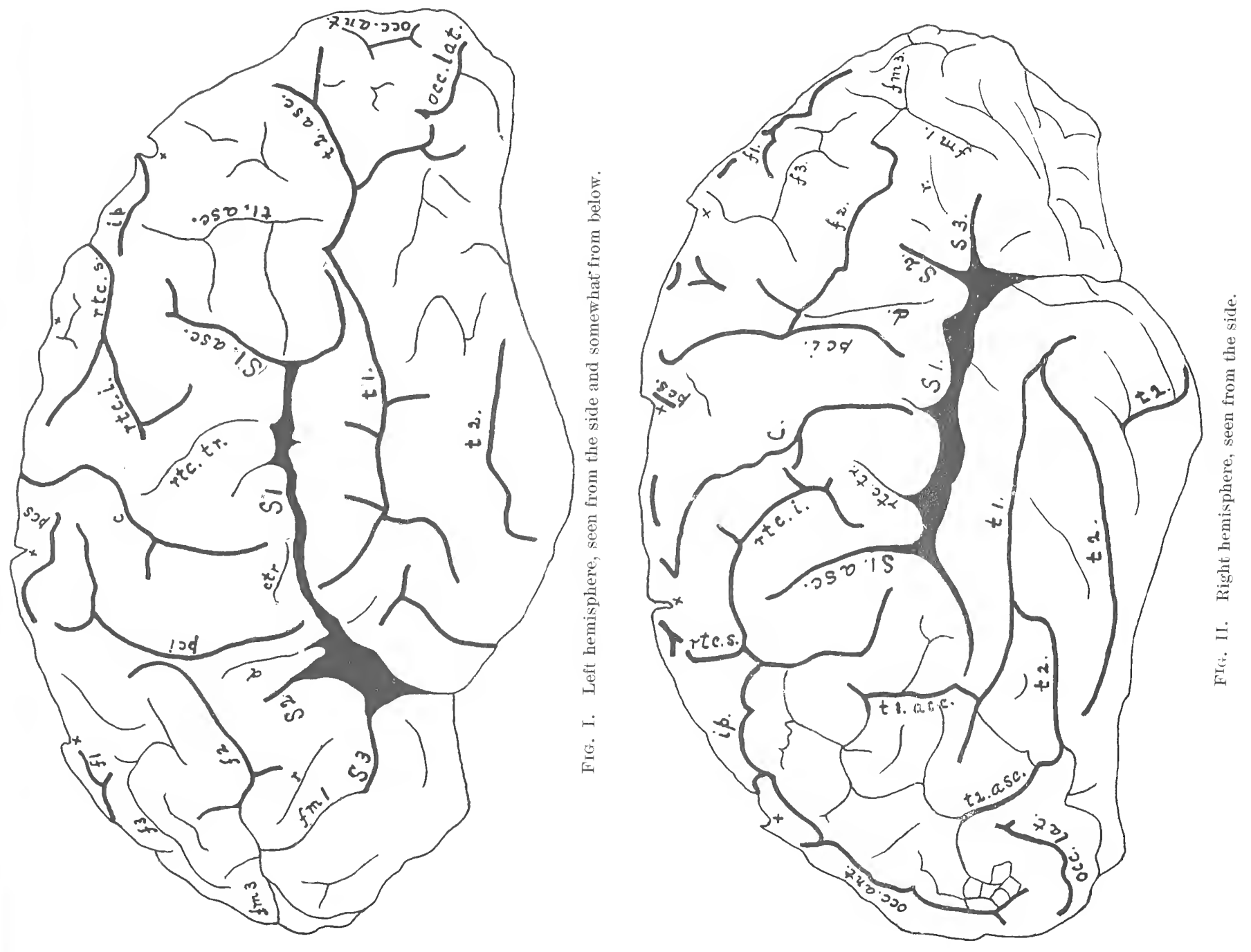




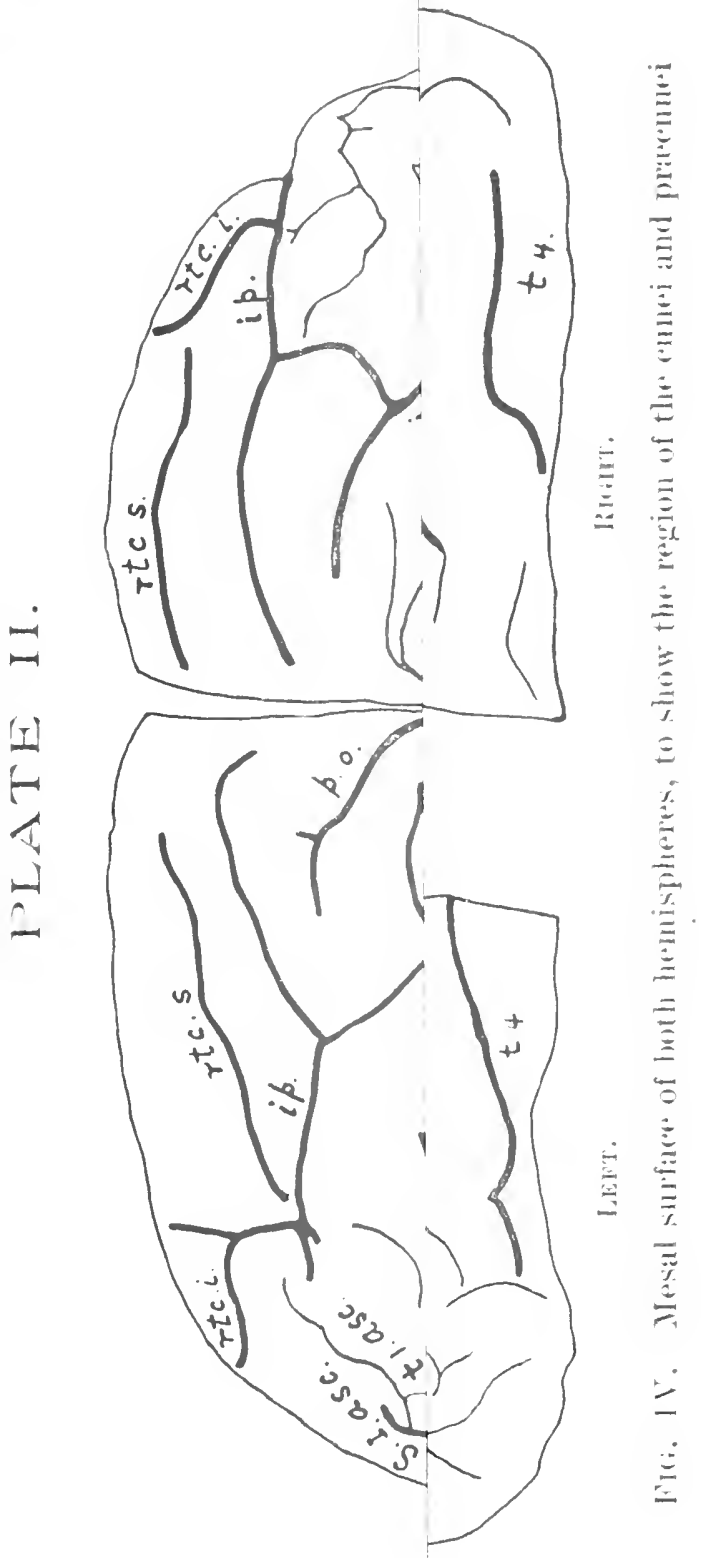




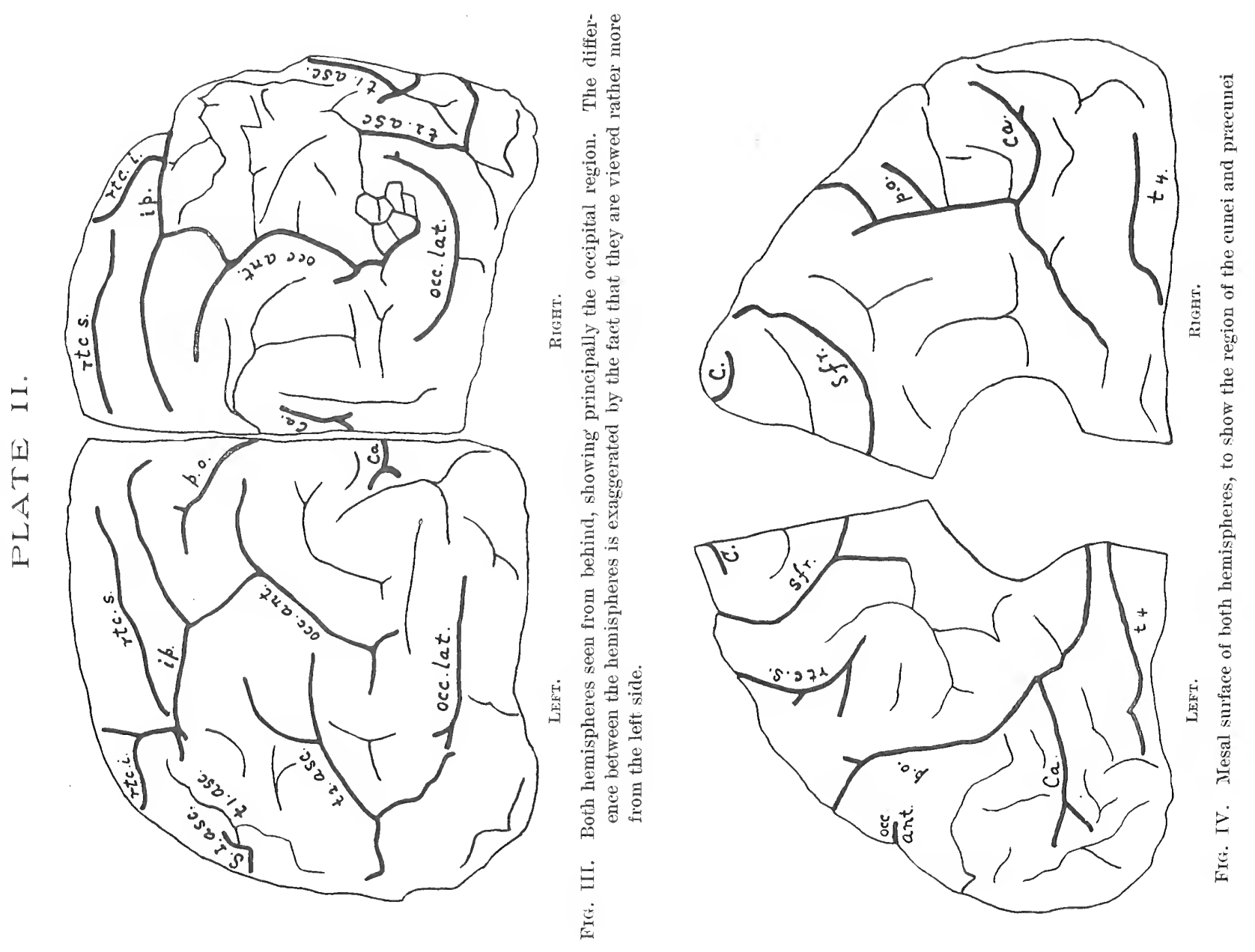




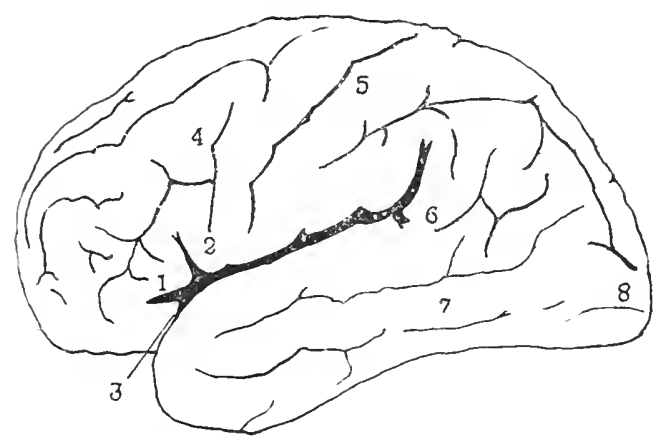

Fir. 1. Lateral aspect. 3 is used to designate the insula here not exposed.

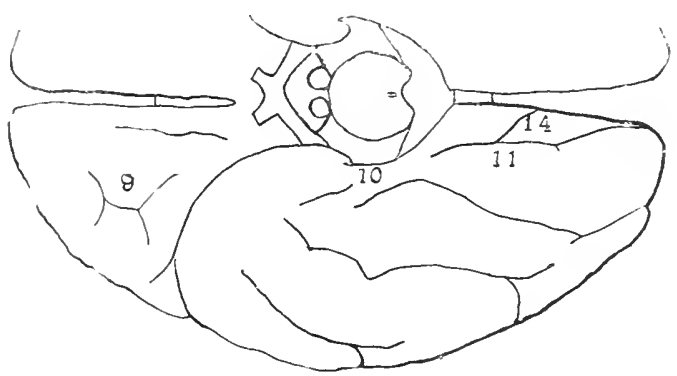

FIC. 2. Veutral aspect.

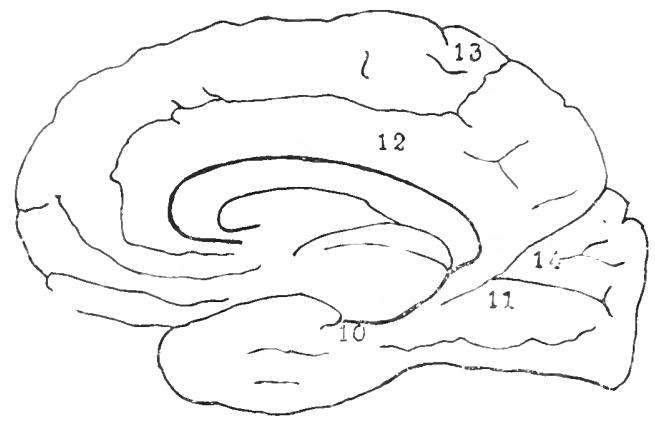

Fur. 3. Mesal aspect.

Explination of Plate III. This plate shows the localities on the hemisphepes from which the samples of aortex were taken. For the physiologial value of these lopalities Tables IlI may be consulted. 

PLATE IV.

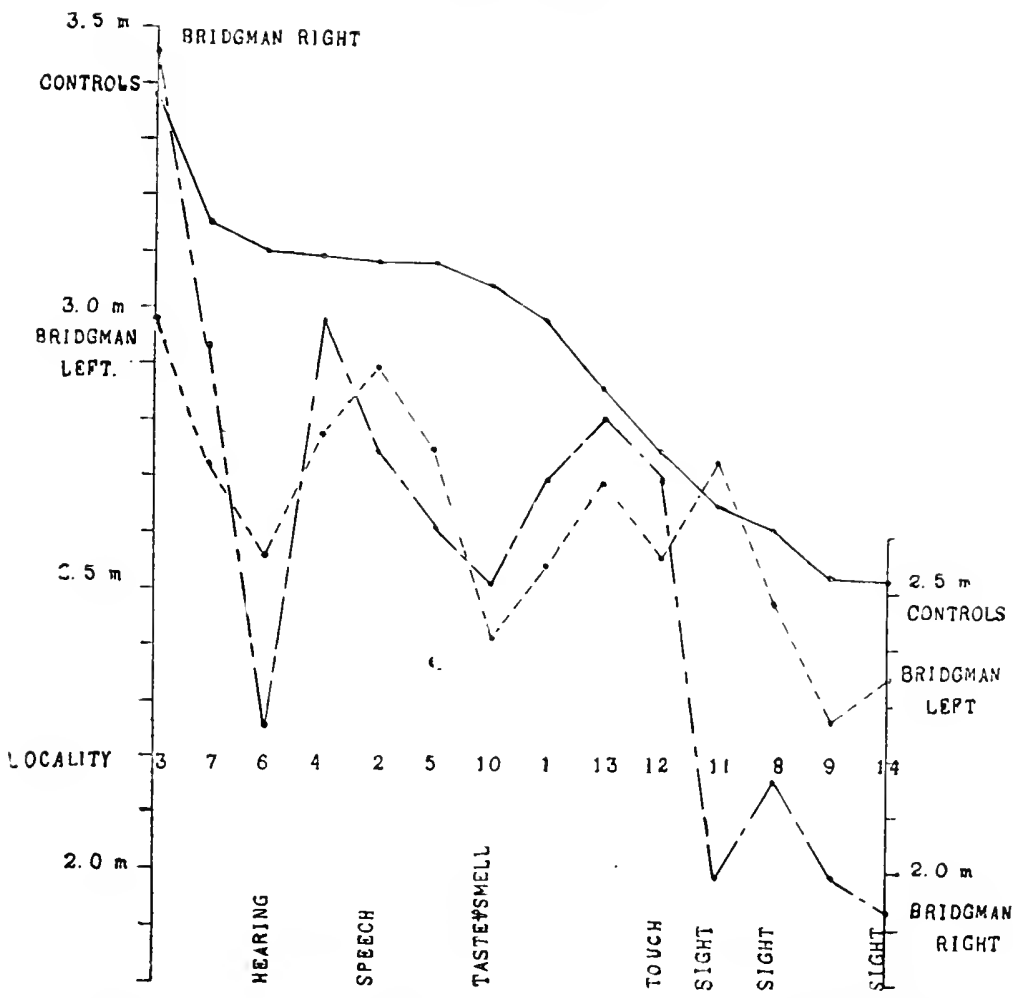

Explanation of Plate IV. The curve was originally plotted so that the thickness of the cortex was magnified 100 times, i. e., .01 $\mathrm{mm}$. of cortex corresponded to $1 . \mathrm{mm}$. on the ordinates. The original has been reduced for printing to somewhat less than six-tenths of its linear scale. The figures placed by the ordinates indicate the thickness of cortex. The summits of the curves are alone represented, there being $1.8 \mathrm{~mm}$. of cortex below what is shown. The figures for the localities cross the plate in a horizontal line, with the important designations below them.

The curve for all controls is in a solid line,

The curve for I. B., right hemisphere, is in long and short dashes, - - The curve for I. B., left hemisphere, is in short dashes, - 






\section{COLUMBIA UNIVERSITY LIBRARIES}

This book is due on the date indicated below, or at the expiration of a definite period after the date of borrowing, as provided by the rules of the Library or by special arrangement with the Librarian in charge.

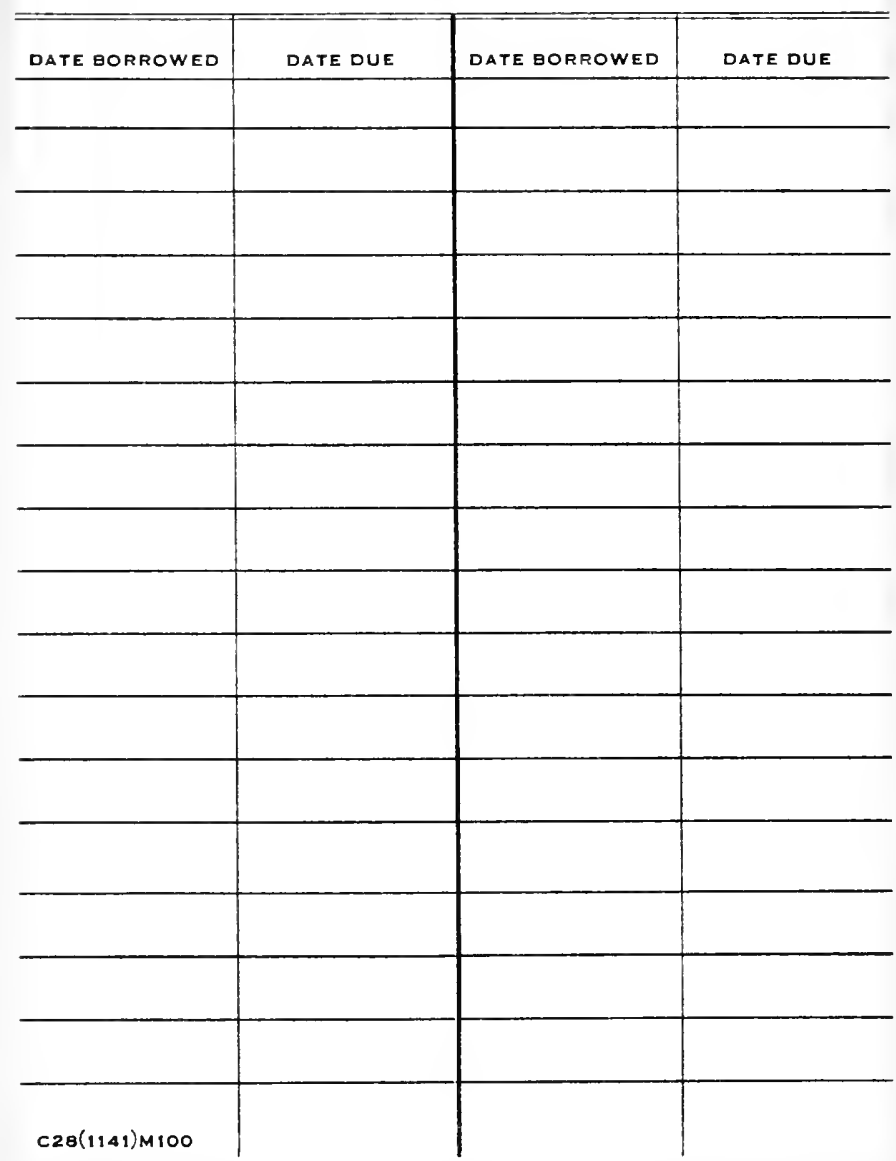


QM455

D71

Donaldson 
